\author{
Universidade de São Paulo \\ Instituto de Física
}

\title{
Estudo de propriedades biofísicas de membrana sob estresse oxidativo e a interação com proteínas formadoras de poros
}

\author{
Robert Garcia Checchia
}

Orientadora: Profa. Dra. Rosangela Itri

Dissertação de mestrado apresentada ao Instituto de Física como requisito parcial para a obtenção do título de Mestre em Ciências.

Banca Examinadora:

Profa. Dra. Rosangela Itri (IFUSP)

Prof. Dr. Omar Mertins (UNIFESP)

Prof. Dr. Pietro Ciancaglini (FFCLRP-USP) 


\title{
University of São Paulo
}

Physics Institute

\section{Study of biophysical properties in membranes under oxidative stress and interaction with pore- forming proteins}

\author{
Robert Garcia Checchia
}

Supervisor: Profa. Dra. Rosangela Itri

Dissertation submitted to the Physics Institute of the University of São Paulo in partial fulfillment of the requirements for the degree of Master of Science.

Examining Committee:

Profa. Dra. Rosangela Itri (IFUSP)

Prof. Dr. Omar Mertins (UNIFESP)

Prof. Dr. Pietro Ciancaglini (FFCLRP-USP) 
Checchia, Robert

ESTUDO DE PROPRIEDADES BIOFÍSICAS DE MEMBRANA SOB ESTRESSE OXIDATIVO E A INTERAÇÃO COM PROTEÍNAS FORMADORAS DE POROS / Robert Checchia; orientadora: Prof. Dra. Rosangela Itri - São Paulo: IFUSP, 2018.

Dissertação (Mestrado - Programa de Mestrado em Física. Área de concentração: Biofísica) - Instituto de Física da Universidade de São Paulo.

1.Física 2. Física Aplicada 3. Biofisica 4. Membranas

Página 3 de 88 


\section{AGRADECIMENTOS}

Thank you God, for holding my hand through all this

Thank you Joe and Marilia, for teaching me things that I could never learn on my own

Thank you, Ignacio and Dirce, for being courageous and hard working

Thank you Wilson and Margot, for showing me that beauty and passion goes well with wisdom and strength

Thank you Lucas and Tina, for keeping me alert and ever evolving. You are my best friends and partners in crime. Thank you for all the times I wanted to give up, and one look into your eyes made me remember who I was

Thank you Mr. Bill Nye, for starting me on this path

Agradeço imensamente à minha orientadora Rosangela Itri, sei que lhe causei muitas dores de cabeça, mas agradeço por sempre me entender e me estimular. Você me ensinou muito a cada palavra dada e cada atitude tomada. Palavras não demontram o quão sou grato por você me ajudar a realizar este sonho

Agradeço à minha melhor amiga no curso, Raffaella de Rosa, por me tirar tantas dúvidas. Você é um exemplo em tudo que faz, e eu sou seu fã \#1

Meu enorme obrigado para a Andreza Gomide, Elisa Morandé Sales, Gustavo Scanavachi Moreira Campos e Maressa Donato, sem vocês não teria começado, me esforçado e nem terminado todo este trabalho. Devo tudo à vocês

Maressa sua ajuda no laboratório foi incalculável. Gustavo, você ajudou a guiar meus esforços e fazer as ideias sairem do papel.

Obrigado também aos professores da USP, sua dedicação e capacidade são exemplares para levar o Brasil adiante. Destaco meu agradecimento aos professores Maria Eliana (Marilyn) Lanio e Carlos Alvarez, vocês me ajudaram com todas as ideias deste projeto e tive a honra de poder aprender com vocês.

Obrigado a toda minha família, tios e tias, primos e primas, e ao pequeno Thomas. Vocês sempre são motivos de alegria e estão presentes em toda comemoração minha 
Thank you Bo, you fixed something that I thought was broken forever, every day you teach me that the means are just as important as the ends. Você me faz uma pessoa melhor, e me lembrou de que tudo que fazemos não vale nada se não tiver alguém para compartilhar.

Qualquer caminho que for trilhar quero ter você do meu lado

Obrigado Fernando e Stella, Marco e Talita (e Lucca), Marta, Ricardo, Ricardinho, e Fernanda e Bruno. Vocês me inspiram, me motivam, me escutam, me aconselham e me levantam. Não posso imaginar amigos melhores que vocês. Eu não teria conseguido sem vocês.

Finalmente, meu enorme agradecimento à CAPES pelo apoio financeiro.

O presente trabalho foi realizado com apoio da Coordenação de Aperfeiçoamento de Pessoal de Nível Superior - Brasil (CAPES) - Código de Financiamento 001.

This study was financed in part by the Coordenação de Aperfeiçoamento de Pessoal de Nível Superior - Brasil (CAPES) - Finance Code 001 


\section{DEDICATÓRIA}

Aos meus pais, que me sempre me incentivaram,

Aos meus avos, por terem lutado e dedicado tanto,

Aos meus irmãos, por me estimularem,

À mulher da minha vida Natália pelo apoio incondicional em todos os momentos, principalmente nos de incerteza, muito comuns para quem tenta trilhar novos caminhos. Sem você nenhuma conquista valeria a pena,

Aos meus amigos, que entenderam e suportaram minha ausência,

À Lila, Minie e Nala, que me ensinaram tanto, e à Veveta que ainda me ensina,

E para mim mesmo... I drove by the fork in the road and went straight

Peace is a lie, there is only passion.

Through passion, I gain strength.

Through strength, I gain power.

Through power, I gain victory.

Through victory, my chains are broken.

The Force shall free me. 


\section{RESUMO}

Neste trabalho investigamos efeitos de fotoirradiação e toxinas sob membranas celulares miméticas. Foram utilizadas, como modelo de membranas lipídicas, vesiculas unilamelares gigantes (GUVs) compostas pro lipídeos oxidados e não oxidados observadas por microscopia ótica de contraste de fase. Inicialmente estudamos a foto-resposta de membranas compostas por POPC e POPG dispersas em solução contendo azul de metileno (MB). Na sequência, estudamos o efeito de toxinas formadoras de poros, Esticolisina I (ST I) e Esticolisina II (ST II), em membranas contendo lipídeos oxidados e não oxidados.

Os resultados de $\mathrm{MB}(10 \mu \mathrm{M})$ disperso em solução de membranas compostas por POPC e o lipídeo aniônico POPG indicaram que o aumento da densidade de carga negativa nas membranas das GUVs, que favorece a ligação da moléculas positivamente carregadas como MB nas membranas, tem como consequência um aumento de permeabilidade da membrana muito mais rápído em relação a membranas compostas apenas por POPC. Isto se deve ao fato que a localização preferencial do MB na membrana de POPC:POPG favorece a formação de oxigênio singlete próximo a dupla ligação da cadeia alquílica, dando início a reação de peroxidação lipídica de maneira mais efetiva que em membrana de POPC.

Os resultados da ação das toxinas STI e STII (21 nM) em GUVs contendo lipídeos não oxidados PC e esfingomielina evidenciam que apenas STII é capaz de permear estas membranas a esta concentração. Mais ainda, nossos resultados sugerem que a existência de separação de fases fluida-gel na bicamada lipidica composta por PC:SM (razão molar 1:1) favorece a ação da toxina StII.

Ao analisarmos membranas contendo lipídeos hidroperoxidados (POPC-OOH) dispersas em solução contendo STII (21 nM) observamos um aumento de permeabilidade na membrana num conjunto de GUVs, associado a formação de poros, apenas em bicamadas lipídicas formadas por misturas de lipídeos oxidados (POPC) e não oxidados (POPC-OOH). Quanto maior a concentração de lipídeos oxidados na membrana mais rapidamente ocorre o aumento de permeabilidade.

Palavras-chave: Vesiculas unilamelares gigantes, GUVs, Azul de Metileno, peroxidação lipídica, Esticolisina I, Esticolisina II 


\begin{abstract}
In this work we investigate the effects of photoirradiation and toxins on mimetic cell membranes. As a model of lipid membranes, giant unilamellar vesicles (GUVs) composed of oxidized and oxidized pro-lipids were observed by optical phase contrast microscopy. Initially we studied the photo-response of membranes composed of POPC and POPG dispersed in solution containing methylene blue (MB). Following, we studied the effect of pore-forming toxins, Sticolysin I (ST I) and Sticolysin II (ST II), on membranes containing oxidized and non-oxidized lipids.

The results of $\mathrm{MB}(10 \mu \mathrm{M})$ dispersed in solution of membranes composed of POPC and the anionic lipid POPG indicated that the increase in the negative charge density in the membranes of GUVs, which favors the binding of positively charged molecules as MB in the membranes, consequently increases membrane permeability in regard to membranes composed only of POPC. This is due to the fact that the preferred location of the MB in the POPC: POPG membrane favors the formation of singlet oxygen near the double bond of the alkyl chain, initiating the lipid peroxidation reaction more effectively than in the POPC membrane.

The results of the action of the STI and STII toxins (21 nM) on GUVs containing non oxidised lipids PC and sphingomyelin show that only STII is able to permeate these membranes at this concentration. Moreover, our results suggest that the existence of fluid-gel phase separation in the lipid bilayer composed of PC:SM (molar ratio 1:1) favors the action of the StII toxin.

When analyzing membranes containing hydroperoxidized lipids (POPC-OOH) dispersed in solution containing STII $(21 \mathrm{nM})$ we observed an increase in membrane permeability in a set of GUVs, associated with pore formation, only in lipid bilayers formed by mixtures of oxidized lipids (POPC-OOH) and non-oxidized ones. The higher the concentration of oxidized lipids in the membrane, the faster the permeability increases.
\end{abstract}

Key words: Giant unilamellar vesicles, GUVs, Methylene Blue, lipid peroxidation, Sticholysin I, Sticholysin II 


\section{Lista de Gráficos e Figuras}

Figura 1: Modelo de mosaico fluido com proteínas de membrana mostradas na representação da superfície embutida na bicamada lipídica.

Figura 2: Exemplos de estrutura química de lipídeos. ........................................................... 18

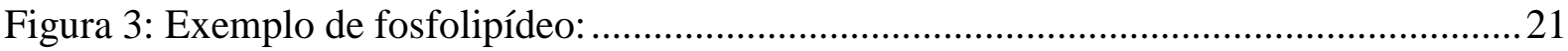

Figura 4: Presença de colesterol nas membranas plasmáticas..............................................22

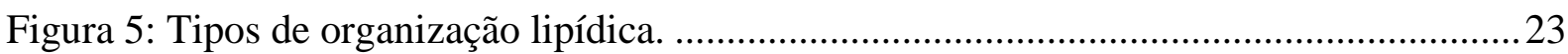

Figura 6: Modelos de sistemas de membrana lipídica..........................................................2 25

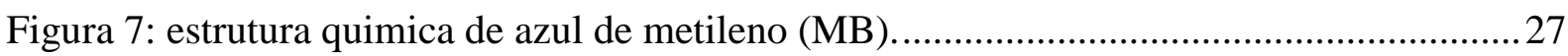

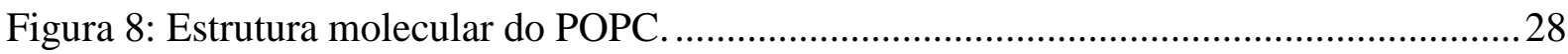

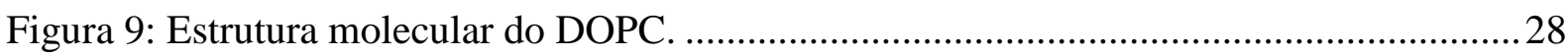

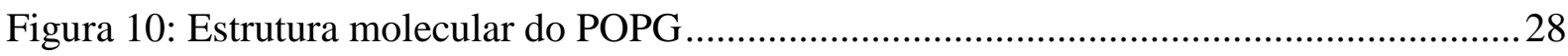

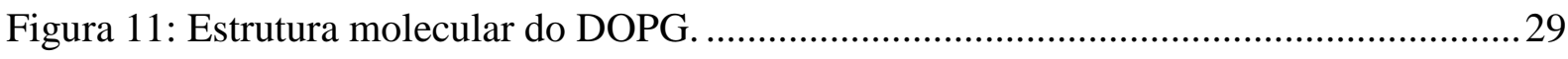

Figura 12: Isômeros estruturais de POPC-OOH. Fórmula C36H70NO10P. ........................... 29

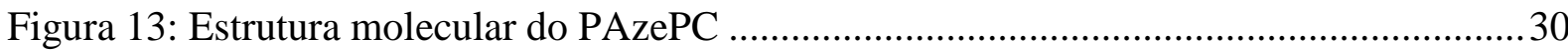

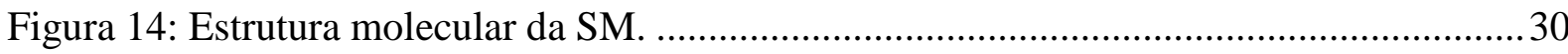

Figura 15: Arranjo experimental para crescimentos de GUVs via eletroformação. .................31

Figura 16: Exemplo de análise do contraste de fase de uma GUV. Figura retirada de Mertins et al. [12].

Figura 17: Fotos das GUVs compostos por POPC:POPG em diferentes razões molares dispersas em solução contendo $\mathrm{MB}(10 \mu \mathrm{M})$ sob irradiação contínua de $\lambda=655 \mathrm{~nm}$, objetiva de $60 \mathrm{x}$.

Figura 18: Evolução da perda de contraste para POPC:POPG em diferentes concentrações (os números na legenda representam a proporção entre POPC e POPG ). Estes dados foram analisados com Image $\mathbf{J}$ e as barras de erro foram calculadas conforme descrito no anexo anexo 6.3 Cálculo de incertezas nas medidas obtidas

Figura 19: adaptada de Souza et al. [25]: no desenho (painel esquerdo) o grupo hidroperóxido está representado por esferas vermelhas $(\mathrm{O})$ e brancas $(\mathrm{H})$ 
Figura 20: Fotos das GUVs dispersas em $10 \mu \mathrm{M}$ de $\mathrm{MB}$, perdendo contraste para DOPC:DOPG em diferentes concentrações de DOPG sob irradiação contínua de $\lambda=655 \mathrm{~nm}$; objetiva de 10x.

Figura 21: perda de contraste ótico para GUVs compostas de DOPC, SM e chol na presença de ST I e ST II 46

Figura 22: Perda de contraste otico para GUVs compostas de DOPC e SM (85:15) na presença de ST I ou ST II, e ST I e ST II juntas (concentração final da toxina $21 \mathrm{nM}$ ).

Figura 23: Evolução temporal das GUVs de POPC puro na presença de STII com concentração de $21 \mathrm{nM}$.

Figura 24: Evolução do contraste otico de GUVs de POPC puro na presença de STII com concentração de $21 \mathrm{nM}$

Figura 25: GUVs de POPC:SM (1:1) sob ação de STII_21nM 50

Figura 26: Evolução do contraste de fase de GUVs compostas por POPC:SM (1:1) na presença de 21nM STII. As barras de erro correspondem a média da análise de 11 GUVs (Tabela 3).

Figura 27: Representação esquemática da forma e aumento de área de lipídios oxidados (POPCOOH e PazePC) em relação ao não oxidado (POPC). 52

Figura 28: Evolução temporal de GUVs compostas por POPC-OOH puro na presença de STII com concentração de $21 \mathrm{nM}$

Figura 29: Evolução temporal do contraste de fase de GUVs compostas por POPC-OOH puro na presença de STII com concentração de $21 \mathrm{nM}$ em comparação com GUVs de POPC........54

Figura 30: Evolução temporal da perda de contraste otico de GUVs de POPC:POPC-OOH na proporção 1:1 na presença de STII com concentração de $21 \mathrm{nM}$.

Figura 31: Evolução temporal do contraste de fase de GUVs de POPC:POPC-OOH na proporção 1:1 na presença de STII com concentração de 21nM. Algumas medidas com a mesma concentração de ST II perdem contraste em tempos diferentes e algumas não perdem contraste. 55

Figura 32: Evolução temporal do contraste de fase de GUVs compostas de POPC:POPCOOH na proporção 1:1 na presença de STII com concentração de $21 \mathrm{nM}$. Os dados se referem as GUVs que perdem contraste mais rapidamente 56 
Figura 33: Evolução temporal de GUVs compostas por POPC:POPC-OOH na proporção 7:3 na presença de STII com concentração de $21 \mathrm{nM}$

Figura 34: Evolução do contraste otico de varias GUVs de POPC:POPC-OOH na proporção 7:3 na presença de STII com concentração de $21 \mathrm{nM}$

Figura 35: Evolução do contraste de GUVs de POPC:POPC-OOH na proporção 7:3 na presença de ST II com concentração de $21 \mathrm{nM}$, agrupando as GUVs que perdem contraste ótico mais rapidamente. 58

Figura 36: Evolução temporal do contraste otico de GUVs comparando POPC;POPCOOH(1:1)_STII_21nM com POPC:POPC-OOH (7:3)_STII_21nM 59

Figura 37:Resumo do \% de GUVS que perderam contraste em função da concentração de POPC em relação a POPC-OOH

Figura 38: Fotos das GUVs perdendo ccontrate para DOPC:AloeVera em diferentes concentrações

Figura 39: Evolução das imagens de GUVs POPC_42nM STII Experiment-1354.

Figura 40: Média da evolução do contraste de fase GUVs de POPC na presença de 42nM STII

Figura 41: Evolução das imagens de GUVs POPC-OOH_42nM STII Experiment-1409.......78

Figura 42: Média da evolução do contraste de fase GUVs de POPC-OOH na presença de 42nM STII 79

Figura 43: POPC;POPC-OOH (9:1) STII_42nM Experiment-1387. 80

Figura 44: Média da evolução do contraste de fase GUVs de POPC;POPC-OOH(9;1) na presença de 42nM STII 80

Figura 45: POPC;POPC-OOH(7:3) STII_42nM. Experiments11799. 81

Figura 46: Média da evolução do contraste de fase GUVs de POPC;POPC-OOH(7;3) na presença de 42nM STII.

Figura 47: POPC;POPC-OOH(1:1) STII_42nM. Experiments1386. 83

Figura 48: Média da evolução do contraste de fase GUVs de POPC;POPC-OOH(1;1) na presença de 42nM STII. 83 
Figura 49: Comparação da evolução do contraste de fase médio das GUVs de POPC e POPCOOH nas proporções de 1:1, 7:3 e 9:1 na presença de 42nM STII

Figura 50: Evolução das imagens de GUVs POPC;PazePC(1;1)_42nM STII Experiment1134.

Figura 51: Média da evolução do contraste de fase GUVs de POPC;PazePC $(9 ; 1)$ na presença de 42nM STII 85

Figura 52: Média da evolução do contraste de fase GUVs de POPC;PazePC(7;3) na presença de 42nM STII 86

Figura 53: POPC;PazePC(1;1). Experimentos 1496, 1497 e 1498 87

Figura 54: Média da evolução do contraste de fase GUVs de POPC e PazePCnas proporções de 7:3 e 9:1 na presença de 42nM ST II 87

Figura 55: POPC-OOH;SM(1;1)_21nM_STII Experiment-11913 88 


\section{Lista de Tabelas}

Tabela 1: Perda de contraste de fase para POPC:POPG em diferentes concentrações ............ 40

Tabela 2: GUVs compostas de DOPC, SM e chol na presença de ST I e ST II .....................46

Tabela 3: GUVs de POPC:SM(1:1) na presença de 21nM STII ..........................................51

Tabela 4: GUVs de POPC:POPC-OOH na proporção 1:1 na presença de STII com

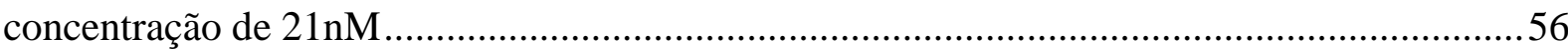

Tabela 5: Contagem de GUVs que perderam contraste nos experimentos com ST II 61

Tabela 6: dados resumidos de perda de contraste para GUVs compostos por lipídeos oxidados

Tabela 7: Contagem de GUVs que perderam contraste nos experimentos com ST II .............76

Tabela 8: GUVs de POPC na presença de 42nM STII........................................................... 78

Tabela 9: GUVs de POPC-OOH na presença de 42nM STII................................................. 79

Tabela 10: GUVs de POPC;POPC-OOH(9;1) na presença de 42nM STII ............................ 81

Tabela 11: GUVs de POPC;POPC-OOH(7;3) na presença de 42nM STII............................82

Tabela 12: GUVs de POPC;POPC-OOH( $1 ; 1)$ na presença de 42nM STII.............................83

Tabela 13: GUVs de POPC;PazePC(9;1) na presença de 42nM STII ...................................86

Tabela 14: GUVs de POPC;PazePC(7;3) na presença de 42nM STII ..................................86 


\section{SUMÁRIO}

CAPÍTULO 1. INTRODUÇÃO ................................................................................................................. 15

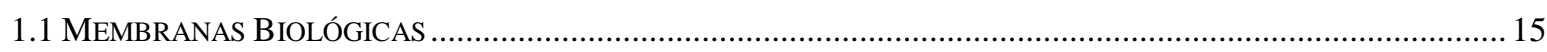

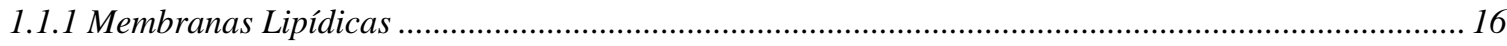

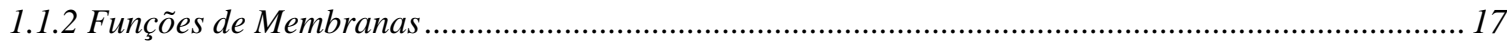

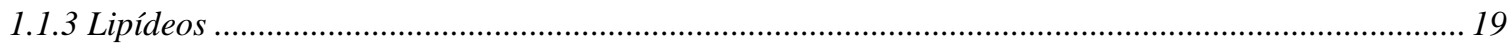

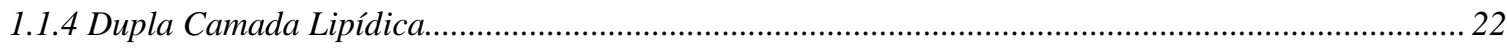

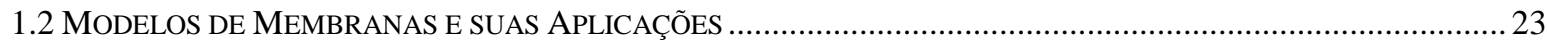

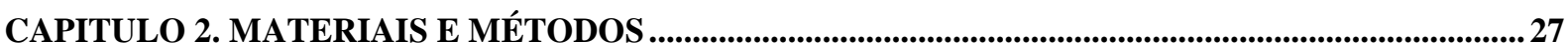

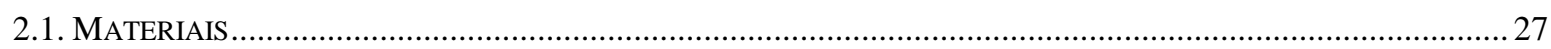

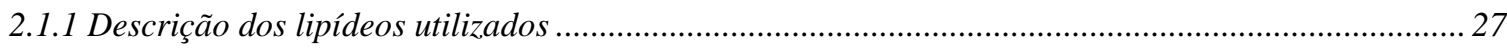

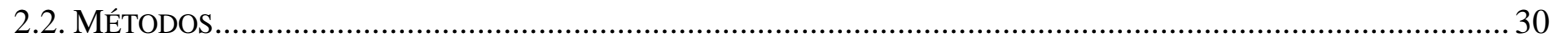

2.2.1 Preparação de Vesículas Unilamelares Gigantes - GUVs e medidas experimentais ......................... 31

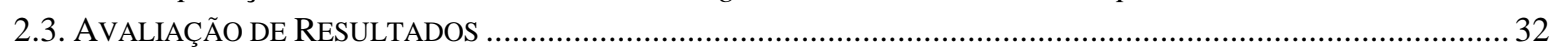

CAPITULO 3. OBJETIVOS E RESULTADOS EXPERIMENTAIS ............................................................35

3.1. DANOS À MEMBRANAS DE GUVS PELO EFEITO DA FOTOIRRADIAÇÃo NA PRESENÇA DE AZUL DE METILENO 38

3.1.1 Medidas com Azul de Metileno disperso em solução de membranas compostas por POPC e POPG 39

3.1.2 Medidas com Azul de Metileno: DOPC:DOPG sob fotoirradiação .................................................. 42

3.2 EFEITO DAS TOXINAS ST I E ST II EM MEMBRANAS MIMÉTICAS OBSERVADAS POR MICROSCOPIA OTICA DE

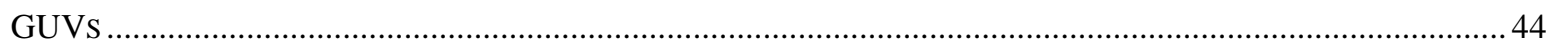

3.2.1 Efeito das Toxinas STI e STII em GUVs Contendo Lipídeos Não Oxidados ...................................... 44

3.3 GUVS COMPOSTAS POR LIPÍDEOS OXIDADOS NA PRESENÇA DE STII.......................................................52

3.4 ESTUDO DO EFEITO DA TOXINA STII A 42 NM EM GUVs COM LIPÍDEOS OXIDADOS................................60

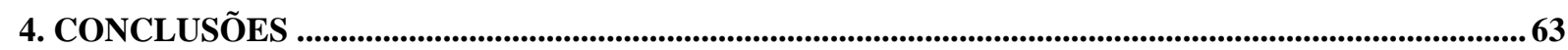

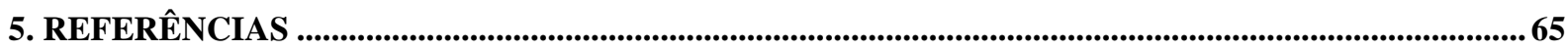

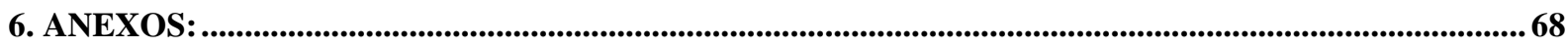

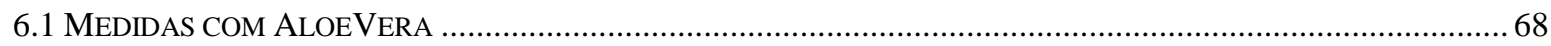

6.2 PREPARO E ANÁLISE DE GUVS COM DIFERENTES METODOLOGIAS .................................................... 70

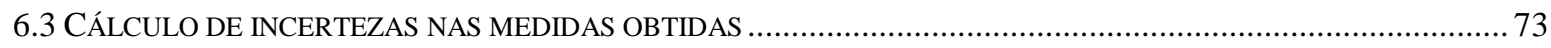

6.4 GRÁFICOS DO ESTUdO do EFEITO DA TOXINA STII A 42 NM EM GUVS COM LiPÍDEOS OXIDADOS ............75 


\section{CAPÍTULO 1. INTRODUÇÃO}

Neste capitulo faremos uma revisão de literatura com o intuito de embasar os principais conceitos no estudo de membranas biológicas utilizados no desenvolvimento do trabalho de mestrado. Começaremos pela descrição de membranas biológicas, passando pelos lipídeos constituintes e modelos utilizados para estudar membranas. A redação aqui apresentada foi baseada no texto de Freddolino et al ([1]). Presentes em todos os experimentos aqui realizados, foram utilizadas Vesiculas Unilamelares Gigantes (GUVs) como modelos de membranas fosfolipídicas, analisadas utilizando a técnica de vídeomicroscopia ótica.

\subsection{Membranas Biológicas}

Membranas biológicas são camadas finas constituídas na maior parte por proteínas e fosfolipídeos que envolvem as células vivas, delimitando as organelas em seu interior, e controlando e regulando a interação da célula com seu entorno e com as moléculas do meio. $\mathrm{O}$ modelo atualmente aceito de membrana plasmática celular foi proposto por Singer $e$ Nicholson [2] denominado de mosaico fluido (Figura 1), e consiste de uma bicamada fluida de lipídeos na qual se inserem proteínas em cada um dos seus lados (proteínas periféricas) ou a atravessam inteiramente (proteínas integrais). O modelo de mosaico fluido propõe que os fosfolipídeos se distribuem lado a lado, deslocando-se constantemente, mas sem perder o contato uns com os outros. Muitas proteínas são encontradas ancoradas na bicamada de lipídeos.

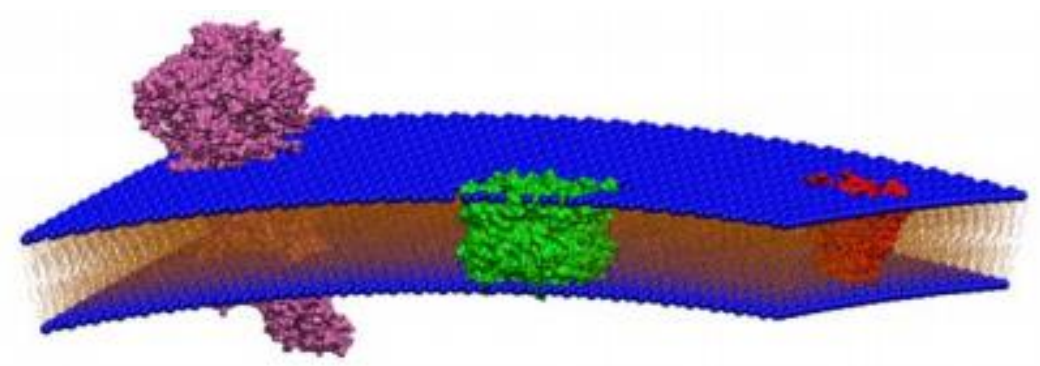

Figura 1: Modelo de mosaico fluido com proteínas de membrana mostradas na representação da superfície embutida na bicamada lipídica.

O interior hidrofóbico da bicamada lipídica é mostrado em laranja com os grupos polares dos fosfolipídeos mostrados em azul. Figura retirada de Karp [3] 
Embora possuam espessura média de cinco nanometros, as membranas biológicas são semipermeáveis, ou possuem permeabilidade seletiva, e exercem grande variedade de funções na atividade celular. Uma destas é o controle da passagem de substâncias, permitindo passagem de compostos químicos determinados e impedindo a passagem de outros, conservando o meio celular interno apropriado às necessidades celulares.

A maior parte das funções das membranas depende das moléculas de proteínas presentes em sua constituição. Certas proteínas constituintes das membranas funcionam como bombas seletivas, regulando a passagem de íons e moléculas menores tanto para dentro quanto para fora da célula. Além disso, tais proteínas geram gradientes de prótons muito importantes para a produção de ATP. Outras delas, localizadas na superfície externa, são capazes de identificar determinadas substâncias no meio, estimulando-a a reagir, como é o caso dos receptores hormonais. Além disso, algumas destas proteínas atuam, ainda, como enzimas, catalisando diversas reações metabólicas.

As membranas se formam em dupla camada, sendo os principais componentes constituintes os lipídeos, cuja organização será responsável pela forma física das membranas biológicas. As moléculas lipídicas possuem regiões hidrofílicas (porção que corresponde à "cabeça" da molécula do lipídeo, sendo polar e, portanto, possui afinidade com moléculas de água) e hidrofóbicas (região que corresponde à "cauda" da molécula, sendo apolares, que, portanto, não se dissolvem em água). Outra categoria de lipídeos que compoem as membranas biológicas compreende o colesterol, que tem ação dupla: pode fluidificar ou enrijecer uma bicamada lipídica dependendo da porcentagem do mesmo na membrana.

\subsubsection{Membranas Lipídicas}

As membranas são essenciais para os organismos celulares, servindo como fortalezas na medida em que proporcionam uma barreira entre o ambiente interior e o meio exterior. Ao contrário das paredes rígidas de uma fortaleza, as membranas são fluidas e podem se curvar e se mover. Conforme descrição em Lehninger [4], os tijolos que formam uma membrana (lipídeos) podem mover-se livremente. As membranas plasmáticas encerram e definem os limites de uma célula, mantendo uma barreira entre o interior de uma célula, o citossol e o ambiente extracelular. Nas células eucarióticas, as membranas também envolvem organelas especializadas, como a mitocôndria, o núcleo e outras organelas ligadas à membrana. Algumas células também podem ter grandes compartimentos ligados à membrana, chamados de vacúolos, que servem uma variedade de funções, incluindo a captura de alimentos, 
seqüestrando material tóxico, envolvendo e eliminando detritos celulares e equilíbrio de fluido de manutenção. As vesículas são denominações para compartimentos ligados à membrana relativamente menores que podem armazenar, transportar ou digerir produtos e resíduos celulares. Por exemplo, organelas celulares como o retículo endoplasmático contêm membranas separando o citoplasma de sua lúmen. No caso do retículo endoplasmático áspero, os ribossomos se ligam à superfície liberando proteínas recém-sintetizadas, através de canais de membrana, translocações, tanto no lúmen como na própria membrana, no caso de proteínas de membrana. Outro exemplo são os lisossomas, vesículas digestivas ligadas à membrana encontradas dentro das células. Eles contêm lisozimas (enzimas digestivas) que podem quebrar as macromoléculas permitindo que as células se alimentem. A membrana dos lisossomas é impermeável às lisozimas, permitindo que as células destruam seus alimentos sem serem digeridas por suas próprias enzimas digestivas. Embora as membranas biológicas tenham diversas funções e composições, todas elas são estruturalmente semelhantes na medida em que são constituídas por uma fina bicamada de lipídeos de 5-10 nm e proteínas, unidas por interações primárias não covalentes.

\subsubsection{Funções de Membranas}

A função das membranas é diversificada, pois formam folhas contínuas que encerram um compartimento interno definido. Esta compartimentalização permite atividades especializadas com interação regulada com o ambiente circundante. Embora as membranas formem uma barreira que permita a compartimentação, elas não formam uma barreira impenetrável. As membranas são seletivamente permeáveis na medida em que permitem certas moléculas, mas excluem outras moléculas. Uma bicamada lipídica pura é ligeiramente permeável à água, mas principalmente impermeável a moléculas solúveis em água, como o sódio, cálcio e potássio. É responsabilidade das proteínas da membrana regular o transporte de tais moléculas. A distribuição e os tipos de proteínas da membrana encontradas dentro de uma membrana particular variam, permitindo assim a personalização de cada espaço interior para os requisitos específicos da célula ou organela. O material desejado pode ser permitido na entrada, enquanto os materiais adversos e dejetos são mantidos à distância do interior celular. O transporte de solutos através da membrana plasmática permite que as células acumulem altas concentrações citoplasmáticas de substâncias como aminoácidos e açúcares que são importantes para o metabolismo e manutenção da célula. A composição iônica dentro de uma célula geralmente difere da do ambiente circundante. As células geralmente mantêm uma elevada concentração citosólica de íons de potássio em comparação com o ambiente exterior e 
uma baixa concentração de íons de sódio citosólicos. Isso cria um gradiente iônico, que permite a difusão passiva de íons de alta a baixa concentração quando os canais de proteína de membrana estão abertos. O movimento dos íons através dos canais cria uma diferença de potencial elétrico onde o interior da célula é aproximadamente $-70 \mathrm{mV}$ mais negativo do que o exterior (segundo Karp et al. [3]). Assim, a membrana plasmática também é chamada de capacitor. As proteínas dentro das membranas, além disso, desempenham um papel na comunicação intercelular e na transdução de sinal.

\subsubsection{Estrutura da Membrana e Composição}

Conforme visto anteriormente, no modelo de mosaico fluido (Figura 1) as bicamadas lipídicas formam o esqueleto estrutural da membrana com uma coleção heterogênea de proteínas. As proteínas integrais de membrana abrangem toda a bicamada lipídica, enquanto as proteínas da membrana periférica se associam vagamente à superfície de uma membrana. Os lipídeos no modelo de mosaico fluido se difundem lateralmente, mantendo a orientação de dentro para fora e fora para dentro. A fluidez da membrana é determinada pela composição dos lipídeos e proteínas constituintes. Ainda segundo Singer e Nicolson, a composição da membrana biológica é aproximadamente metade de lipídeos e metade proteínas [2]. Existe uma grande variedade de lipídeos nas membranas biológicas, mas os mais prevalentes são os fosfolípideos, os esfingolípideos e os glicolípideos (Lipídeos que contem ácido fosfórico, esfingosina e ácido graxo, respectivamente) (Figura 2).
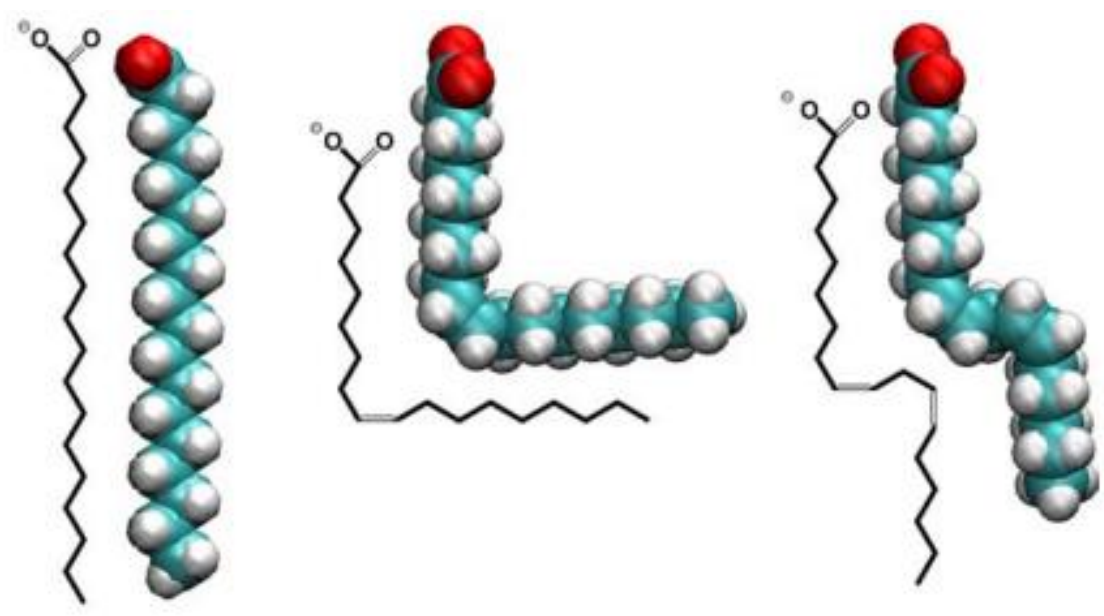

Figura 2: Exemplos de estrutura química de lipídeos.

a) Ácido esteárico saturado, b) ácido oleico monoinsaturado com uma única ligação dupla, e c) ácido linoleico poliinsaturado com duas ligações duplas. Figura retirada de Freddolino et al. [1] onde disponibilizam arquivos pdb para visualização. 


\subsubsection{Lipídeos}

Os lipídeos são moléculas insolúveis em água, porém solúveis em solventes orgânicos. Os lipídeos mais comuns são compreendidos na forma de gorduras e óleos; alguns hormônios (como a testosterona), também são lipídeos. Conforme dito anteriormente, as membranas são principalmente constituídas por lipídeos anfifílicos (contendo uma parte polar e hidrofilica e outra apolar e hidrofóbica), como os fosfolípidos. Estes lipídeos têm um grupo hidrofóbico que busca se afastar da água, composto pela cauda do lipídeo e um grupo hidrofílico, que se atrai à água. Os lipídeos nas membranas se formam em estruturas de bicamadas, com as caudas hidrofóbicas interagindo entre si e as partes hidrofílicas polares interagindo com os ambientes internos e externos aquosos.

\subsubsection{Tipos de Lipídeos}

Novamente de acordo com a definição de Nelson [4], os ácidos graxos são os principais blocos de construção dos lipídeos, sendo compostos por uma longa cadeia de hidrocarbonetos com um grupo de cabeça de ácido carboxílico. Embora os ácidos graxos não sejam encontrados livremente na natureza, são as cadeias de hidrocarbonetos que compõem os grupos de cauda da maioria dos lipídeos. Geralmente há entre 14 e 20 carbonos dentro de uma cadeia de hidrocarbonetos de ácidos graxos. As cadeias de hidrocarbonetos de ácidos graxos são descritas como saturadas, insaturadas e poli-insaturadas (assim como encontrado frequentemente em rótulos de alimentos). Um ácido graxo saturado não contém ligações duplas, e produzem hidrocarbonetos longos de cadeia linear, enquanto que os ácidos graxos insaturados contêm ligações duplas e os poli-insaturados contem mais de duas ligações poliinsaturadas. A presença de uma ligação dupla provoca uma torção ou dobra ("kink") na cadeia de hidrocarbonetos, conforme a imagem do meio da figura 2. A maioria das gorduras e óleos que ocorrem naturalmente em plantas e animais consiste em misturas de triglicerídeos, que são triésteres de glicerol com três cadeias de ácido graxos conectadas (conforme figura 3 acima). Triglicerídeos simples têm três ácidos graxos idênticos enquanto que os triglicerídeos mistos mais comuns têm 2 ou 3 tipos de ácidos graxos. Gorduras e óleos são compostos de misturas de triglicerídeos e, embora não estejam presentes em membranas e bicamadas 
lipídicas, constituem a principal maneira pela qual as gorduras são armazenadas para necessidades energéticas de um organismo biológico.

Segundo Freddolino et al. [1], o tipo mais comum de lipídeo encontrados nas membranas biológicas são os fosfolípidos. Os fosfolípidos têm um fosfato de glicerol, onde o glicerol é esterificado nas posições $\mathrm{C} 1$ e $\mathrm{C} 2$ em dois ácidos graxos e o grupo fosforil presente na cabeça do lipídeo. Nas membranas biológicas, os grupos de cabeças são freqüentemente derivados de álcoois polares, como colina, serina e etanolamina. A posição C1 é tida como esterificada para ácidos graxos saturados contendo 16 ou 18 carbonos. Em contraste, a posição C2 geralmente tem ácidos gordos não saturados entre 16 a 20 carbonos. Conforme dito, os fosfolipídeos são todos de natureza anfifílica com grupos de cabeças hidrofíticas polares e caudas hidrofóbicas não polares (conforme Figura 3). Os tipos comumente encontrados de fosfolipídeos sintéticos em experimentos de laboratório incluem dipalmitoilglicero-fosfocolina (DPPC), 1-palmitoil-2-oleoil-glicerol-fosfocolol (POPC) e 1palmitoil-2-oleoil-glicerofosfatoetanolamina (POPE). Ao longo deste trabalho serão desenvolvidos diversos experimentos utilizandos estes dentre outros fosfolipídeos.

DPPC tem grupos de caudas de ácidos graxos saturados, enquanto POPC e POPE têm uma cauda saturada e uma insaturada. DPPC e POPC têm um grupo de cabeça polar de fosfocolina, enquanto o POPE possui uma cabeça menor de fosfoetanolamina. A composição dos grupos de cabeça e cauda de lipídeos afeta a estrutura geral, incluindo a área superficial de cada lipídeo, e os agregados lipídicos resultantes. Outro tipo de lípideo encontrado em membranas biológicas são esfingolípideos que, em vez de glicerol em fosfolípidos, possuem uma esfingosina de aminoácidos de cadeia longa com um ácido graxo ligada à posição C2 na esfingosina. A adição de um grupo de cabeça polar à posição $\mathrm{C} 1$ forma um esfingolipídeo. Existem três tipos de esfingolipídeos dependentes do tipo de grupo de cabeça polar que esteja ligada. As esfingomicinas são ceramidas com um grupo de cabeça de fosfocolina ou fosfoetanolina, muitas vezes são classificados como um fosfolipdeo devido à cabeça polar contendo algum fosfato. 


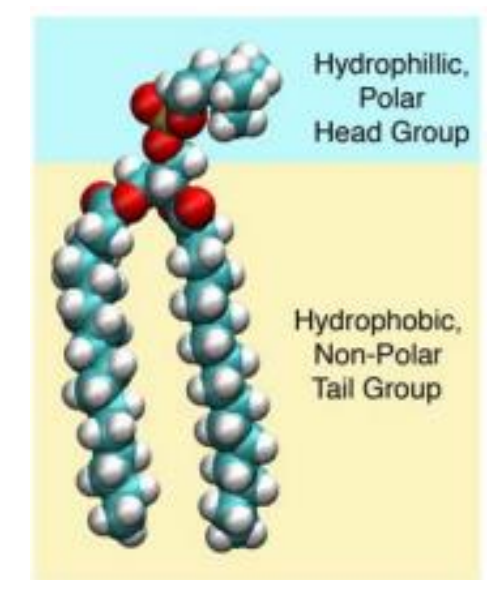

Figura 3: Exemplo de fosfolipídeo:

São moleculas anfifílicas com um grupo hidrofílico e dois grupos de cauda hidrofóbica. Os fosfoiípideos têm uma forma cilíndrica e formam facilmente bicamadas lipídicas. Figura retirada de [1].

Os glicolípídeos possuem em sua cabeça polar algum açúcar, e ocorrem principalmente na superfície da membrana plasmática. Os gangliosídeos são esfingolipídeos mais complexos, na medida em que possuem oligosacarídeos como grupos de cabeças com pelo menos um resíduo de ácido siálico. Isso produz um lipídeo carregado negativamente com um $\mathrm{pH}$ neutro. Os esfingolipídeos geralmente servem como receptores em sítios biológicos. O tipo final de lipídeos são os esteroides, que incluem hormônios, testosterona e estrogênio, que regulam o desenvolvimento sexual; e metabolismo de carboidratos, assim como os níveis de colesterol no organismo. Atenção especial pode ser dada ao colesterol, encontrado nas membranas plasmáticas das células animais. O colesterol é importante para uma ampla gama de funções, incluindo o transporte de ácidos graxos, além do metabolismo e produção de hormônios, sais biliares e vitaminas. Níveis elevados de colesterol no sangue podem causar um aumento no risco de doenças cardíacas. O colesterol também é uma molécula anfifílica com um grupo de cabeça polar hidroxila e um corpo hidrocarboneto hidrofóbico. A região do esteróide circundante é rígida e quando o colesterol é inserido em uma bicamada lipídica, ele interage com os primeiros vários carbonos nos fosfolípidos que os mantêm imóveis (vide Figura 4). As membranas que contêm colesterol podem, portanto, ser menos flexíveis e menos sensíveis à pequena permeabilidade à molécula solúvel em água. O colesterol somente é encontrado nas membranas plasmáticas dos animais. Aqueles organismos onde o colesterol não é encontrado, como bactérias, geralmente requerem uma parede celular para mantê-los rígidos. A concentração de colesterol na membrana plasmática tem um ponto ótimo de 
equilíbrio, isto é, com pouco colesterol a membrana plasmática torna-se muito fluida, porém, com muito colesterol as células tornam-se demasiadamente rígidas.

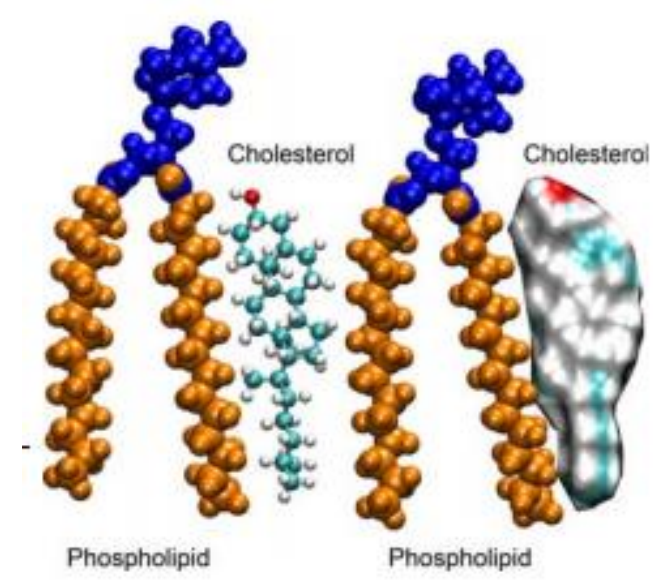

Figura 4: Presença de colesterol nas membranas plasmáticas.

Figura retirada de Freddolino et al. [1].

\subsubsection{Dupla Camada Lipídica}

A bicamada lipídica das membranas geralmente consiste em uma proporção específica de vários tipos de lipídeos e proteínas. Essa relação varia entre organismos e funções específicas das membranas. A mileína humana possui $30 \%$ peso de proteínas, 30\% de fosfolípidos, $19 \%$ de colesterol e vestígios de outros lipídeos. No entanto, a membrana celular interna de E. coli possui $75 \%$ de proteínas, $25 \%$ de fosfolípidos e nada de colesterol. Usando uma analogia com construção, existem uma grande variedade de constituintes que são usados e adaptados para diversas funções e ambientes específicos. Devido ao efeito hidrofóbico, os lipídeos formam agregados em ambientes aquosos. Eles podem formar bicamadas e lipossomas dependendo do tipo de lipídeo utilizado. As membranas biológicas são compostas de vários tipos de lipídeos sendo lenta a difusão lateral de lipídeos dentro de uma bicamada (a taxa de difusão de lipídeos é da ordem de $10^{-8} \mathrm{~cm}^{2} / \mathrm{s}$ (de acordo com Gennis [5]). 


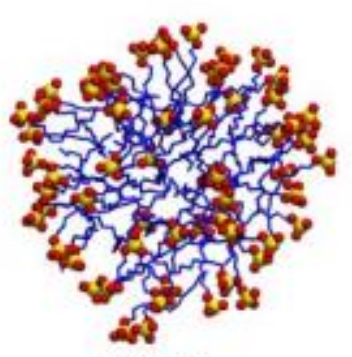

a) Micelle

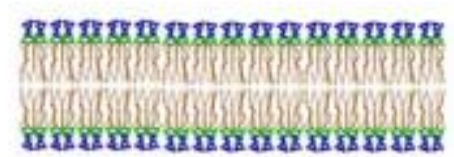

b) Lipid Bilayer

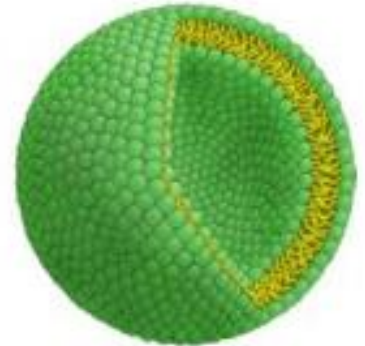

c) Liposome

Figura 5: Tipos de organização lipídica.

a) exemplo de micelizacao: o surfactante dodecilsulfato de sódio (SDS) tem uma grande cabeça hidrofílica e uma pequena cauda hidrofóbica (12 carbonos). Quando presente em concentrações acima da concentração micelular crítica, o SDS forma micelas em solução. As caudas hidrofóbicas da SDS são enterradas no interior da micela e são protegidas do ambiente aquoso pelos seus grupos de cabeca polar hidrofilicas. b) As bicamadas lipídicas são planas e se formam quando uma monocamada lipídica orienta suas caudas hidrofóbicas para as caudas hidrofóbicas de uma segunda monocamada, formando um interior hidrofóbico. c) Os lipossomas também assumem uma estrutura em bicamada, mas em vez de assumir uma forma planar, a bicamada se encaixa sobre si mesma (para estabilizar as bordas de uma bicamada lipídica) formando uma cavidade aquosa no meio. Figura retirada de Freddolino et al. [1], onde estão disponibilzados os arquivos pdb.

\subsection{Modelos de Membranas e suas Aplicações}

A complexidade das membranas biológicas tem motivado o desenvolvimento de uma ampla variedade de sistemas utilizados como modelos mais simples e cujo tamanho, geometria e composição podem ser adaptados com grande precisão. Abordagens destacadas nesta revisão são ilustradas na Figura 6, retirada de Freddolino et al. [1], incluindo vesículas, bicamadas e sistemas de membranas híbridas. Estes têm sido utilizados para estudar questões que vão desde análise de fases de membranas até fusão de membranas. Os modelos experimentais de membrana continuam avançando em complexidade com relação à arquitetura, tamanho e composição, como as simulações computacionais de suas propriedades e dinâmicas.

Técnicas analíticas, como espectrometria de massa de íons secundários de imagem, também foram desenvolvidas e refinadas para fornecer resolução espacial e conteúdo de informação cada vez maiores na composição da membrana.

Conforme mencionado anteriormente, a função mais básica das membranas biológicas é definir um limite, seja entre ou dentro das células e organelas (Figura 6, centro). Muitos processos celulares dependem da capacidade da membrana de separar áreas diferentes, 
permitindo a comunicação e o transporte rigidamente regulado dentro e através das membranas. Toda a comunicação célula-célula e posterior montagem em tecidos, órgãos e organismos são mediadas por tais interações. As membranas biológicas variam tremendamente na composição mesmo dentro de uma célula eucariótica, e sua organização deve ser dinâmica a fim de mediar e modular mudanças conformacionais, sinalização, tráfico e reconhecimento. Como eles desempenham um papel tão fundamental e porque as membranas naturais são tão complexas, foram criados muitos sistemas de modelo diferentes que retêm a estrutura essencial da bicamada lipídica, mas simplificam o sistema para que os papéis dos componentes individuais possam ser avaliados e sua organização e dinâmica podem ser visualizados. Sistemas modelo e abordagens que obtiveram grandes progressos nos últimos anos são mostrados esquematicamente na Figura 6, na ordem (sentido horário) que serão discutidos. Estas incluem: bicamadas na forma de vesículas que variam em tamanho, desde pequenas vesículas unilamelares (SUV's) a dezenas de microns (vesículas unilamelares gigantes, GUV's) que estão livres ou presas a suportes; bicamadas planares suportadas interagindo diretamente com um substrato sólido ou amarradas ao substrato; ilhas de bicamada envoltas por proteínas; e fragmentos de membranas celulares naturais. Em muitos casos, revisões detalhadas sobre esses sistemas foram publicadas nos últimos dois anos, e elas são referenciadas juntamente com avanços específicos que são destacados. Quase todos os métodos de imagem foram aplicados a modelos e membranas nativas, especialmente no formato planar que combina bem com técnicas sensíveis à superfície originalmente desenvolvidas para estudos em ciência de materiais, materiais eletrônicos, geoquímica e catálise. Como até mesmo os sistemas modelo mais simples envolvem a automontagem de muitas moléculas lipídicas na água, elas ampliam as fronteiras das simulações atomísticas e levam a tentativas de casar modelos totalmente atomísticos com abordagens de granulação grossa ou contínuas. Uma forte sinergia entre simulações em todas as escalas e experimentos é um dos principais impulsionadores desse campo. 


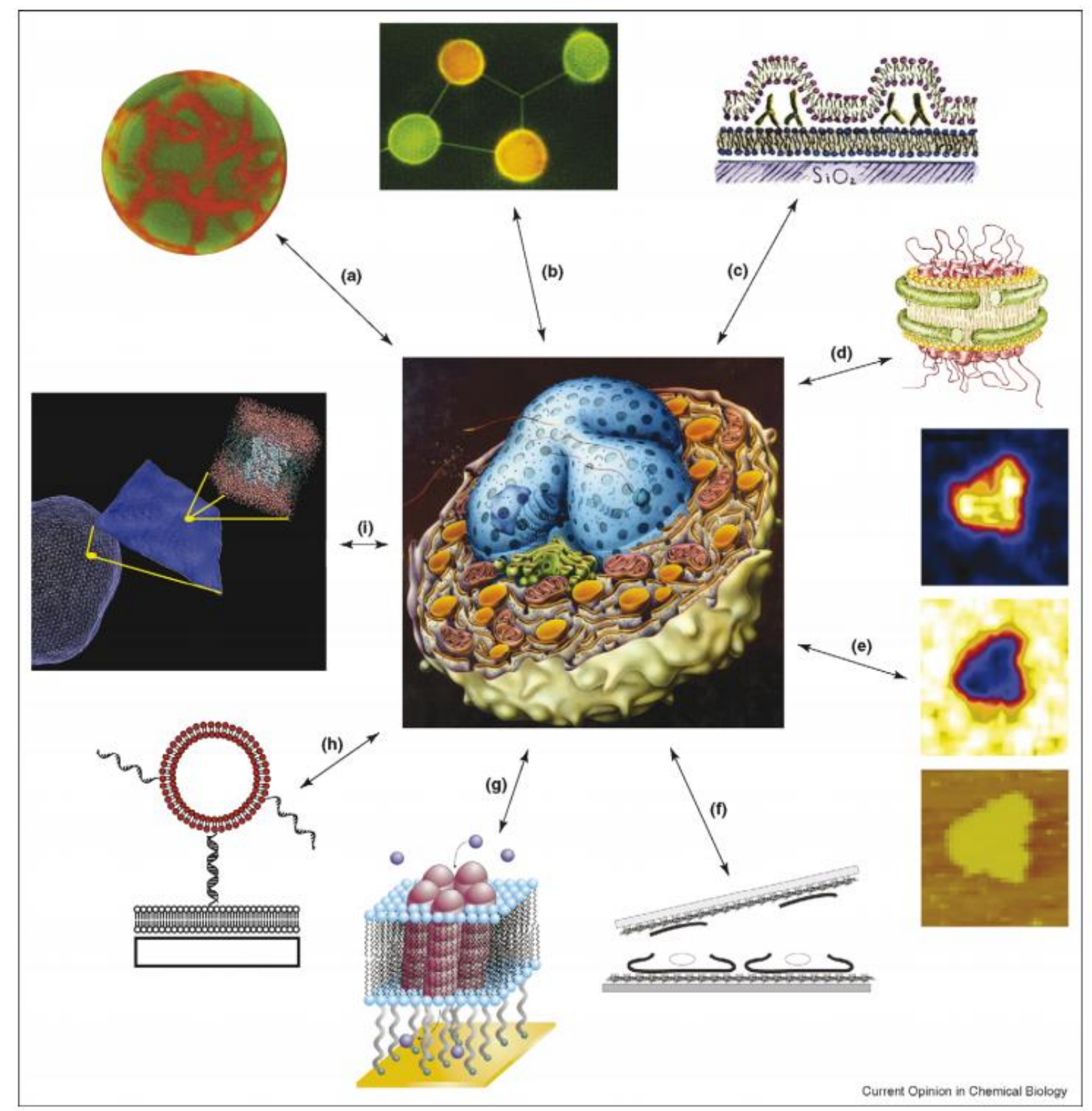

Figura 6: Modelos de sistemas de membrana lipídica.

No sentido horário, começando pelo canto superior esquerdo: (a) Vesículas unilamelares gigantes; (b) redes de vesículas gigantes ligadas por microtúbulos lipídicos; (c) GUV rompidas em bicamadas sólidas suportadas; (d) nanodiscos de membrana contendo proteinas de membrana; (e) bicamadas lipídicas suportadas analisadas pelo NanoSIMS; (f) membranas celulares rompidas em suportes sólidos; ( $g$ ) Bicamadas ligadas a um suporte sólido contendo canais iónicos; h) vesículas ligadas a uma bicamada lipídica suportada por DNA; (i) representação visual de simulações em escala múltipla. Imagem retirada de Chan et al. [6].

De acordo com Fenz et al. [7] um enorme progresso tem sido feito nos últimos anos na compreensão do funcionamento da célula viva, incluindo sua microanatomia, redes de 
sinalização e regulação de genes. No entanto, uma compreensão dos fenómenos celulares usando leis fundamentais a partir de princípios básicos e universais ainda está muito distante.

Parte da razão é que uma célula é um sistema ativo e extremamente complexo, onde cada parte está ligada à outra. Assim, é difícil ou mesmo impossível projetar experimentos que sondam seletiva e exclusivamente um aspecto escolhido da célula. Vários tipos de sistemas idealizados e modelos de células foram usados para contornar esse problema. Um exemplo importante é uma vesícula gigante unilamelar (GUV, também chamada de lipossoma gigante), que fornece um volume confinado do tamanho de uma célula para estudar reações bioquímicas, bem como processos de automontagem que ocorrem na membrana. A membrana de GUV pode ser projetada adequadamente para apresentar proteínas de membrana celular selecionadas, orientadas corretamente, cuja mobilidade está confinada a duas dimensões.

Neste trabalho de mestrado, utilizou-se vesículas unilamelares gigantes (GUVs) de composições lipídicas diferentes para:

1. Investigar a resposta de uma membrana com carga superficial negativa (mimetizando em primeira aproximação uma membrana de bactéria) sob foto-oxidação mediada pela fotoativação de um fotosensibilizador, azul de metileno (MB), disperso em solução aquosa.

2. Investigar a ação de duas toxinas formadoras de poros em membranas (Esticolisina I e Esticolisina II, ST I e ST II, respectivamente) em membranas contendo coexistência de fases fluido-gel e domínios lipídicos líquido ordenado (Lo) e Líquido Desordenado (Ld).

3. Investigar a ação de ST II em membranas contendo lipídeos oxidados.

Os próximos capítulos contextualizarão o estado da arte de cada tema, descrevendo os respectivos objetivos do trabalho em relação ao tema estudado. 


\section{CAPITULO 2. MATERIAIS E MÉTODOS}

Neste capítulo serão descritos os materiais utilizados para realização dos experimentos deste trabalho. Em suma, os materiais utilizados são lipídeos escolhidos para mimetizar membranas lipidicas. Vesiculas unilamelares gigantes (GUVs) foram formadas por dois métodos: eletroformação e método Gel de PVA, e observadas por microscopia ótica de contraste de fase e fluorescência. Na sequência, as imagens capturadas de cada experimento foram analisadas utilizando softwares como o ImageJ [8] e o PIPA (Package for Image Processing and Analysis desenvolvida pelo doutorando Gustavo Scanavachi do grupo de estudos da professora Rosangela Itri. Software ainda não disponiblizado, mas em [9] mostrase outro processador de imagem com funcionamento semelhante - Tracker Video Analysis and Modeling Tool) para processamento de imagens e avaliação da perda de contraste ótico das GUVs ao longo do tempo.

\subsection{Materiais}

Neste trabalho foram utilizados sacarose, glicose, azul de metileno obtido da SigmaAldrich, além dos lipídeos POPC, DOPC, POPG, DOPG, esfingomielina de cérebro e colesterol, todos obtidos da Avanti Polar Lipids.<smiles>CN(C)c1ccc2nc3ccc(=[N+](C)C)cc-3sc2c1</smiles>

Figura 7: estrutura quimica de azul de metileno (MB).

\subsubsection{Descrição dos lipídeos utilizados}

Abaixo são descritos sucintamente cada lipídeo utilizado, conforme website do provedor dos materiais, a Avanti Polar Lipids:

\subsubsection{POPC}

POPC (Figura 8) possui em sua cabeça polar a fosfatidilcolina (PC), e tem o nome completo 1-palmitoil-2-oleoil-sn-glicero-3-fosfocolina. Segundo Sligar et al. [10], trata-se de um fosfolipídeo importante para experimentos biofísicos e tem sido usado para estudar vários assuntos como domínios e jangadas lipídicas em membranas. Ainda segundo a mesma referência, o POPC também é usado em sistemas que simulam a membrana celular, como os Nanodiscs. Este lipídeo está disponível comercialmente sinteticamente (Avanti Polar Lipids) e está naturalmente presente nas membranas celulares eucarióticas. 


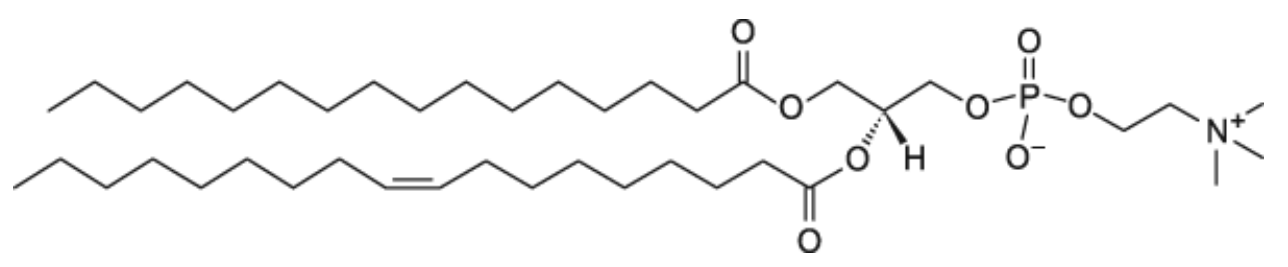

Figura 8: Estrutura molecular do POPC.

Fórmula $\mathrm{C}_{42} \mathrm{H}_{82} \mathrm{NO}_{8} \mathrm{P}$, informações $e$ figuras disponíveis em https://avantilipids.com/product/850457/

\subsubsection{DOPC}

O DOPC (Figura 9) é denominado 1,2-Dioleoil-sn-Glicerol-3-Fosfocolina, e também possui cabeça polar fosfatidilcolina (PC), o que faz este lipídeo muito semelhante ao POPC e DPPC. Este lipídeo é um componente importante das membranas biológicas e pode ser facilmente obtido a partir de uma variedade de fontes prontamente disponíveis, como gema de ovo ou soja, extraída mecanicamente ou quimicamente.

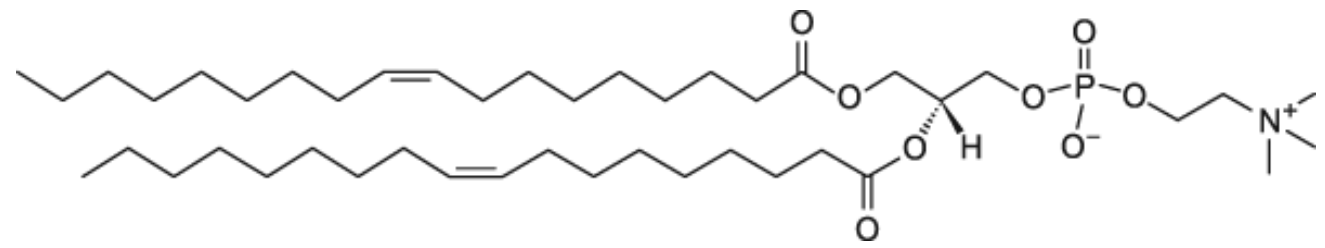

Figura 9: Estrutura molecular do DOPC.

Fórmula $\quad \mathrm{C}_{44} \mathrm{H}_{84} \mathrm{NO}_{8} \mathrm{P}$, informações e figuras disponíveis em https://avantilipids.com/product/850375/

\subsubsection{POPG}

O POPG (Figura 10) trata-se de um glicerofosfolipídeo (fosfolipídeo baseado em glicerol), com cabeça polar denominada fosfatidilglicerol. Segundo King et al. [11], tipicamente é encontrado no surfactante pulmonar (ainda segundo a mesma referência, as proteínas e lipídeos presentes no surfactante pulmonar reduzem a tensão superficial na interface entre o líquido presente na cavidade alveolar e o ar).

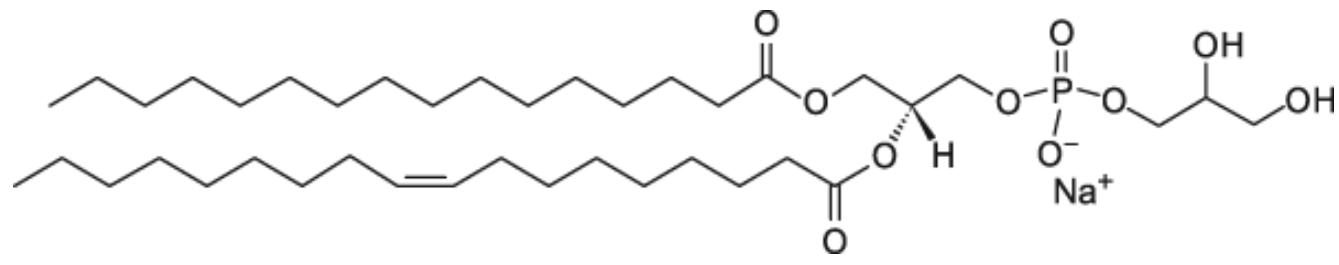

Figura 10: Estrutura molecular do POPG 
Fórmula $\quad \mathrm{C}_{40} \mathrm{H}_{77} \mathrm{O}_{10} \mathrm{P}$, informações e figuras disponíveis em https://avantilipids.com/product/840457/

\subsubsection{DOPG}

O DOPG (Figura 11) também se trata de um glicerofosfolipídeo, possuindo a mesma cabeça polar que o POPG, o fosfatidilglicerol, mas insaturação nas duas caudas.<smiles>CCCCCCCCC/C=C\CCCCCCCCC(=O)OC[C@H](COP(=O)([OH2+])OCC(O)CO)OC(=O)CCCCCCCCCCCC</smiles>

Figura 11: Estrutura molecular do DOPG.

Fórmula $\mathrm{C}_{42} \mathrm{H}_{79} \mathrm{O}_{10} \mathrm{P}$, informações e figuras disponíveis em https://avantilipids.com/product/840475/

\subsubsection{POPC-OOH}

Hidroperóxido lipídico (Figura 12), gentilmente produzido e fornecido pela Dra. Helena C. Junqueira do IQUSP. Conforme informação privada da Dra Junqueira, a foto-oxidação de POPC por MB pode gerar uma mistura das duas formas esquematizadas de POPC-OOH (Figura 12).<smiles>CCCCCCCC=CC(O)CCCCCCCCC(=O)OC[C@H](COP(=O)([O-])OCC[N+](C)(C)C)OC(=O)CCCCCCCCCCCC</smiles><smiles>CCCCCCCCCCCCCCCC(=O)OC[C@H](COP(=O)([O-])OCC[N+](C)(C)C)OC(=O)CCCCCC/C=C/C(O)CCCCCCCC</smiles>

Figura 12: Isômeros estruturais de POPC-OOH. Fórmula C36H70NO10P.

\subsubsection{PazePC}

Trata-se de lipídeo oxidado (Figura 13) obtido comercialmente junto à Avanti Lipids. 


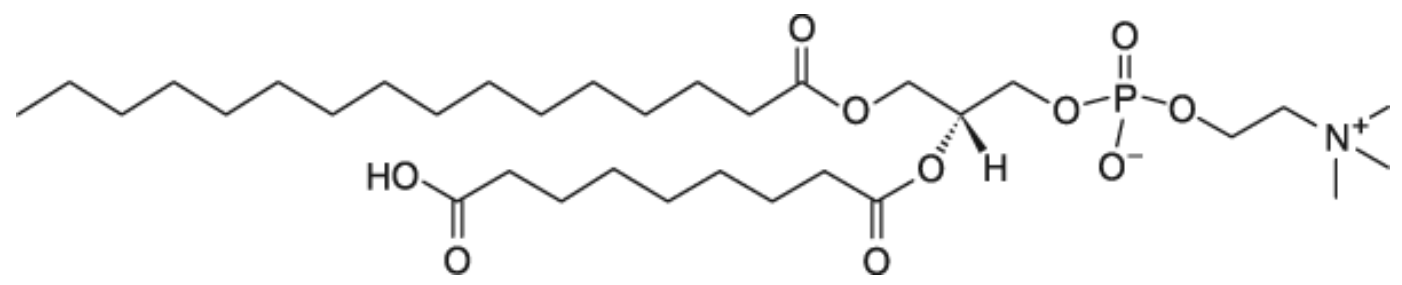

Figura 13: Estrutura molecular do PAzePC

Fórmula $\mathrm{C}_{33} \mathrm{H}_{64} \mathrm{NO}_{10} \mathrm{P}$, informações e figuras disponíveis em https://avantilipids.com/product/870600

\subsubsection{Esfingomielina (SM) (Figura 14)}

Como principal constituinte das membranas celulares, a esfingomielina é encontrada em concentrações particularmente elevadas nas membranas das células nervosas (nas bainhas de mielina) e nos glóbulos vermelhos.

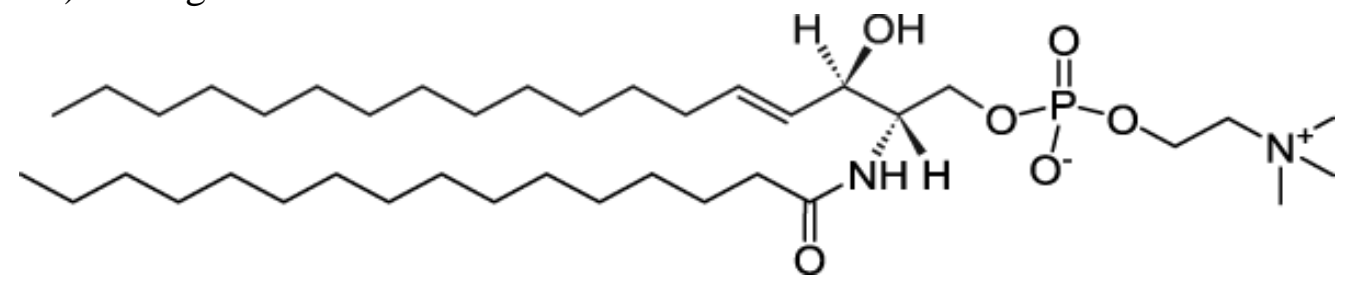

Figura 14: Estrutura molecular da SM.

Figuras disponíveis em https://avantilipids.com/product/860061

\subsection{Métodos}

$\mathrm{Na}$ preparação das vesículas gigantes foram utilizados um gerador de função de onda (Minipa MFG-4201A), um multímetro digital DT-830B e um osmômetro Gonotec Osmomat 030 .

Para a obtenção das imagens das vesículas gigantes utilizamos o microscópio invertido (Zeiss, Axio Observer D1, Germany) equipado com as objetivas Plan Neo-Fluar 63x Ph2 (NA 0.75) e A-plan 10x Ph1 (NA 0.25) e uma câmera AxioCam MRm acoplada. Filtros com excitação em 538-563 nm e emissão em 570-564 nm (Zeiss filter set $43 \mathrm{HE}$ ) e uma lâmpada de mercúrio HXP-R 120W foram utilizados para observar vesículas fluorescentes contendo DOPE-Rodamina. Filtros de excitação e emissão ( lâmpada de 103W HG (HXP 120, Kubler, Carl Zeiss e $\lambda_{\mathrm{ex}}=665 \mathrm{~nm}$ e $\lambda_{\mathrm{em}}=725 \mathrm{~nm}$ ) do Azul de Metileno (MB) foram utilizados para irradiar as amostras in situ, quando o caso. 


\subsubsection{Preparação de Vesículas Unilamelares Gigantes - GUVs e medidas experimentais}

A formação de GUVs foi realizada pelo método de eletroformação. De maneira resumida, o método consiste em espalhar cerca de 20 microlitros da solução de lipídeo sobre duas lâminas de vidro recobertas por uma liga de óxido de índio e óxido de estanho formando uma superfície condutora (ITO). Um espaçador de teflon de $2 \mathrm{~mm}$ de espessura é colocado entre as duas lâminas que são presas com duas presilhas formando uma câmara semifechada. A câmara é preenchida por uma solução de sacarose $0,2 \mathrm{~mol} / \mathrm{L}$. Um gerador de função é conectado em cada uma das lâminas e uma tensão de $2 \mathrm{~V}$ é aplicada com uma frequência de $10 \mathrm{~Hz}$ em corrente alternada por 2 horas (vide Figura 15 abaixo). Quando estudamos GUVs contendo esfingomielina (SM) na composição da membrana, a câmara era colocada num forno a temperatura de $55{ }^{\circ} \mathrm{C}$ por 2 horas e depois deixada resfriar lentamente até a temperatura ambiente antes da utilização.

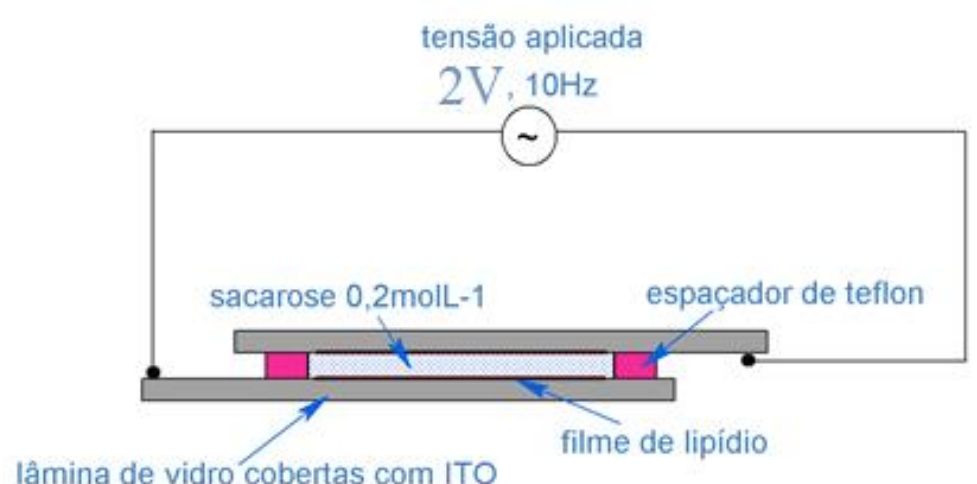

Figura 15: Arranjo experimental para crescimentos de GUVs via eletroformação.

Depois desse período de espera tem-se uma solução contendo GUVs embebidas com sacarose dentro e fora da vesícula. Essa solução é então diluída cerca de 10 vezes numa solução de glicose de mesma osmolaridade (0,2 mol/L), compondo assim, uma solução de vesículas cujo interior possui sacarose e na parte exterior existe glicose. Essa diferença nas soluções interna e externa permite que haja um contraste ótico na análise visual via microscópio de contraste de fase, pois o índice de refração da sacarose é diferente do da glicose, possibilitando a observação no microscópio óptico, além de fazer com que as vesículas decantem na lamínula uma vez que a sacarose possui uma densidade molecular maior, facilitando a observação através do microscópio invertido. Vale ressaltar aqui que as soluções de glicose e sacarose possuem rigorosamente a mesma osmolaridade (medida com o 
auxílio de um osmômetro) para evitar diferenças de pressão osmótica sobre a membrana. No caso de GUVs dispersas em solução de MB, a solução inicial de GUVs será diluida numa solução de glicose contendo azul de metileno $(10 \mu \mathrm{M})$.

\subsubsection{Preparação de Vesículas Unilamelares Gigantes pelo Método Gel}

No interior de poços de teflon são espalhados $200 \mu \mathrm{L}$ de PVA. Em seguida os poços são levados a uma estufa para que o PVA possa secar e formar uma camada de gel. Logo após é espalhada uma pequena quantidade de solução lipídica diluída em clorofórmio, e levada a um dessecador por 15 minutos. Em seguida acrescenta-se $200 \mu \mathrm{L}$ de solução de sacarose e após 90 minutos tem-se GUVs prontas. Porém para ser possível a visualização em contraste de fase é necessário realizar a diluição das GUVs (normalmente 1:100) em glicose 0,2mol/L.

Somentes as GUVs contendo PazePC foram crescidas utilizando esta metodologia, pois devido a sua estrutura quimica com uma grupo carboxila na região terminal da cadeia alquilica truncada (Figura 13), apenas o método gel propiciou a formação de GUVs.

\subsection{Avaliação de Resultados}

Após preparar e crescer as diferentes GUVs, todas foram analisadas via microscopia ótica, registrando as imagens ao longo do tempo.

Desta maneira, em todos os experimentos realizados, buscou-se avaliar trocas na permeabilidade da membrana, através de variações do contraste de fase da medida experimental. Tal variação indica possível formação de nanoporos ou defeitos na bicamada lipídica que permite a troca de glicose e sacarose das soluções externas e internas das lipossomas gigantes.

Para obter medidas quantitativas da variação do contraste de fase, foram analisadas fotografias da evolução temporal das GUVs. Inicialmente, estas análises foram feitas uma a uma "manualmente", utilizando o software ImageJ [8]. Este software de domínio público, foi feito em Java sendo destinado ao processamento de imagens, desenvolvido inicialmente pelo National Institute of Health [8]. Este programa de computador permite traçar o perfil de pela imagem da GUV analisando os niveis de cinza, em um dado momento do tempo, obtendo assim um valor para a base e outro para o pico maximo do contraste de fase. Desta maneira, ao traçar o perfil das GUVs ao longo do tempo, e medir a evolução da diferença entre a base e o pico do contraste de fase, pode-se traçar graficamente a evolução temporal do contraste de fase. A partir desta análise gráfica, pretende-se inferir sobre quais os possíveis efeitos que 
podem estar ocorrendo na membrana da GUV, causando (ou não) sua perda de contraste ótico e como evolui ao longo do tempo dependendo da composição lipídica da GUV.

Na figura abaixo está um exemplo de perfil traçado para um exemplo de GUV. Notase que os picos do perfil se encontram justamente no entorno da membrana da GUV, e conforme ocorre a perda do contraste de fase, a diferença entre o pico e a base do perfil diminui.

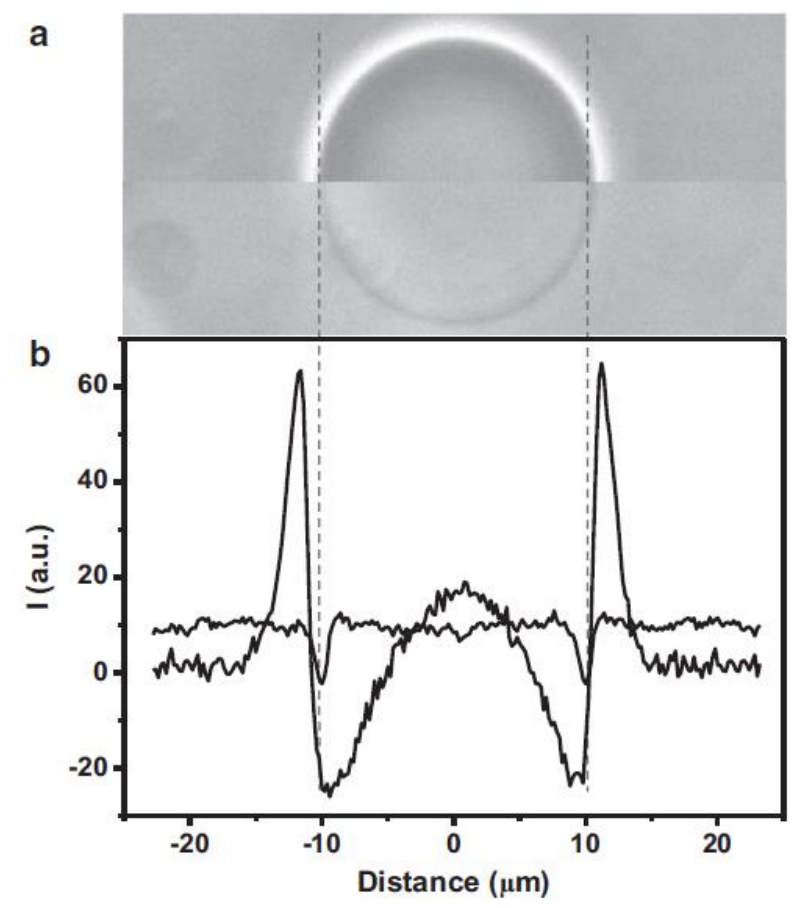

Figura 16: Exemplo de análise do contraste de fase de uma GUV. Figura retirada de Mertins et al. [12].

A metade superior da parte (a) da figura mostra a GUV na presença de MB antes de ser irradiada. Já a parte debaixo da figura (a) mostra a mesma GUV na presença de MB após receber fotoirradiação, demonstrando que existe a perda de contraste e evidenciando a formação de poros na membrana.

Na parte (a) da figura pode-se notar a microscopia de contraste de fase de uma GUV, e o decaimento do contraste de fase (neste exemplo gerado pela ação do Azul de Metileno fotoativado a $665 \mathrm{~nm}$ ). A imagem da GUV está cortada na metade para mostrar a diferença entre o "antes" e "depois" da perda de contraste de fase.

$\mathrm{Na}$ parte (b) da figura está destacado uma comparação dos perfis de intensidade no centro da GUV. Neste gráfico, o eixo y mede o nível de intensidade do contraste e o eixo x corresponde à posição (em micrometros) na imagem. Desta maneira, a curva de intensidade 
mais alta mostra o nível de contraste de fase no inicio do experimento e e a curva de intensidade mais baixa (intencionalmente deslocada até a média zero) mostra o nível de contraste de fase após a GUV perder completamente o contraste.

Após a análise dos experimentos utilizando o software ImageJ, foi desenvolvido pelo doutorando Gustavo Scanavachi, do grupo de estudos da Profa. Rosangela Itri, uma nova rotina de análise de imagens de maneira automatizada (ainda a ser publicado futuramente, mas já batizado como PIPA - Package for Image Processing and Analysis). Tal software, (semelhante ao "Tracker" [9], para análise de vídeo e modelagem). Foi aproveitado a oportunidade de comparar os resultados obtidos "manualmente" com aqueles obtidos pelo novo software. Ficou muito claro que o programa funciona muito bem ao comparar os resultados analiticos obtidos. Ressalta-se aqui que o objetivo deste trabalho não foi validar o novo software. Mas como este se mostrou mais rápido e confiável para análise dos dados experimentais, todos os gráficos e tabelas apresentados neste trabalho de mestrado foram feitos utilizando o novo software. 


\section{CAPITULO 3. OBJETIVOS E RESULTADOS EXPERIMENTAIS}

Esta dissertação de mestrado envolve o estudo de membranas lipídicas utilizando vesículas unilamelares gigantes (GUVs) como modelos. Foram crescidas GUVs com diferentes composições lipídicas, com dois diferentes métodos e expostas ao impacto de agentes externos, como irradiação com luz na presença de um fotosensibilizador ou expostas em ambientes aquosos contendo toxinas formadoras de poros em membrana.

O primeiro assunto explorado foi o efeito da fotoirradiação sobre GUVs com diferentes composições lipídicas na presença de uma solução contendo Azul de Metileno (MB). Este estudo vem em continuidade ao artigo "Physical Damage on Giant Vesicles Membrane as a Result of Methylene Blue Photoirradiation" [12]. Neste artigo verificou-se que aumentando a concentração de $\mathrm{MB}$, acelera-se a perda de contraste de fase da membrana de GUVs compostas por POPC e DOPC, evidenciando que houve modificação da mesma via formação de poros na membrana. Nos estudos aqui realizados, manteve-se constante a concentração de MB, e variou-se a composição lipídica das membranas das GUVs.

Estudar estes efeitos de oxidação lipídica da membrana celular é de suma importância para a compreensão dos mecanismos envolvidos em terapia fotodinâmica, fotoenvelhecimento e algumas doenças neurodegenerativas. O estresse oxidativo promove peroxidação lipídica [13], que por sua vez gera danos na membrana e desencadeia cascatas de sinalizações que levam a morte celular. De maneira interessante, sabe-se que peroxidação lipídica pode ser responsável pela separação de diferentes tipos de fosfolipídeos em membranas, chamados domínios ou rafts lipídicos - coexistência de fase líquido ordenada e líquido desordenada (conforme Haluska et al [14] e Tsubone et al. [15]). A coexistência de fase pode ser um dos fatores determinantes para a atividade de proteínas específicas. Neste trabalho, investigaremos o mecanismo de ligação e possível agregação de duas proteínas formadoras de poros Esticolisina I e II (ST I e STII) em membranas contendo lipídeos oxidados, domínios contendo lipídeos oxidados em comparação com membranas não oxidadas e que possuem uma certa carga superficial, determinando alterações nas propriedades biofísicas das membranas na ausência e presença de estresse oxidativo.

O assunto seguinte estudado neste trabalho aborda a variação do comportamento das membranas das GUVs na presença das toxinas ST I e ST II. Estes estudos têm como referência o artigo de Pedrera et al. [16]. A Esticolisina I e II (ST I e ST II, respectivamente) são produzidas pela anêmona Stichodactyla helianthus, do Mar do Caribe, pertencente à 
família das actinoporinas. Utilizamos microscopia óptica e investigamos os efeitos de ST I e II com diferentes concentrações em GUVs formadas a partir dos lipídeos DOPC, POPC, POPC-OOH, Esfingomielina (SM) e Colesterol (CHOL). Segundo proposto em Pedrera et al. [16], a presença de CHOL e a coexistência de fases lipídicas aumentam a ligação das toxinas à membrana alvo e a capacidade de formação de poros das mesmas.

Ao longo do mestrado foram estudados outros assuntos também, que não fazem parte desta dissertação mas contribuiram para o desenvolvimento do aluno. Por exemplo, no anexo deste encontra-se estudo sobre a utilização de extrato de aloe vera para blindar membranas de GUVs dos efeitos de radiação UV. Os estudos aqui demonstrados foram utilizados para publicação do paper "Mechanism of Aloe Vera extract protection against UVA: Shelter of lysosomal membrane avoids photodamage" [17] .

O envelhecimento prematuro da pele caracterizado por rugas, textura de couro e pigmentação é uma consequência bem documentada da exposição à luz solar. O UVA é um importante fator de risco para câncer humano também associado à indução da inflamação, imunossupressão, fotoenvelhecimento e melanogênese. Embora compostos fitoterápicos sejam comumente usados como fotoprotetores contra os efeitos nocivos dos UVA, os mecanismos envolvidos no fotodano não são precisamente conhecidos. Investigou-se no trabalho em questão os efeitos da Aloe Vera (Aloe barbadensis mil) na proteção contra a morte celular modificada pela UVA. De fato, a aloe vera exibiu notável capacidade de reduzir dano por irradiação.

\section{OBJETIVOS DA DISSERTAÇÃO:}

Este trabalho de mestrado teve como objetivo estudar o comportamento de membranas lipídicas, usando como modelo Vesiculas Unilamelares Gigantes (GUVs), com diferentes composições e também em diferentes condições. O foco principal é determinar como variações na composição lipídica da membrana alteram propriedades físicas das mesmas, como a formação de poros, de dominios e a subsequente perda de contraste de fase na ausência e presença de estresse oxidativo.

Particular ênfase será dada na comparação de membranas zwiteriônicas (eletricamente neutro mas com cargas opostas em diferentes átomos) versus aniônicas, membranas oxidadas e membranas contendo domínios lipídicos. Os objetivos específicos são, portanto: 
1) Nos trabalhos comparativos com Mertins et al. [12], busca-se investigar, por microscopia ótica de contraste de fase, GUVs compostas por POPC (membranas zwiteriônicas) e POPG (aniônicas) dispersas em solução contendo a molécula fotosensibilizadora azul de metileno, $\mathrm{MB}$, a $10 \mu \mathrm{M}$, sob irradiação com comprimento de onda de $600 \mathrm{~nm}$ (próximo ao máximo de absorção do MB). Será avaliado o aumento de permeabilidade da membrana através da variação de contraste de fase. Estudaremos também GUVs de DOPC e DOPG. Ambos fosfolipídeos diferem de POPC e POPG, respectivamente, tendo uma insaturação em cada cauda alifática (cadeia carbônica aberta).

2) Nos estudos baseados em Pedrera et al. [16], buscou-se analisar como a ação das toxinas ST I e ST II em membranas das GUVs diferem para distintas composições lipídicas.

3) Nos estudos baseados em Itri et al. [13] buscou-se analisar qual a influência de lipídeos oxidados em membranas sob ação da toxina ST II. 


\subsection{Danos à Membranas de GUVs pelo efeito da fotoirradiação na presença de azul de metileno}

A era "dourada" dos antibióticos está prestes a chegar a um final abrupto, uma vez que as bactérias estão adquirindo resistência contra todas as drogas atualmente no mercado e enquanto o repertório molecular para novos antibiótios está secando. $\mathrm{O}$ desenvolvimento de melhores estratégias terapêuticas é preditivo de benefícios clínicos e sociais significativos. Curiosamente, PDT (Photodynamic Therapy ou terapia fotodinâmica) tem sido recentemente demonstrado ser uma alternativa interessante no combate a algumas bactérias. Este tipo de PDT é chamado de PDT antimicrobiano (ou aPDT). Uma característica atraente da aPDT é a falta de um alvo específico da terapia, o que reduz significativamente a chance de desenvolvimento de resistência. De fato, a resistência à aPDT ainda não foi observada. Os requisitos para o PS (fotosensibilizador) a ser usado em aPDT são muito comparáveis aos da PDT anticancerígena e o direcionamento de células bacterianas pode até ser mais fácil do que no câncer, uma vez que são fundamentalmente diferentes de células humanas. Com a ameaça iminente de resistência antibiótica generalizada, PDT antimicrobiana (aPDT) detém um tremendo potencial e pode ser uma nova abordagem necesssária para combater as superbactérias emergentes, resistentes à multidrogas (Foote et al. [28] e Liu et al. [29]).

Os estudos de Mertins et al. [12] analisam de maneira detalhada o fotodano promovido em membranas de vesículas unilamelares gigantes compostas por DOPC e POPC, por irradiação do MB presente na solução de vesículas gigantes unilamelares. Por meio de experimentos de microscopia ótica e de eletro-deformação, o dano físico na membrana da vesícula foi seguido e a oxidação dos fosfolipídios foi avaliada em termos de mudanças na área de superfície da membrana e permeabilidade. Conforme esperado, a oxidação modifica as características estruturais dos fosfolipídios que levam a alterações notáveis na membrana. Ao comparar DOPC - com membranas feitas por POPC, o estudo mostra que a taxa de formação de poros e degradação de vesículas em função da concentração de azul de metileno segue uma lei de difusão no caso de DOPC e uma variação linear no caso de POPC. Atribuiuse esse cenário ao processo de nucleação de espécies oxidadas seguindo um regime de crescimento limitado por difusão para DOPC e, no caso de POPC, um processo de nucleação homogênea. Esta informação mostra que o resultado das reações de fotossensibilização é criticamente dependente do tipo de lipídeo presente na membrana.

Em continuidade e buscando entender o efeito de fotoirradiar MB em membranas miméticas de bactérias, investigamos neste trabalho, numa primeira aproximação, 
membranas compostas por POPC:POPG e DOPC:DOPG, variando a carga superficial da membrana através de variações da quantidade de fosfolipídeo carregado negativamente POPG e DOPG. Os resultados são apresentados abaixo:

\subsubsection{Medidas com Azul de Metileno disperso em solução de membranas compostas por POPC e POPG}

As imagens abaixo (Figura 17) mostram qualitativamente a perda de contraste ótico em função do tempo de irradiação de GUVs, na presença de MB para diferentes proporções de POPC:POPG (8:2 na imagem superior direita, 9:1 na imagem inferior esquerda e 1:1 na imagem inferior direita). Amostras controle sem irradiação não apresentaram perda de contraste ótico até 20 minutos de observação.

À primeira percepção, nota-se que na medida onde não existe a presença do POPG (imagem superior esquerda) a GUV não perde contraste após 20 minutos de irradiação.
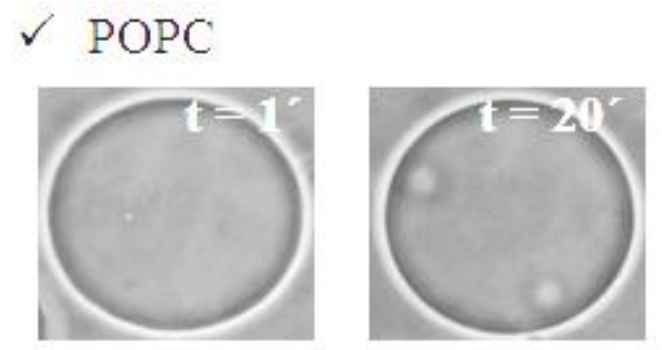

$\checkmark$ POPC:POPG $-(9: 1)$

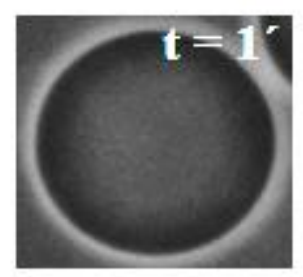

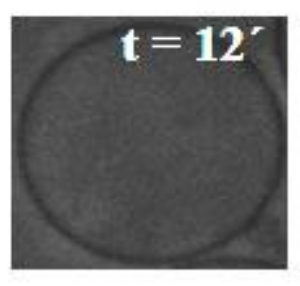
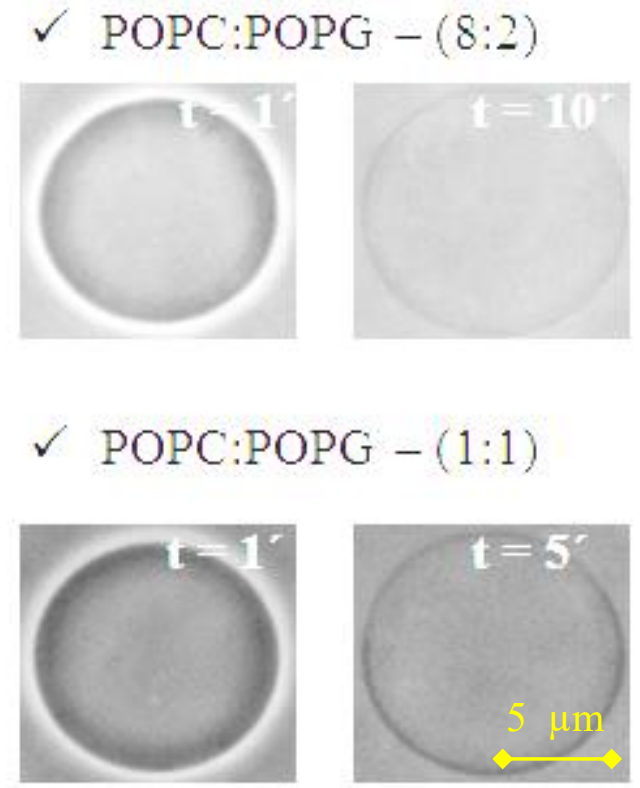

Figura 17: Fotos das GUVs compostos por POPC:POPG em diferentes razões molares dispersas em solução contendo $M B(10 \mu M)$ sob irradiação contínua de $\lambda=655 \mathrm{~nm}$, objetiva de $60 x$.

Após análise exploratória visual das GUVs sob diferentes composições, foi feito a análise da perda da intensidade de contraste ao longo do tempo para as diferentes proporções de POPG para POPC. Abaixo apresentamos o gráfico (Figura 18) mostrando evolução temporal da perda de contraste para GUVs compostos por POPC e POPG em diferentes proporções (POPC:POPG 1:0, POPC:POPG 9:1, POPC:POPG 8:2, POPC:POPG 7:3 e POPC:POPG 1:1). 
Nota-se que as GUVs de POPC puro não perdem contraste durante o experimento até 1.200 s de foto irradiação, ao passo que todas as outras medidas mostram perda de contraste ao longo do tempo. A segunda observação do gráfico abaixo refere-se ao fato que conforme aumenta-se a proporção de POPG na composição lipídica da membrana, a perda de contraste ocorre de maneira mais rápida. Todas as medidas com POPG mostram que a intensidade diminui até um nivel semelhante de contraste ( em torno de $10 \%$ da intensidade máxima de cada caso), ocorrendo de maneira mais rápida conforme aumenta-se a proporção de POPG.

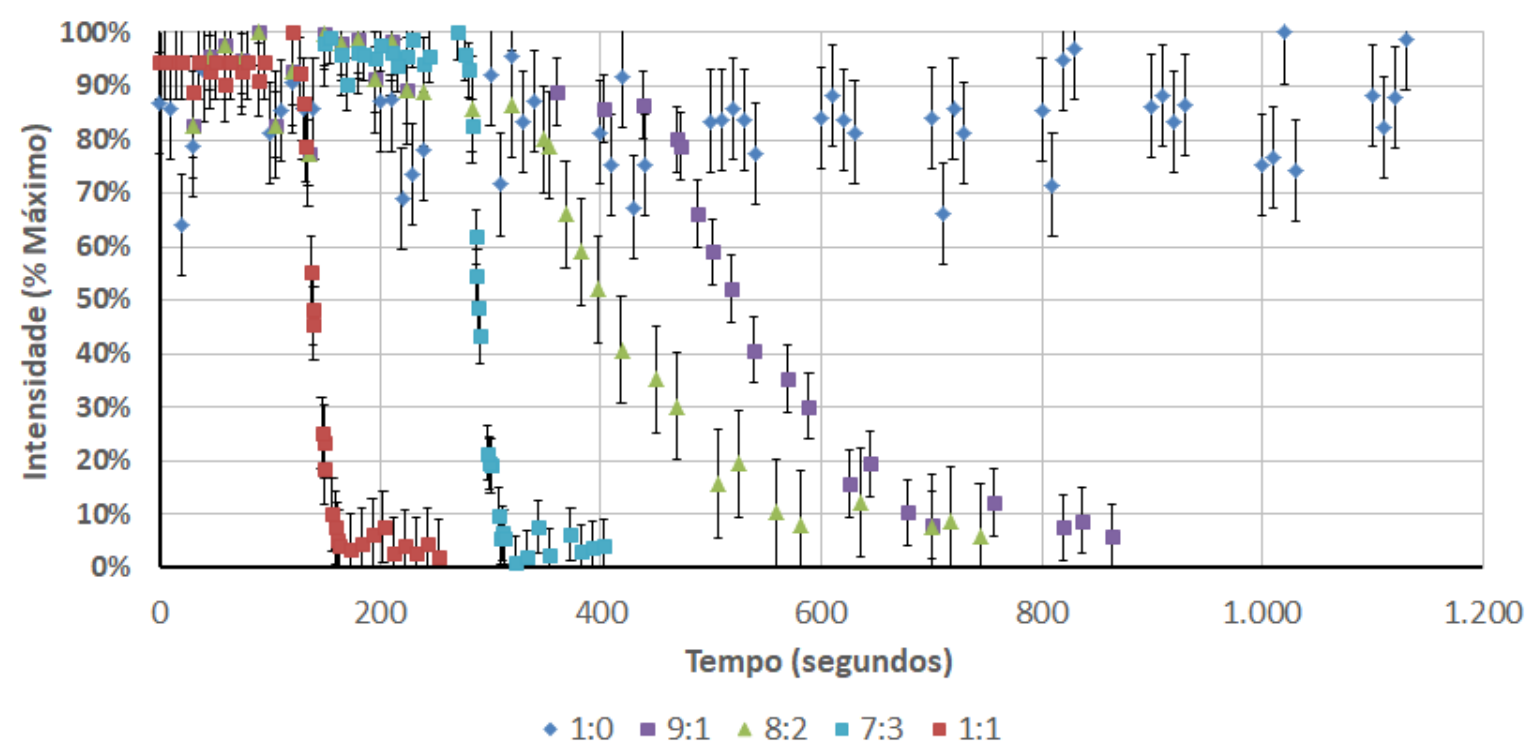

Figura 18: Evolução da perda de contraste para POPC:POPG em diferentes concentrações (os números na legenda representam a proporção entre POPC e POPG ). Estes dados foram analisados com Image $J$ e as barras de erro foram calculadas conforme descrito no anexo anexo 6.3 Cálculo de incertezas nas medidas obtidas .

Estes resultados estão de acordo com aqueles encontrados em Mertins et al. [12], uma vez que as medidas de POPC puro somente começam a perder contraste para tempos acima de 1.000s. Por outro lado, obervamos neste trabalho que conforme a concentração de POPG aumenta na membrana, e portanto aumento da densidade superficial de carga negativa, mais rápidamente as GUVs perdem contraste. A tabela 1 mostra os resultados evidenciando o tempo de irradiação para que se inicie a perda de contraste otico, até atingir metade do nivel de contraste inicial e tempo até perda total de contraste ótico.

\begin{tabular}{|l|r|r|r|r|r|}
\hline & $\mathbf{1 : 0}$ & $\mathbf{9 : 1}$ & $\mathbf{8 : 2}$ & $\mathbf{7 : 3}$ & \multicolumn{1}{c|}{$\mathbf{1 : 1}$} \\
\hline Tempo para início de queda (s) & - & 434 & 382 & 301 & 173 \\
Tempo até atingir metade intensidade (s) & - & 532 & 403 & 307 & 180 \\
Nível de estabilidade (\% Intensidade) & 90 & 11 & 8 & 6 & 5 \\
Tempo até atingir estabilidade (s) & - & 685 & 583 & 364 & 193 \\
\hline
\end{tabular}

Tabela 1: Perda de contraste de fase para POPC:POPG em diferentes concentrações 
Portanto, concluimos que o aumento da densidade de carga negativa na membrana favorece a ligação do azul de metileno na membrana de POPC:POPG, uma vez que MB (Figura 7) possui carga positiva no $\mathrm{pH}$ estudado (em torno de 6.0). Como consequência, a fotoirradiação de MB ligado na bicamada lipídica favorece a produção de uma grande quantidade de oxigênio singlete próximo a dupla ligação da cadeia alquílica. Isto dispara a reação de peroxidação lipídica de maneira mais acentuada do que quando MB está disperso em solução contendo membranas apenas de POPC. Vale a pena ressaltar aqui que o tempo de vida de oxigênio singlete em solução aquosa é da ordem de microsegundos. Assim, apenas as moléculas de oxigênio singlete produzidas no entorno de $100 \mathrm{~nm}$ de membranas de POPC são capazes de atingir a membrana e atacar as duplas ligações lipidicas. Desta maneira, a presença de POPG na membrana favorece a ligação de MB e induz, de maneira indireta, a formação mais rápida de poros nas bicamadas lipidicas, aumentando sua permeabilidade e consequentemente diminuindo o contraste observado.

É bem conhecido que a formação de poros em membranas por foto-oxidação está associada a formação de lipídeos de cadeia encurtada [12]. Resultados de dinâmica molecular mostram que fosfolipídeos de cadeia encurtada contendo grupos aldeido ou carboxila na terminação, como PazePC (Figura 13) por exemplo, induzem a geração de poros na membrana, sendo mais rápido quanto maior a quantidade de lipídeo oxidado na membrana [20]. Vale a pena ressaltar aqui que membranas contendo uma grande quantidade de lipídeos oxidados de cadeia curta perdem a estabilidade e sofrem ruptura [18].

Para melhor entender os passos de oxidação lipidica e os efeitos observados neste trabalho, apresentamos a Figura 19 a seguir. O inicio da oxidação lipidica acontece através da formação de oxigênio singlete, via desexcitação do MB por mecanismo tipo II (transferência de energia para oxigênio molecular). O oxigênio singlete ataca a dupla ligação da cauda lipidica, gerando um hidroperóxido com um grupo $\mathrm{OOH}$ ligado à cauda (no caso de POPC-OOH por exemplo ver Figura 12). Conforme trabalhos anteriores experimentais do grupo e dados de dinâmica molecular, a formação de POPC-OOH promove aumento de área superficial da membrana, mas não induz abertura de poros ([22], [23] e [24]).

Para que ocorra a formação de poros na membrana foto-oxidada, a reação de oxidação deve continuar. Foi mostrado recentemente por dinâmica molecular que o azul de metileno no estado excitado tripleto (Figura 19) se orienta na membrana ficando proximo do grupo $\mathrm{OOH}$ (Figura 19). Nesta situação a localização do MB no estado excitado tripleto favorece a 
abstração do proton do grupo $\mathrm{OOH}$ (mecanismo tipo I), dando continuidade a reação e levando a formação de fosfolipídeos de cadeia truncada [25].

Portanto, nossos resultados experimentais evidenciam que o aumento da quantidade de POPG na membrana deve favorecer um aumento da ligação de MB na membrana por atração eletrostática. Como consequência, a subsequente foto-oxidação do MB gera inicialmente POPC-OOH e POPG-OOH cuja taxa de produção é maior quanto mais POPG está contido inicialmente na membrana. Na sequência ocorre a continuidade da reação levando a formação de poros na membrana, identificada como perda de contraste ótico das GUVs por videomicroscopia.
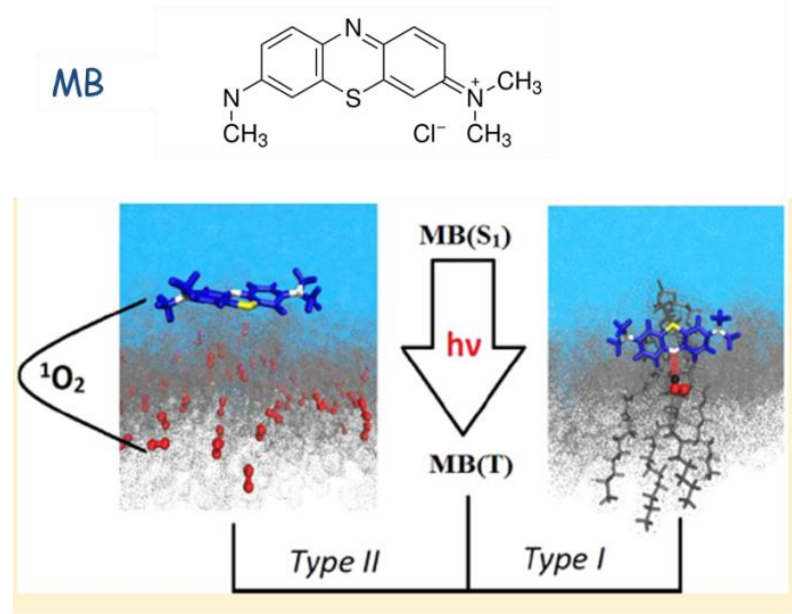

Lipideos oxidados de cadeia encurtada

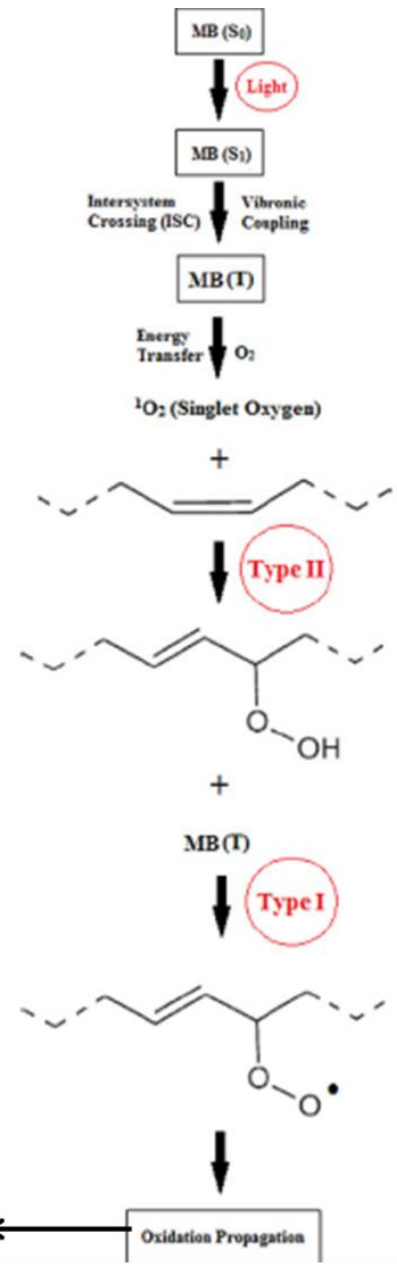

Figura 19: adaptada de Souza et al. [25]: no desenho (painel esquerdo) o grupo hidroperóxido está representado por esferas vermelhas $(O)$ e brancas $(H)$.

\subsubsection{Medidas com Azul de Metileno: DOPC:DOPG sob fotoirradiação}

Foi repetido o procedimento experimental, mas utilizando GUVs com membranas compostas por DOPC e DOPG ao invés de POPC e POPG. Novamente variou-se as 
concentrações de DOPG, também contribuindo com carga negativa na membrana, mas que contém uma insaturação em cada cadeia alifática. Porém, não foi possivel observar perda de contraste uma vez que praticamente todas as GUVs estouravam espontaneamente para a mesma concentração de $\mathrm{MB}$ de $10 \mu \mathrm{M}$ disperso em solução. Abaixo estão imagens de algumas das medidas realizadas, demonstrando que em relativamente pouco tempo, todas as GUVs estouravam. Portanto, concluimos que o fato dos lipídeos possuirem duas insaturações induz a formação acentuada de poros e desestabilização rápida da membrana, nas mesmas condições do experimento anterior.
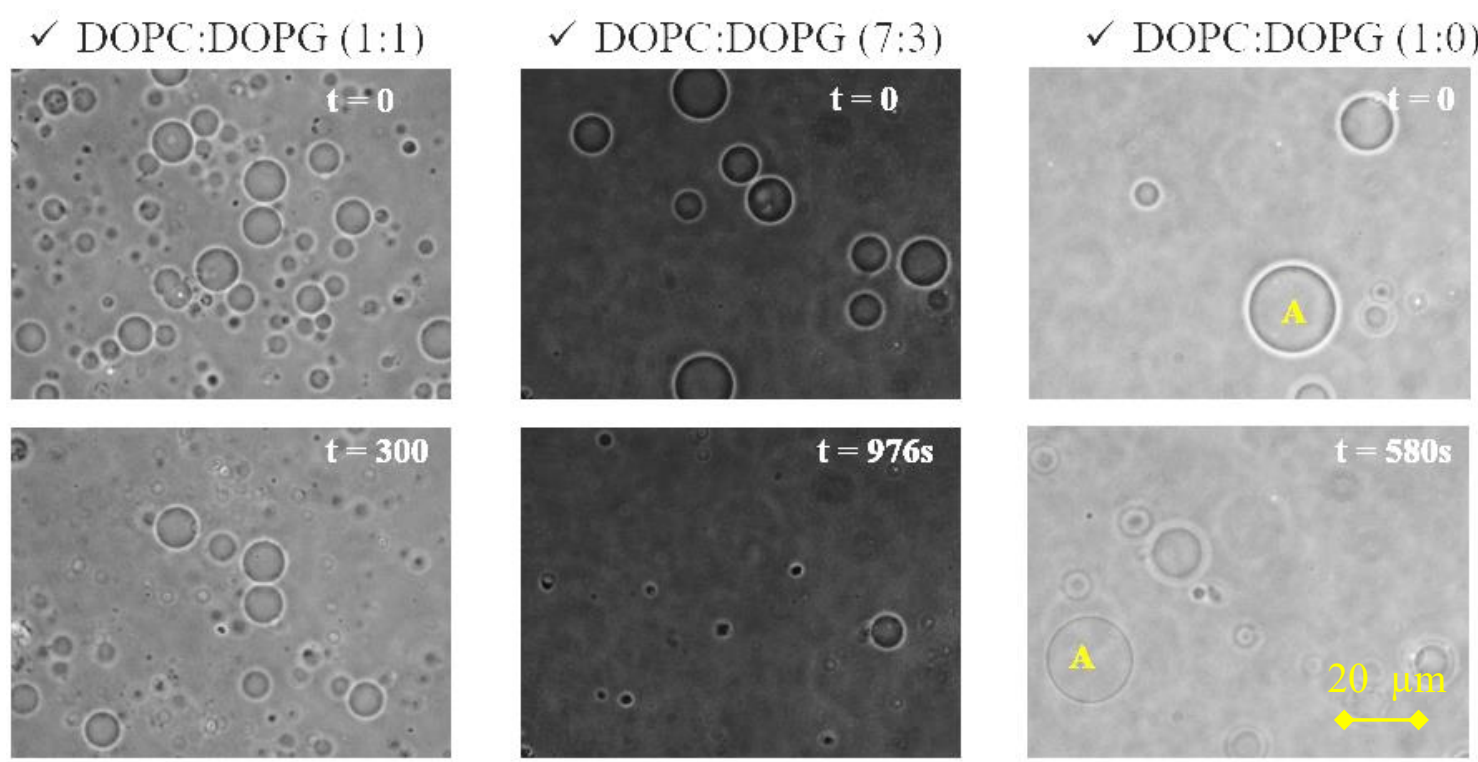

Figura 20: Fotos das GUVs dispersas em $10 \mu M$ de $M B$, perdendo contraste para DOPC:DOPG em diferentes concentrações de DOPG sob irradiação contínua de $\lambda=655 \mathrm{~nm}$; objetiva de $10 x$.

Vale ainda ressaltar que para nos assegurar que o problema não era de GUVs estourando por absorção rápida no substrato (lamínula de vidro), utilizou-se o procedimento de preencher o porta-amostra com GUVs, irradiá-las, esperar absorção no vidro e novamente preencher o porta-amostra com nova solução de GUVs. Forma-se um filme de lipídeos que protege, em princípio, a absorção de GUVs subsequentes. Porém, mesmo utilizando este procedimento as GUVs compostas por DOPC:DOPG estouravam rapidamente por fotoirradiação. 


\subsection{Efeito das Toxinas ST I e ST II em membranas miméticas observadas por microscopia otica de GUVs}

Nos próximos itens do Capitulo, investigamos o efeito de toxinas em membranas modelo, sendo que inicialmente comparamos a ação de STI e STII em GUVs compostas por lipídeos não oxidados, para na sequência estudarmos GUVs formados por lipídeos oxidados na presença de toxinas. Esta parte do trabalho foi feita em colaboração parcial da profa Dra Maria Eliana Lanio-Ruiz e do prof.Carlos Alvarez, ambos da Universidade de Havana, Cuba.

\subsubsection{Efeito das Toxinas STI e STII em GUVs Contendo Lipídeos Não Oxidados}

Conforme descrito anteriormente, a Esticolisina I (St I) é uma toxina formadora de poros (PFT) produzida pela anêmona do mar do Caribe, Stichodactyla helianthus, pertencente à família das proteínas actinoporinas, uma classe única de PFT eucarióticos. Quanto às actinoporinas, foi proposto no trabalho de Pedrera et al. [16] que a presença de colesterol (Chol) e a coexistência de fases lipídicas aumentam a ligação da toxina à membrana alvo e à capacidade de formação de poros. No entanto, pouco se sabe sobre o papel da estrutura e dinâmica da membrana (estado de fase, fluidez e presença de domínios lipídicos) na atividade das actinoporinas ou quais regiões da membrana são as mais favoráveis para a inserção de proteínas, oligomerização e eventualmente formação de poros. Para obter uma visão sobre o papel das propriedades da membrana sobre a atividade funcional de St I, Pedrera et al [16] estudaram a ligação de StI a monocamadas e vesículas de fosfatidilcolina (POPC), esfingomielina (SM), ergosterol ou colesterol - Chol na presenca de domínios de fase líquido ordenado (Lo) e líquida desordenado (Ld). O estudo revelou que a St I se liga e permeabiliza membranas contendo esteróis com maior eficiência independentemente da presença de domínios lipídicos. O papel da fase Ld é apontado como a plataforma mais adequada para a formação de poros. A esse respeito, tais regiões em membranas contendo Chol parecem ser as mais favorecidas devido a sua maior fluidez; essa propriedade promove a inserção, a difusão e a oligomerização da toxina, levando à formação de poros [16].

Nesta parte do trabalho estendemos as investigações iniciadas em Pedrera et al. [16] comparando a atividade de STII em relação a STI em função da composição da membrana.

A Esticolosina I e a Esticolosina II (St I e St II), são citolisinas produzidas pela anêmona do mar Stichodactyla helianthus, e pertencem à família das actinoporinas [17]. Estas toxinas apresentam apresentam grande semelhanças em suas sequências (93\%, segundo de los Rios et al. [17]) e atuam pela formação de poros em membranas, sendo o seu suposto receptor 
a esfingomielina (SM). Todavia, as diversas etapas de ligação à membrana, oligomerização e formação de poros não são completamente compreendidos no nível molecular [18].

St I e St II diferem em treze aminoácidos, dos quais apenas três resíduos não conservados estão localizados na região N-terminal. Como resultado, St II apresenta maior capacidade de interação com membranas (de los Rios et al. [17] e Carretero et al. [18] demonstram no caso de células sanguineas maior atividade hemolítica do STII do que St I).

\subsubsection{GUVs formadas por DOPC e SM na presença e ausência de colesterol com diferentes concentrações na presença de STI e STII}

A Figura 21 mostra de maneira comparativa a ação das toxinas STI e STII (21 nM) em GUVs compostas por DOPC:SM (1:1) e DOPC:SM:Chol (1:1:1). Esta última composição é conhecida pelas membranas apresentarem coexistência de fases Ld-Lo ([26] e [27]). Conforme podemos observar, $21 \mathrm{nM}$ de St I não permeabiliza a membrana num tempo de incubação e observação de até 1800 s (30 min). Por outro lado, a mesma concentração de STII promove permeabilização das membranas de maneira similar em termos de tempo de perda de contraste ótico (Figura 20 e Tabela 2), independente da presença de colesterol e, portanto, da coexistência de fases Ld-Lo na membrana, contrário aos resultados de Pedrera et al. [16] em monocamadas. Ressalta-se aqui que resultados anteriores mostraram que as toxinas não permeabilizam membranas compostas apenas por PC [16]. Portanto, a presença da SM deve ter um papel importante na ação da toxina, conforme já descrito [17]. 


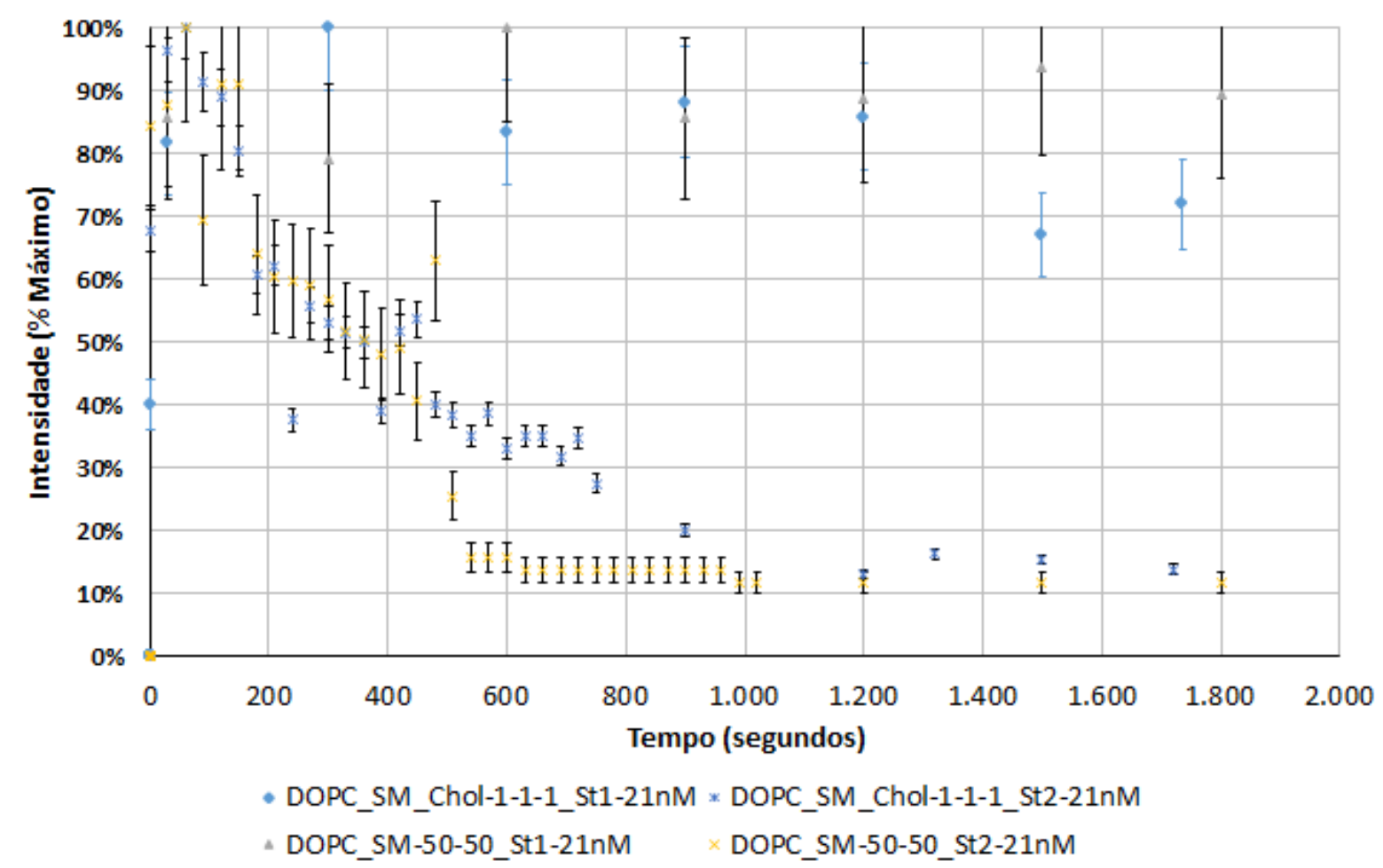

Figura 21: perda de contraste ótico para GUVs compostas de DOPC, SM e chol na presença de ST I e ST II

\begin{tabular}{|l|r|r|r|r|}
\hline & \multicolumn{2}{|c|}{ DOPC_SM_CHOL (1:1:1) } & \multicolumn{2}{c|}{ DOPC_SM (1:1) } \\
\cline { 2 - 5 } & ST I 21 nM & ST II 21nM & ST I 21 nM & ST II 21nM \\
\hline Amostragem (\# GUVs analisadas) & 8 & 12 & 13 & 9 \\
Tempo para início de queda (s) & - & 30 & - & 18 \\
Tempo até atingir metade intensidade & & & & \\
(s) & - & 302 & - & 304 \\
Nível de estabilidade (\% Intensidade) & 79 & 18 & 91 & 13 \\
Tempo até atingir estabilidade (s) & - & 912 & - & 520 \\
\hline
\end{tabular}

Tabela 2: GUVs compostas de DOPC, SM e chol na presença de ST I e ST II

Para avaliarmos a influência da SM na membrana, na Figura 22 abaixo foram analisados sistemas compostos por DOPC:SM com uma concentração menor de SM (DOPC:SM 85:15), na presença de ST I, ST II e ST I junto com ST II para verificarmos se existe uma potencialização da ação das toxinas quando juntas. Em nenhum dos casos verificou-se a perda de contraste ótico das GUVs. 


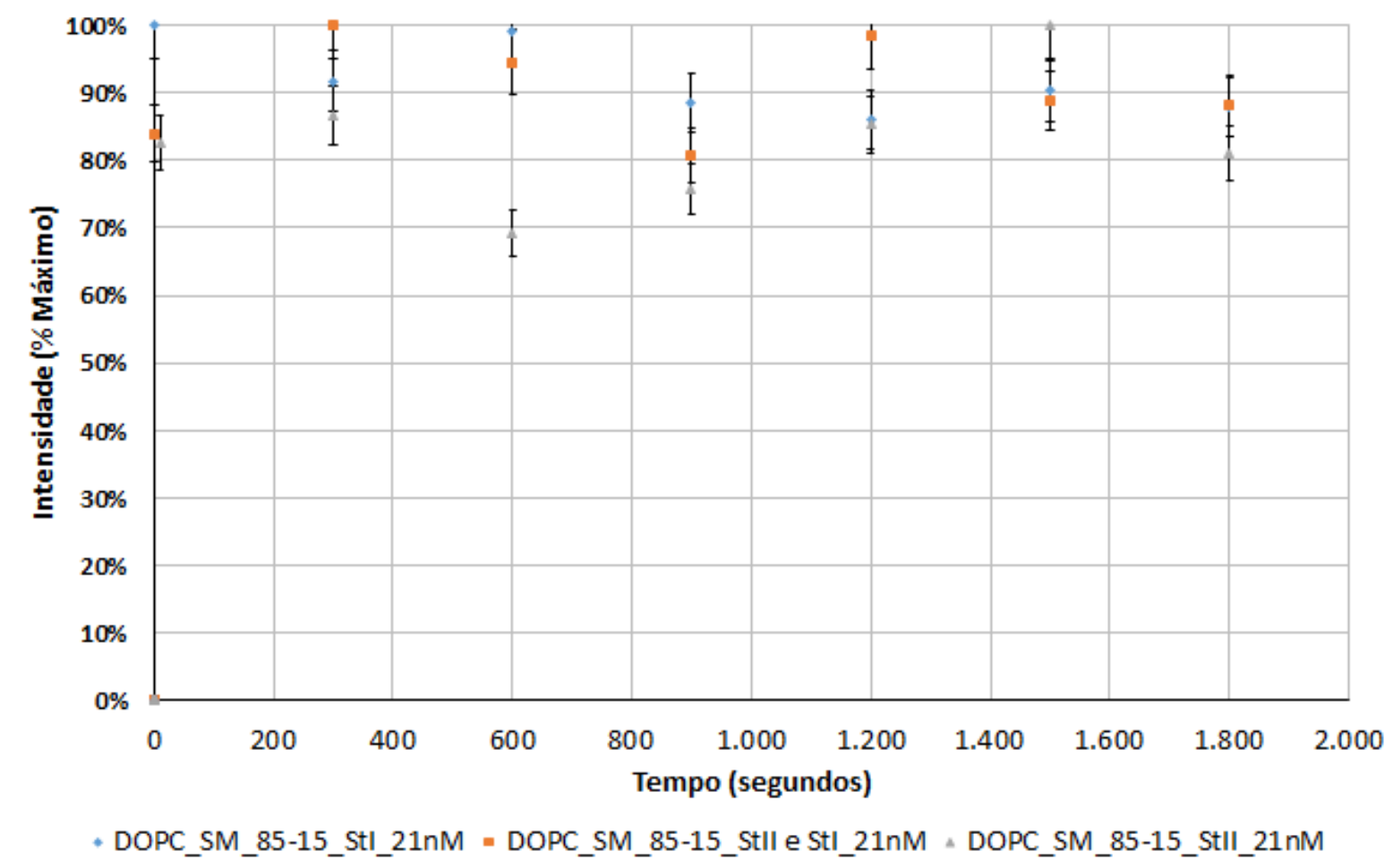

Figura 22: Perda de contraste otico para GUVs compostas de DOPC e SM (85:15) na presença de ST I ou ST II, e ST I e ST II juntas (concentração final da toxina 21 nM).

Levando em consideração que membranas compostas por DOPC:SM (1:1) apresentam separação de fase fluido-gel, DOPC:SM (85:15) não apresentam separação de fases, enquanto DOPC:SM:Chol (1:1:1) apresentam coexistência Ld-Lo ([26] e [27]), parece que a ação da toxina STII (21 nM) se deve a existência das interfaces de separação de fases na membrana, e não necessariamente do papel do lipídeo SM e/ou colesterol de maneira individualizada. Portanto, nossos resultados sugerem que a estrutura da membrana determina a ação da toxina ST II na concentração estudada.

\subsubsection{GUVs Compostas por POPC e SM sob ação de STII_21nM}

Dando continuidade, investigamos GUVs compostas por POPC e SM escolhendo a toxina ST II, uma vez que esta demonstrou ser mais eficiente em termos de formação de poros em membranas que a ST I na concentração de $21 \mathrm{nM}$ (item anterior). O fosfolipídeo DOPC foi substituido por POPC, uma vez que na sequência investigaremos como membranas contendo fosfolipídeo hidroperoxidado POPC-OOH respondem à toxina ST II, em comparação com as não oxidadas. Foi descrito anteriormente que o módulo elástico diminue de $200 \mathrm{mN} / \mathrm{m}$ em membranas de POPC para $50 \mathrm{mN} / \mathrm{m}$ em membranas de POPC-OOH ([23]). 
Buscamos inicialmente entender o efeito da toxina ST II, com uma concentração de 21 $\mathrm{nM}$, em uma membrana composta somente por POPC. Conforme pode ser visualizado na Figura 25 abaixo, as GUVs não perderam contraste até 1500 s de observação, sugerindo que nesta concentração a toxina não teve efeito na membrana.

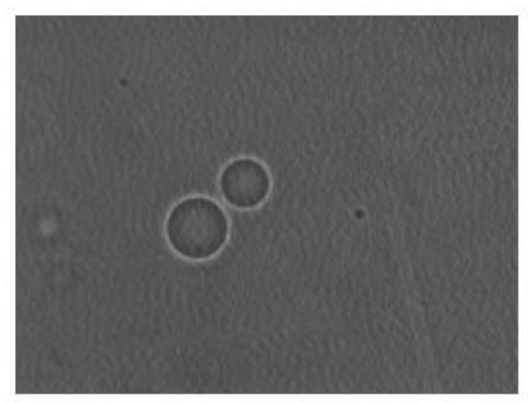

$\checkmark \quad \mathrm{T}=1 \mathrm{~s}$

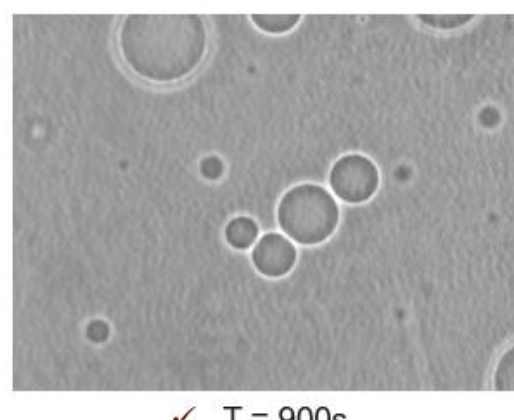

$\checkmark \quad \mathrm{T}=900 \mathrm{~s}$

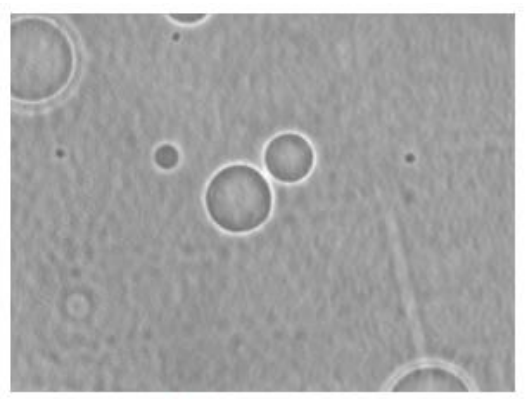

$\checkmark \quad \mathrm{T}=300 \mathrm{~s}$

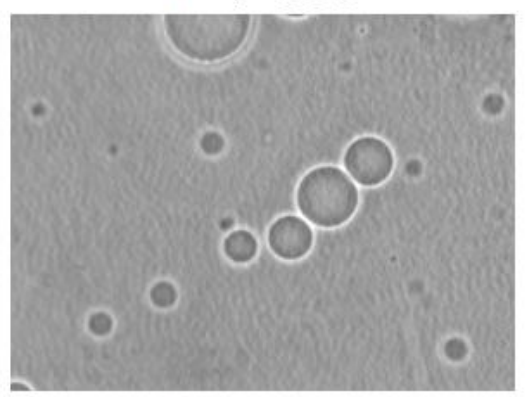

$T=1200 \mathrm{~s}$

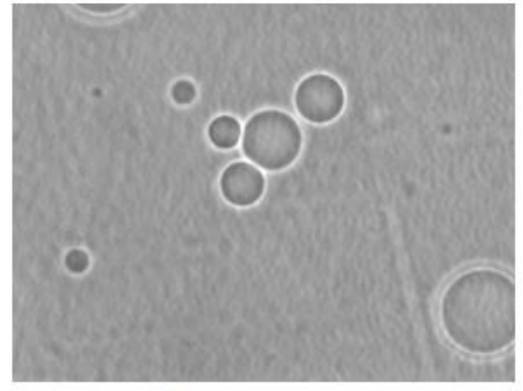

$\mathrm{T}=600 \mathrm{~s}$

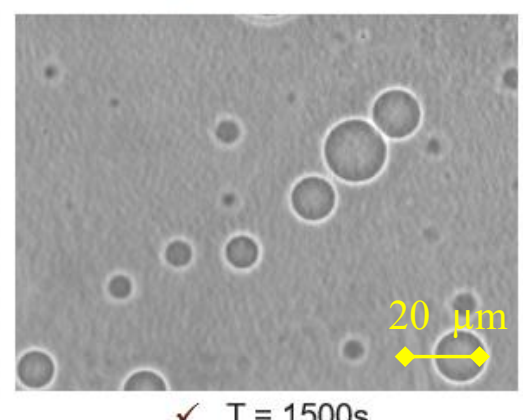

Figura 23: Evolução temporal das GUVs de POPC puro na presença de STII com concentração de $2 \ln M$.

Tal sugestão pode ser confirmado através da análise do gráfico da Figura 24 onde se nota que, para diversas medidas, todas as GUVs mostram estabilidade no nível de contraste ao longo do tempo. A legenda refere-se às médias dos experimentos realizados, e ao fim a média geral dos valores encontrados. 


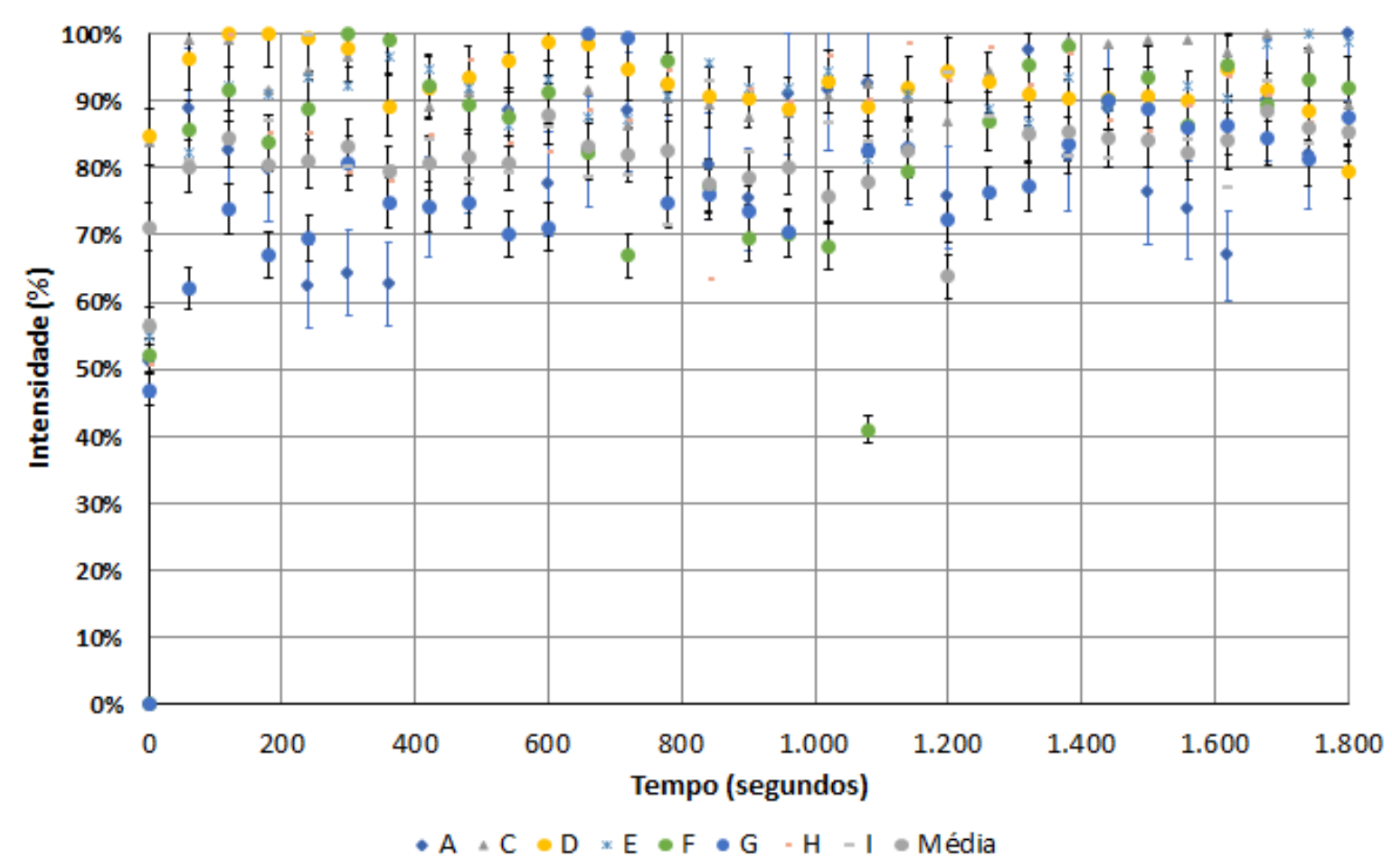

Figura 24: Evolução do contraste otico de GUVs de POPC puro na presença de STII com concentração de $2 \ln M$

Por outro lado, GUVs compostas por POPC:SM (1:1) são permeabilizadas pela ação da toxina ST II (21 nM) e se mantém estáveis na ausência desta (dados não apresentados). A Figura 25 abaixo mostra um exemplo da ação de ST II em GUVs de POPC:SM (1:1), enquanto a Figura 26 mostra a evolução temporal da perda de contraste de fase de um conjunto de GUVs e a Tabela 3 sumariza os dados correspondentes. 


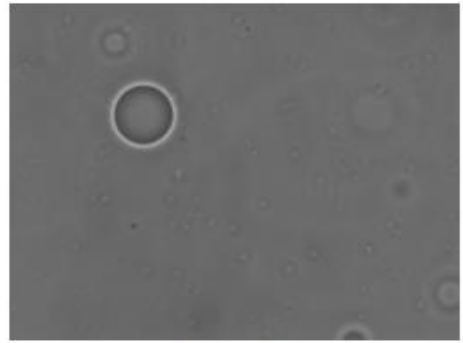

$\checkmark T=0 s$

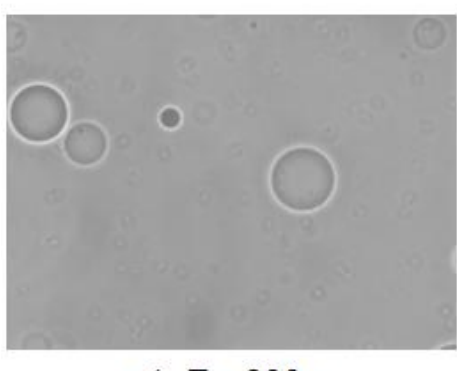

$T=900 \mathrm{~s}$

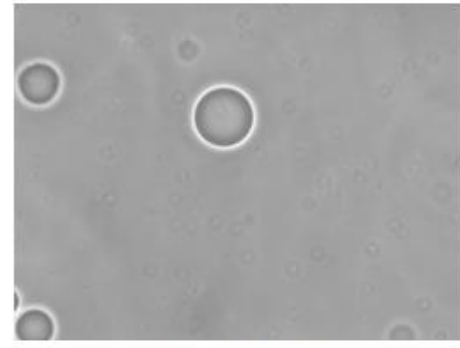

$T=300 \mathrm{~s}$

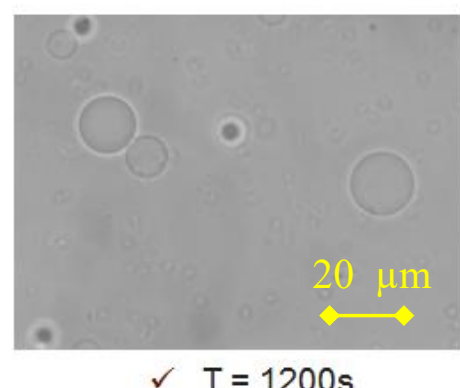

$T=1200 s$

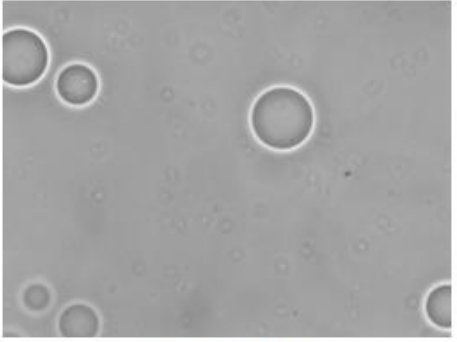

$\checkmark T=600 \mathrm{~s}$

Figura 25: GUVs de POPC:SM (1:1) sob ação de STII_21nM

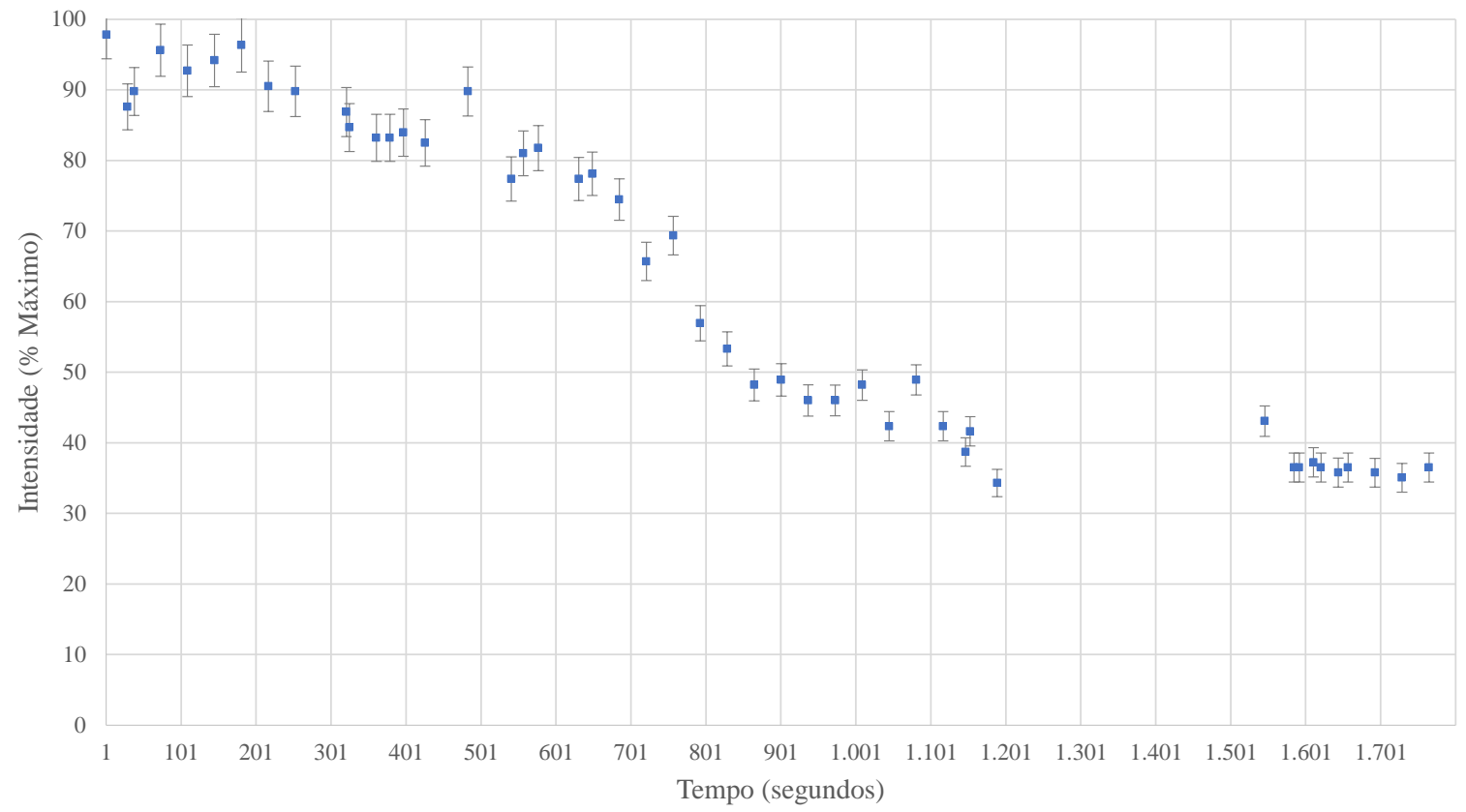

Figura 26: Evolução do contraste de fase de GUVs compostas por POPC:SM (1:1) na presença de 21nM STII. As barras de erro correspondem a média da análise de 11 GUVs (Tabela 3) 


\begin{tabular}{|c|c|}
\hline Amostragem (\# GUVs analisadas) & 11 \\
\hline Tempo para início de queda (s) & 490 \\
\hline Tempo até atingir metade intensidade (s) & 830 \\
\hline Nível de estabilidade (\% Intensidade) & 36 \\
\hline Tempo até atingir estabilidade (s) & 912 \\
\hline
\end{tabular}

De maneira interessante observamos que em membranas contendo POPC:SM (1:1) o tempo médio inicial para as GUVs iniciarem a perder contraste é significativamemte maior que em GUVs contendo DOPC:SM (1:1), comparando dados das Tabelas 2 e 3 (490 s versus $18 \mathrm{~s}$ ). Tal resultado pode ser devido ao fato de DOPC ter uma insaturação em cada cauda enquanto POPC apenas uma das caudas é insaturada, conferindo menor fluidez à membrana de POPC. 


\subsection{GUVs compostas por lipídeos oxidados na presença de STII}

Neste item estudaremos membranas compostas por lipídeos oxidados POPC-OOH (hidroperóxido lipídico) e PazePC (Figura 13, similar ao POPC mas com uma cauda mais curta com um grupo carboxila na porção terminal) mistas ou não com POPC. A Figura 27 abaixo apresenta uma representação esquemática das estruturas moleculares de cada fosfolipídeo ressaltando a forma e o aumento de área impostos pelos lipídeos oxidados POPCOOH e PazePC em relação ao não oxidado POPC.
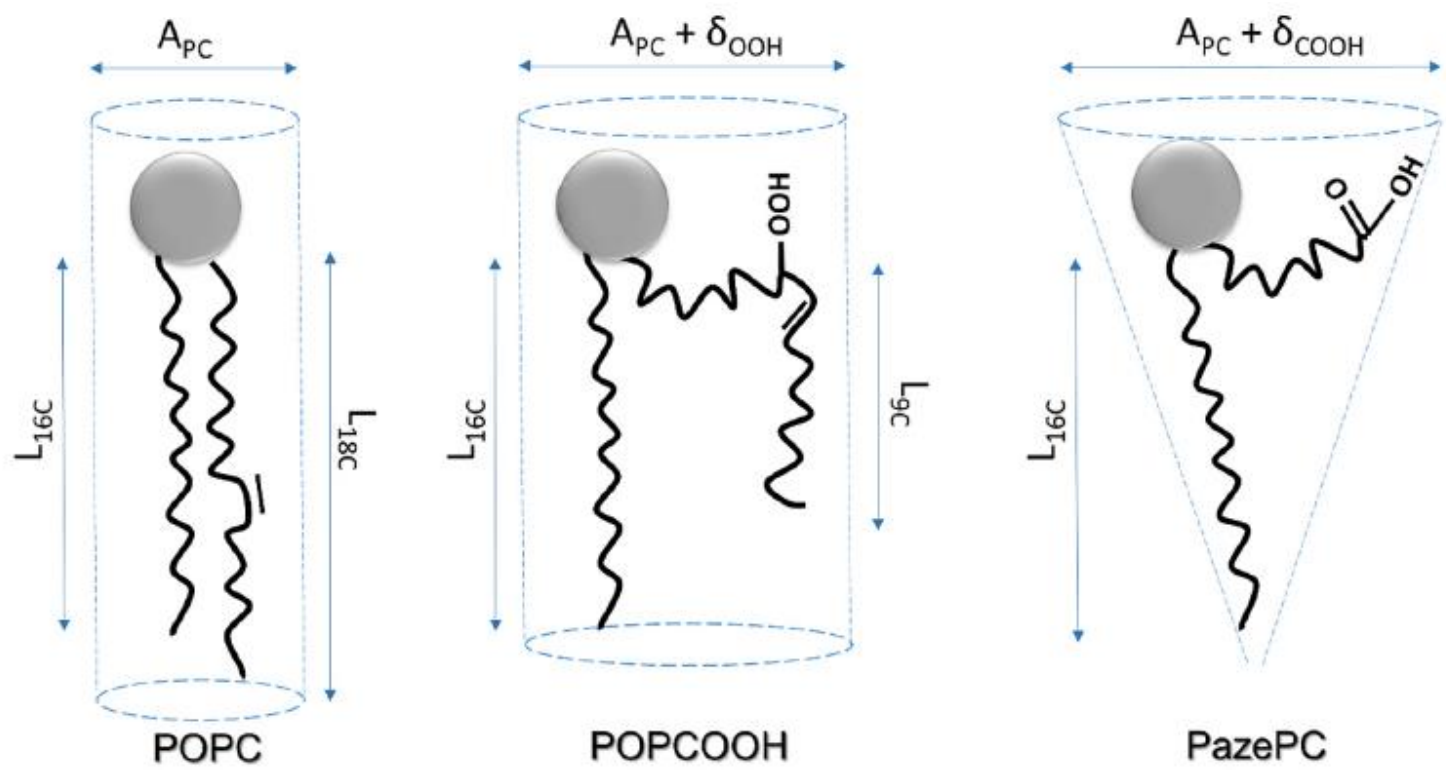

Figura 27: Representação esquemática da forma e aumento de área de lipídios oxidados (POPCOOH e PazePC) em relação ao não oxidado (POPC).

Figura adaptada de Tsubone et al. [15] . APC significa área de fosfatidilcolina (PC), $\delta_{\mathrm{ooh}} \mathrm{O}$ aumento de área causado pela cauda com hidroperóxido $(\mathrm{OOH})$ e $\delta_{\text {cooh }}$ o aumento de área causado pela cauda com ácido carboxílico $(\mathrm{COOH}) . \mathrm{L}_{16 \mathrm{C}}$ refere-se a cadeias de hidrocarbonetos acilo com 16 carbonos de comprimento, $\mathrm{L}_{18 \mathrm{C}}$ corresponde a 18 carbonos de comprimento e $\mathrm{L}_{9 \mathrm{C}}$ significa 9 carbonos de comprimento

\subsection{1: GUVs compostas por POPC-OOH puro na presença de STII com concentração de $21 \mathrm{nM}$}

$\mathrm{Na}$ sequência do trabalho, trocamos POPC pelo hidroperóxido lipídico POPC-OOH (Figura 27) buscando verificar se a presença deste lipídeo oxidado, com caracteristicas moleculares tão diferentes do POPC (o grupo OOH reside na interface aquosa e promove um aumento de área superficial do lipídeo em torno de 15\% (Weber et al. [23] e Riske et al. [22]) e uma diminuição do módulo elástico (Weber et al. [23]) afetariam a resposta da membrana exposta à toxina ST II. Nossos resultados evidenciam (Figura 28), de maneira 
similar a GUVs compostas apenas por POPC, que membranas de POPC-OOH incubadas em solução contendo $21 \mathrm{nM}$ de ST II não são permeabilizadas pela mesma.

A análise da não evolução temporal do contraste de fase das GUVs compostas por POPC e POPC-OOH são apresentadas na Figura 29 para ressaltar os resultados descritos. Portanto, nossos resultados sugerem novamente que não houve interação da toxina com a membrana e/ou o modo de ação da toxina é diferente de quando investigamos membranas que contém SM em sua composição ou separação de fases. Medidas de constante de ligação da toxina em membranas com diferentes composiçoes lipidicas seriam necessárias para melhor entender a não permeabilização de membranas puras de POPC e de POPC-OOH por ST II verificadas neste trabalho de mestrado, mas estão além do escopo do mesmo. Planeja-se medidas futuras em colaboração com o grupo da Universidade de Havana, Cuba.

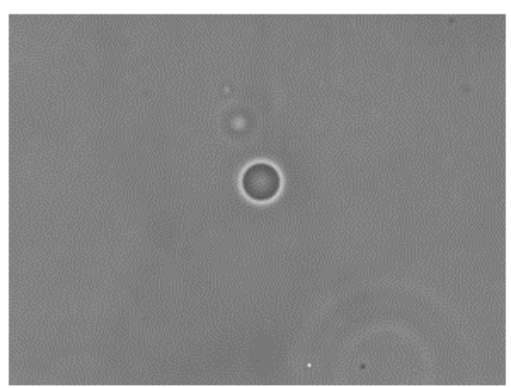

$\checkmark \mathrm{T}=1 \mathrm{~s}$

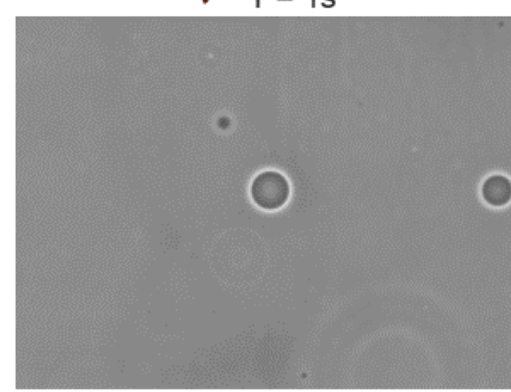

$\mathrm{T}=900 \mathrm{~s}$

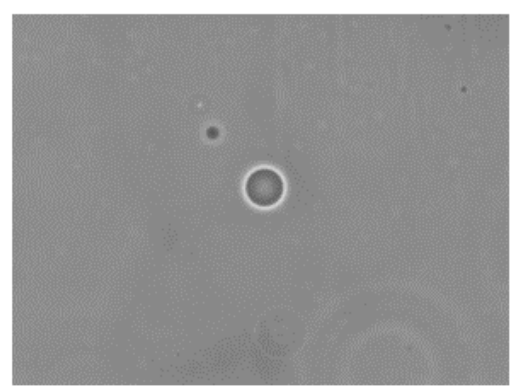

$\checkmark T=300 s$

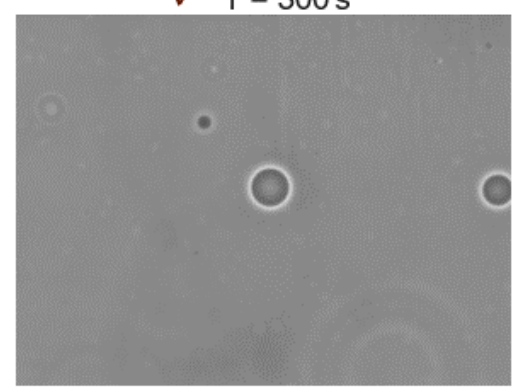

$\checkmark \quad T=1200 \mathrm{~s}$

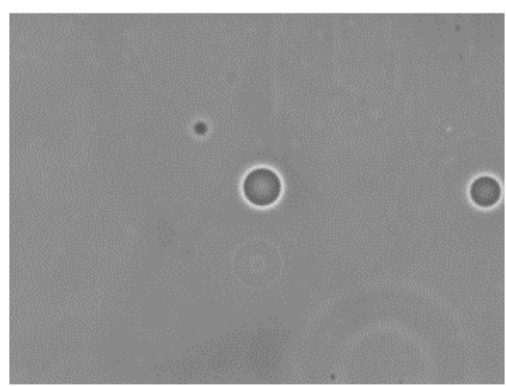

$\checkmark \quad \mathrm{T}=600 \mathrm{~s}$

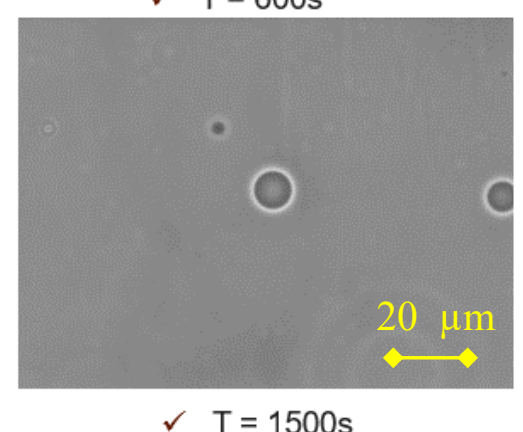

Figura 28: Evolução temporal de GUVs compostas por POPC-OOH puro na presença de STII com concentração de $2 \ln M$ 


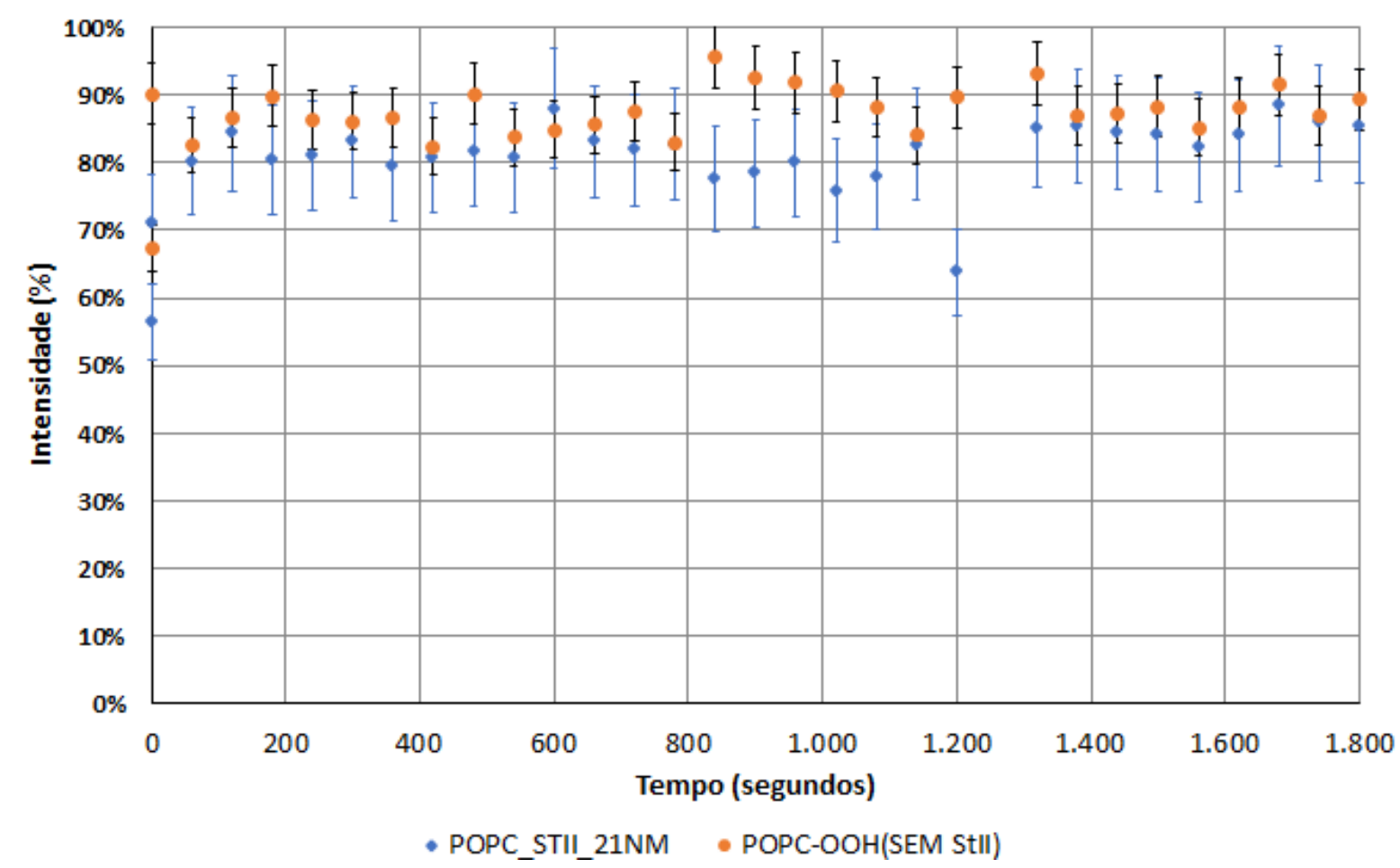

Figura 29: Evolução temporal do contraste de fase de GUVs compostas por POPC-OOH puro na presença de STII com concentração de 21 nM em comparação com GUVs de POPC.

Os resultados são relativos a uma amostragem de 15 GUVs para POPC-OOH e 23 GUVs para POPC.

\subsubsection{GUVs compostas por POPC:POPC-OOH na proporção 1:1 na presença de STII com concentração de $21 n M$}

Analisando agora membranas mistas de POPC:POPC-OOH (razão molar 1:1), observamos na Figura 30: Figura 30 que St II altera a permeabilidade desta membrana. De maneira interessante então constatamos que os dois lipídeos não devem formar uma mistura homogenea uma vez que possuem caracteristicas diferentes, o que oferece para a toxina regiões de nano ou micro separação de domínios lipídicos. Fizemos um experimento incluindo $0.1 \mathrm{~mol} \%$ de DOPE-Rodamina na composição das GUVs mas não observamos algum tipo de separação de fases (dados não apresentados aqui), provavelmente devido a que os dois lipídeos se encontram em fase fluida.

Entretanto, durante os experimentos notamos que algumas GUVs perdem contraste em tempos diferentes, e algumas não chegam a ser afetadas e não perdem contraste. A Figura 31 apresenta alguns dados comparativos. 


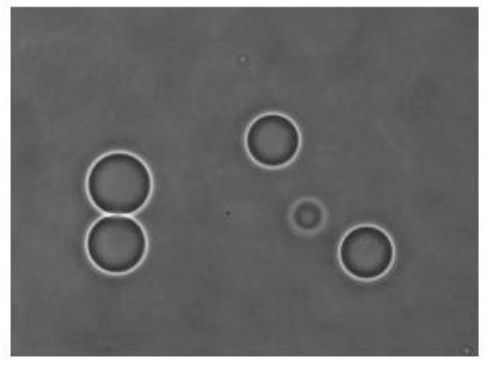

$\checkmark \quad T=1 \mathrm{~s}$

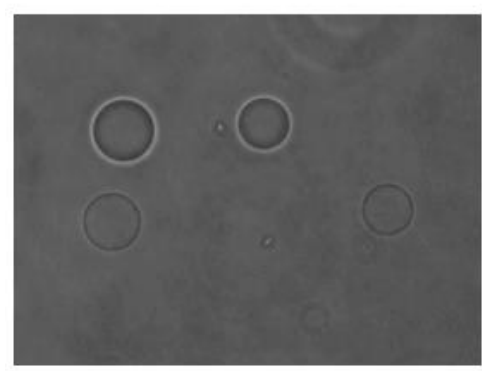

$\checkmark T=360 \mathrm{~s}$

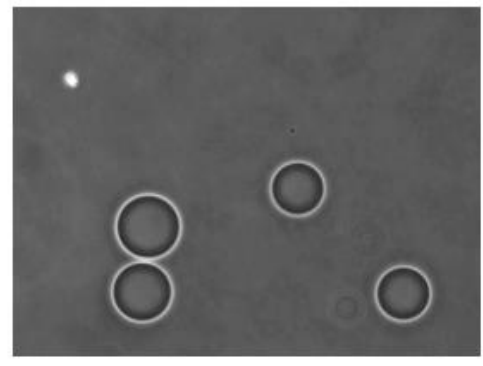

$\checkmark T=120 \mathrm{~s}$

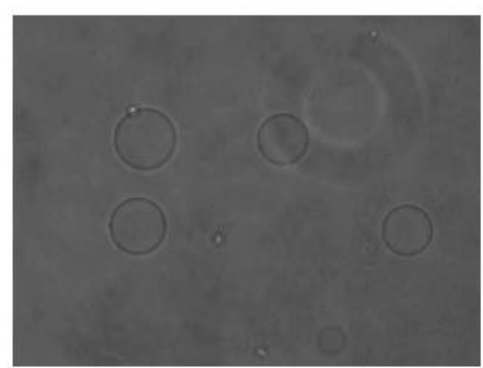

$\checkmark T=480 \mathrm{~s}$

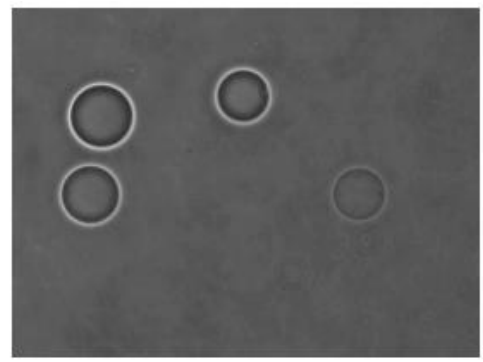

$\checkmark \quad T=240 s$

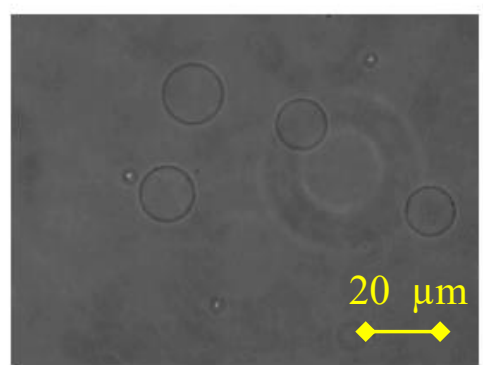

$\checkmark T=600 \mathrm{~s}$

Figura 30: Evolução temporal da perda de contraste otico de GUVs de POPC:POPC-OOH na proporção 1:1 na presença de STII com concentração de 21nM.

Tal sugestão pode ser verificada na análise gráfica da perda de constraste. Nota-se que houveram algumas medidas onde não houve perda de contraste, neste caso sugere-se que a concentração da toxina foi baixa para o caso onde não surtiu efeito.

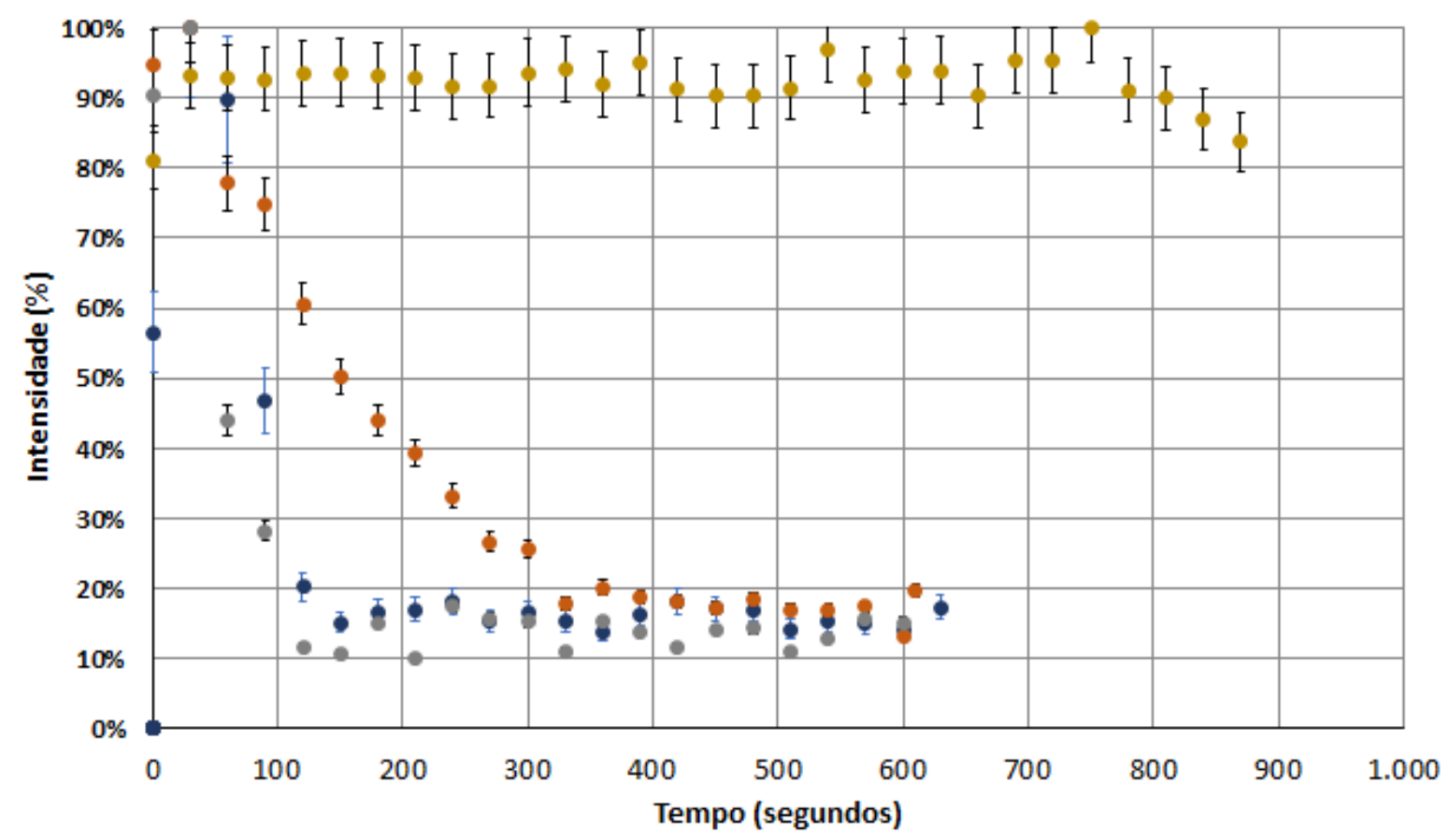

Figura 31: Evolução temporal do contraste de fase de GUVs de POPC:POPC-OOH na proporção 1:1 na presença de STII com concentração de 21nM. Algumas medidas com a 
mesma concentração de ST II perdem contraste em tempos diferentes e algumas não perdem contraste.

A Figura 32 mostra um conjunto de dados de GUVs que perdem contraste em tempos diferentes, enquanto a Tabela 4 analisa estes dados com as principais informaçoes obtidas.

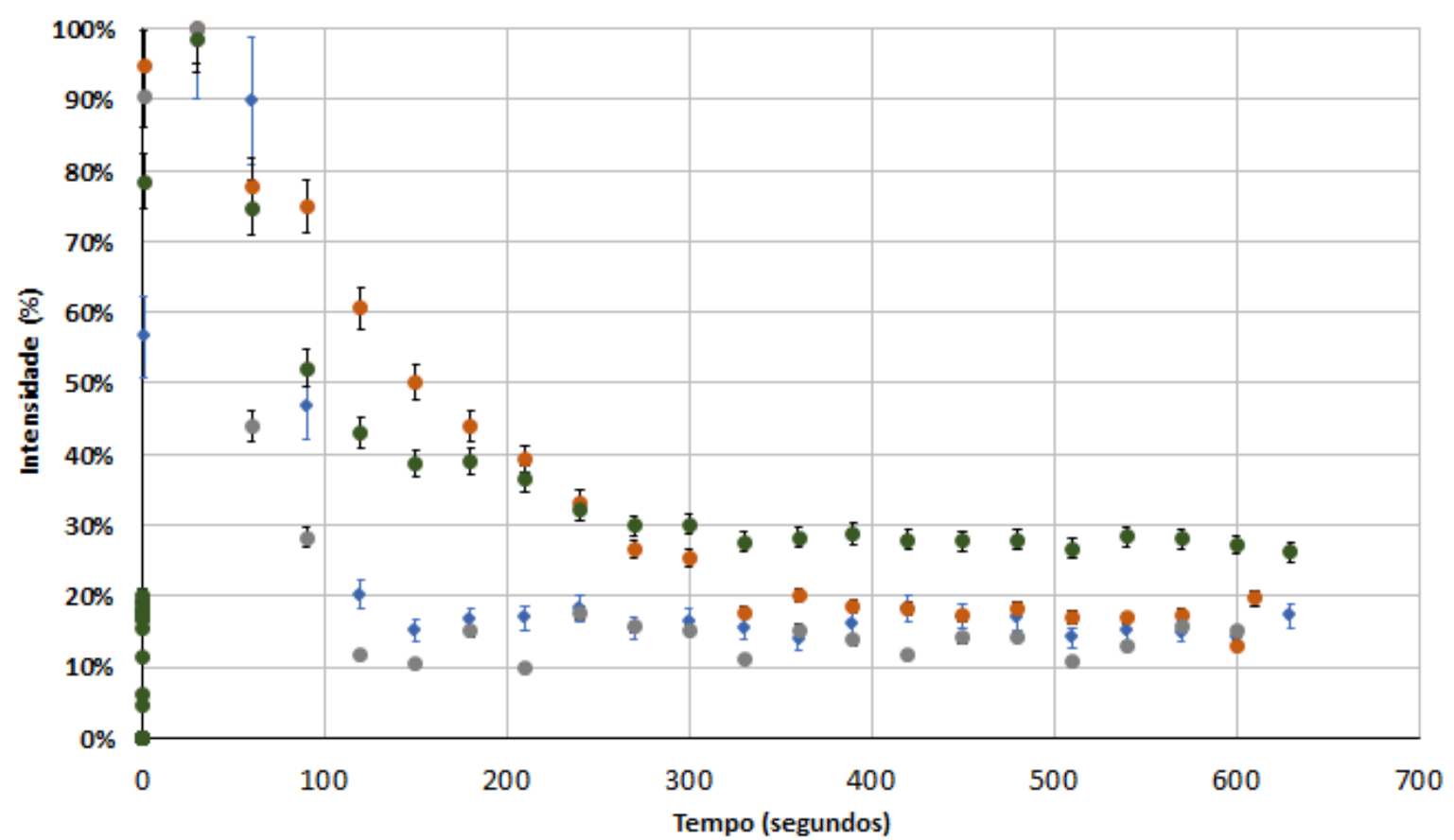

Figura 32: Evolução temporal do contraste de fase de GUVs compostas de POPC:POPCOOH na proporção 1:1 na presença de STII com concentração de 21nM. Os dados se referem as GUVs que perdem contraste mais rapidamente

\begin{tabular}{|l|r|}
\hline & \\
\hline Amostragem (\# GUVs analisadas) & 9 \\
Tempo para início de queda (s) & 23 \\
Tempo até atingir metade intensidade (s) & 98 \\
Nível de estabilidade (\% Intensidade) & 20 \\
Tempo até atingir estabilidade (s) & 156 \\
\hline
\end{tabular}

Tabela 4: GUVs de POPC:POPC-OOH na proporção 1:1 na presença de STII com concentração de $2 \ln M$

Um ponto que chamou nossa atenção então na análise foi o tempo de perda de contraste das GUVs de algumas medidas variou ligeiramente. Verificamos que os tempos de 
perda não variaram de maneira expressiva: começando por volta do tempo $\sim 50$ s e terminando por volta de $\sim 200$ s.

No último item avaliaremos a ação de STII em concentrações maiores sobre GUVs de POPC:POPC-OOH para avaliarmos se o efeito observado se deve a concentração da toxina.

\subsubsection{GUVs compostas por POPC:POPC-OOH na proporção 7:3 na presença de STII com concentração de $21 n M$}

As próximas medidas tambem foram realizadas com POPC: POPC-OOH mas agora com uma proporção de 7:3. Novamente as imagens indicam que houve perda de contraste ao longo do tempo (Figura 33).

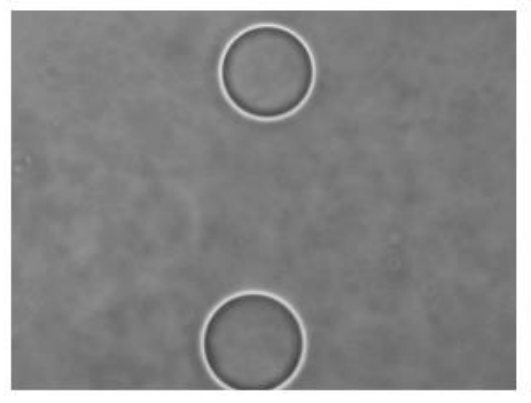

$\checkmark \mathrm{T}=1 \mathrm{~s}$

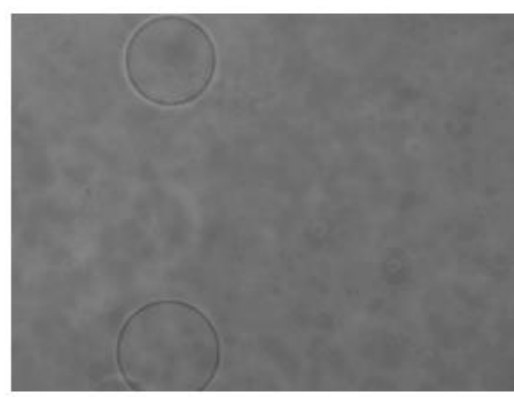

$\checkmark \quad \mathrm{T}=360 \mathrm{~s}$

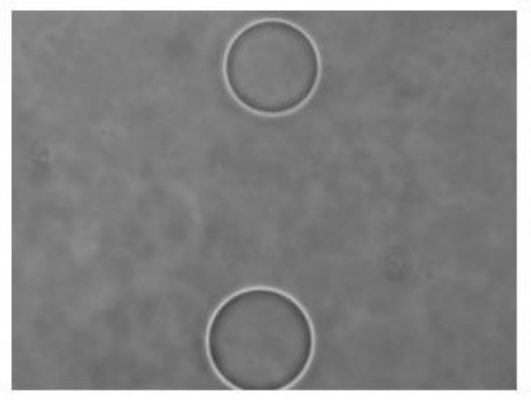

$\checkmark \quad \mathrm{T}=120 \mathrm{~s}$

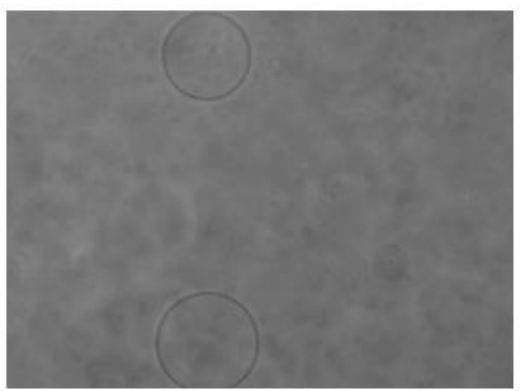

$\checkmark \quad \mathrm{T}=480 \mathrm{~s}$

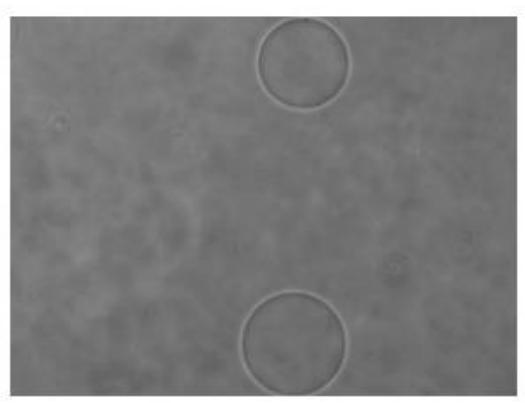

$\checkmark \quad T=240 \mathrm{~s}$

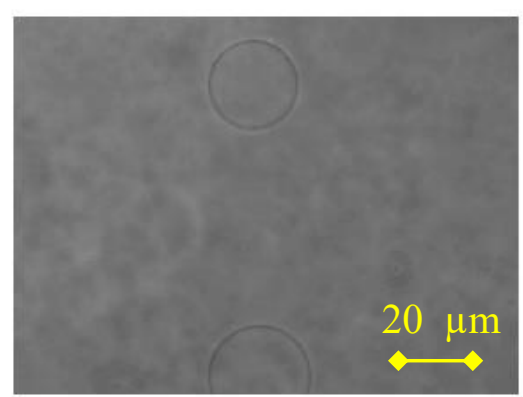

$\checkmark \quad \mathrm{T}=600 \mathrm{~s}$

Figura 33: Evolução temporal de GUVs compostas por POPC:POPC-OOH na proporção 7:3 na presença de STII com concentração de 21 nM

Portanto, nossos resultados claramemte indicam que a mistura de lipídeos na presença de ST II oferece mecanismo para criação de poros e consequente perda de contraste. Novamente observamos entretanto em algumas medidas que a perda de contraste ocorre em instantes mais avançados (Figura 34). A Figura 35 agrupa as GUVs que perderam contraste mais rapidamente. 


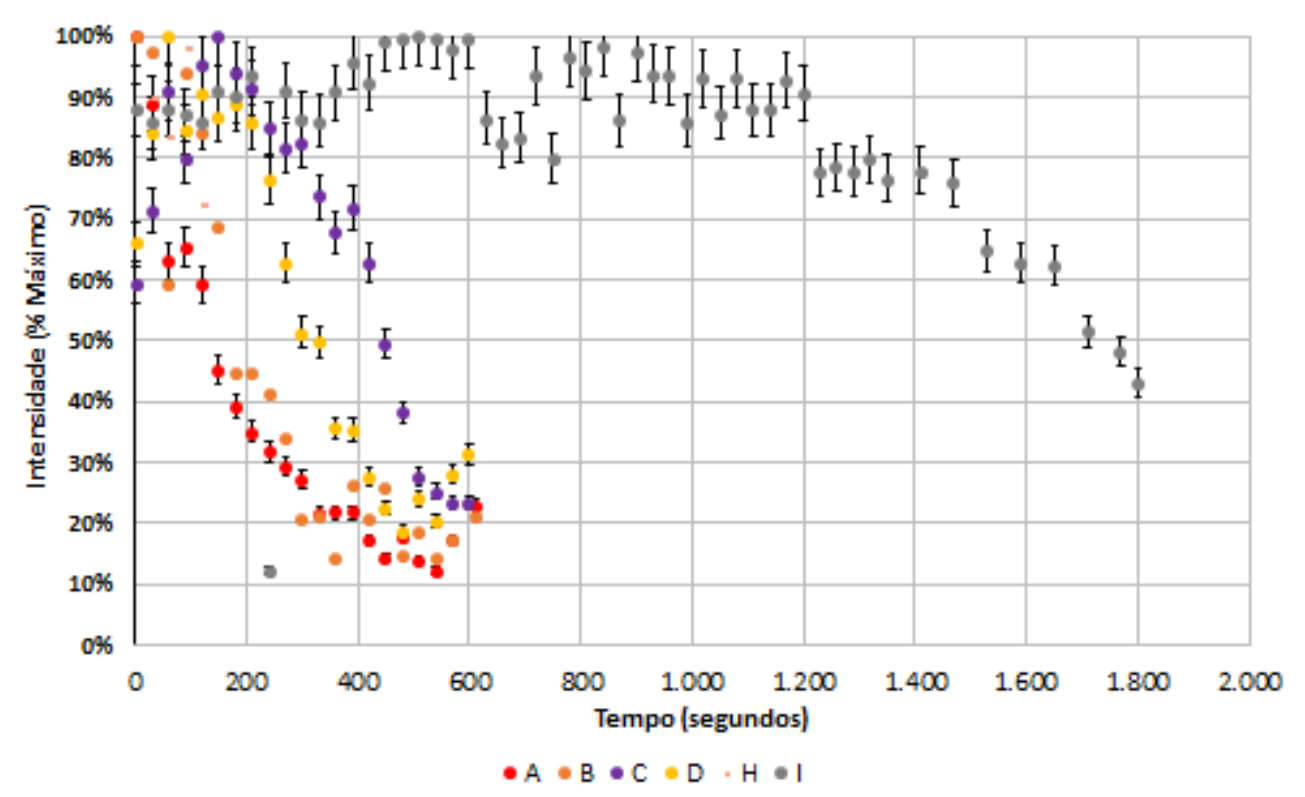

Figura 34: Evolução do contraste otico de varias GUVs de POPC:POPC-OOH na proporção 7:3 na presença de STII com concentração de 21nM

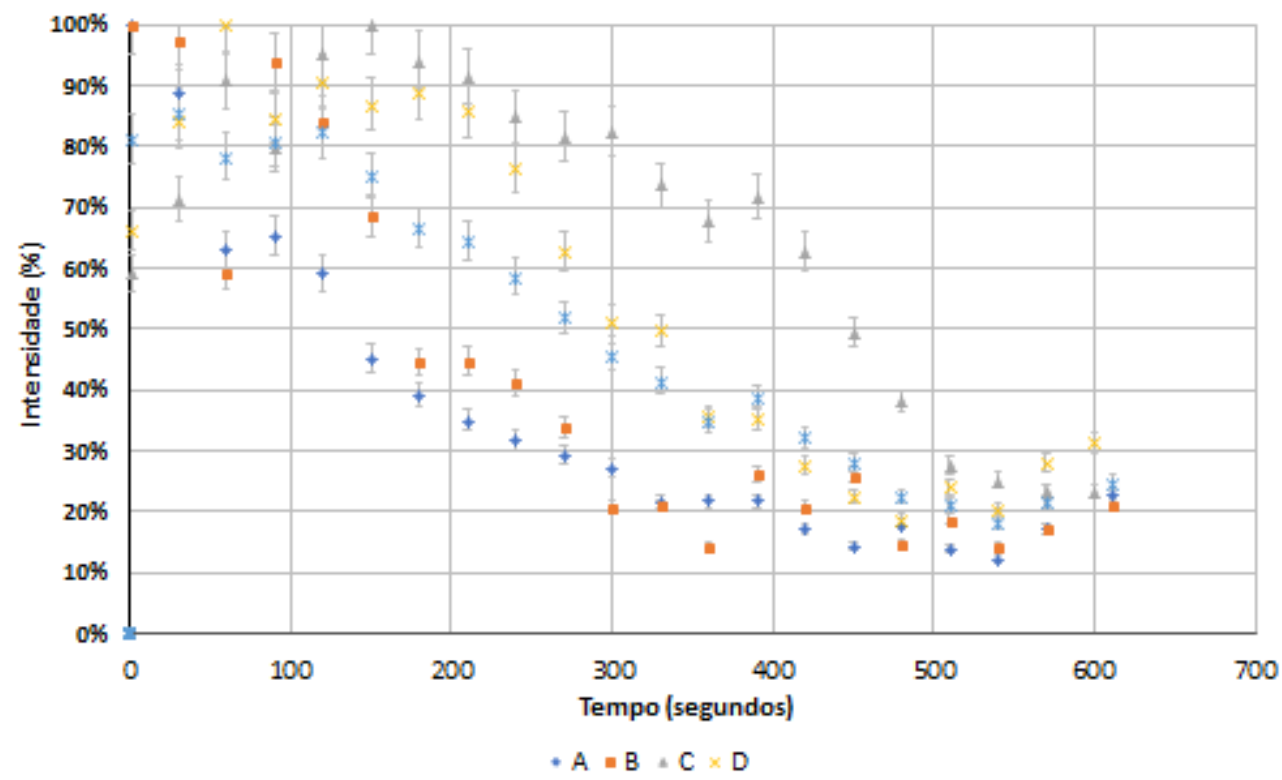

Figura 35: Evolução do contraste de GUVs de POPC:POPC-OOH na proporção 7:3 na presença de ST II com concentração de 21nM, agrupando as GUVs que perdem contraste ótico mais rapidamente. 


\subsubsection{Comparação dos resultados de GUVs compostas por POPC:POPC-00H na presença de STII com concentração de 21nM}

Buscando entender a relação da velocidade de perda de contraste com a concentração de POPC-OOH perante POPC, analisou-se o gráfico abaixo (Figura 32) mostrando as curvas de intensidade para as concentrações de POPC:POPC-OOH em 1:1 e 7:3. Verifica-se que a perda de contraste para a concentração de POPC-OOH 1:1 ocorre mais rapidamente do que na concentração de 7:3. Portanto, parece que existe um efeito da concentração de POPC-OOH na atividade da toxina, lembrando que St II não altera a permeabilidade de membranas puras de POPC-OOH. Mais estudos experimentais são necessários para entender melhor estes resultados, incluindo a determinação das constantes de ligação dependentes da composição lipídica. O único ponto que poderíamos especular neste momento é que embora a mistura de POPC-POPC-OOH não deve formar uma mistura homogênea, a quantidade e/ou tamanho de domínios lipídicos devem impactar na ação da toxinas. Necessitamos de estudos mais aprofundados neste ponto que será alvo de trabalhos futuros.

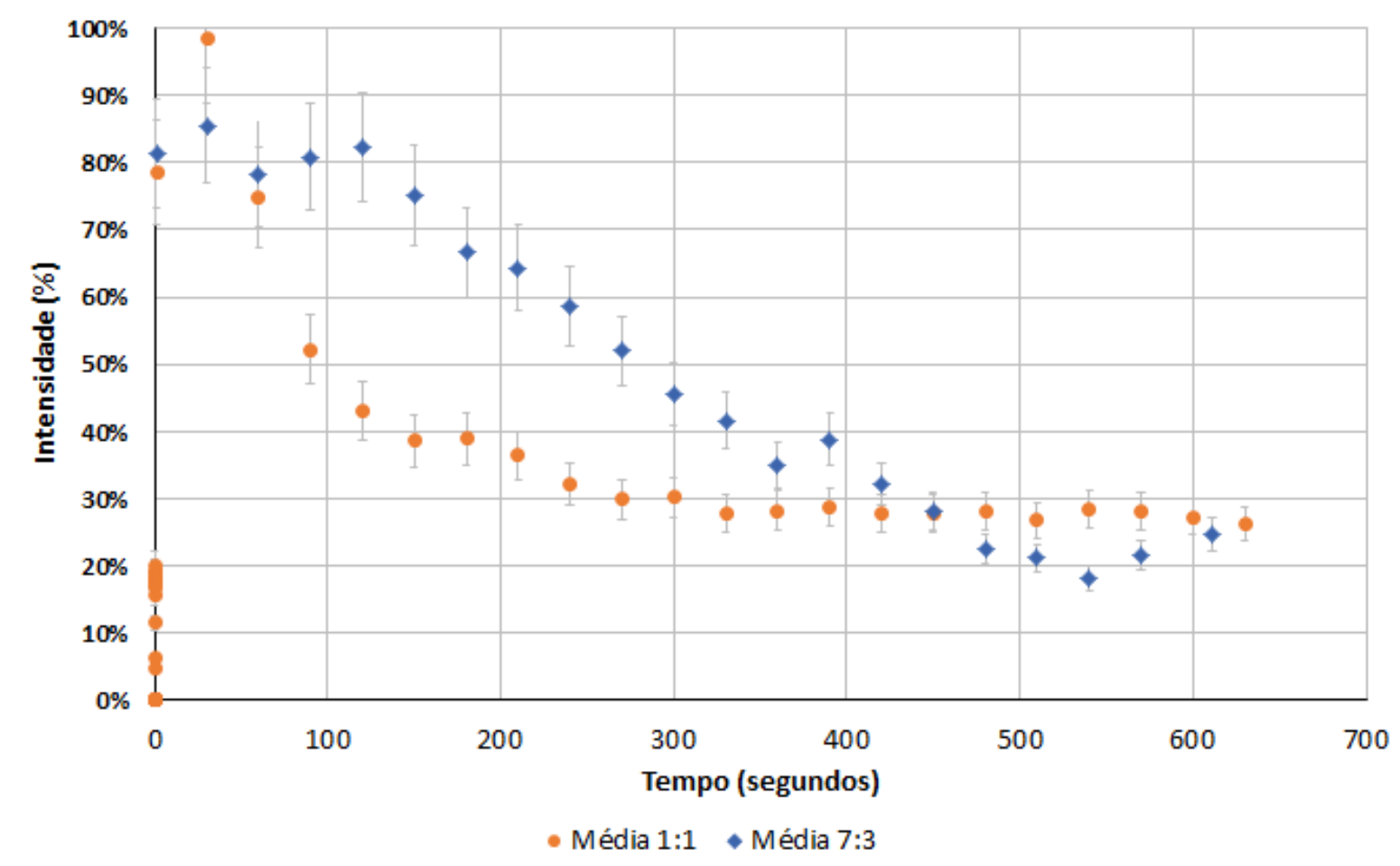

Figura 36: Evolução temporal do contraste otico de GUVs comparando POPC;POPCOOH(1:1)_STII_21nM com POPC:POPC-OOH (7:3)_STII_21nM 


\subsection{Estudo do Efeito da Toxina STII a $42 \mathrm{nM}$ em GUVs com Lipídeos Oxidados}

Nos experimentos aqui realizados, foram medidos GUVs formados por POPC, PazePC e POPC-OOH, em concentrações puras, com e sem a presença de STII $42 \mathrm{nM}$, para tentar isolar o efeito de cada variável. Na sequência foram variadas as proporções das misturas dos lipídeos, buscando verificar qual o impacto do aumento da concentração de lipídeos oxidados na composição das membranas.

Conforme foi verificado anteriormente, para buscar garantir o efeito das toxinas sob as membranas, utilizou-se uma concentração maior (desta vez 42nM).

Os dados estão apresentados na Tabela 5 abaixo resumindo a quantidade de GUVs com diferentes composições lipídicas que efetivamente perderam contraste ao longo do tempo, durante o experimento sob ação de ST II 42 nM. De maneira mais visível, estão apresentados também no gráfico abaixo:

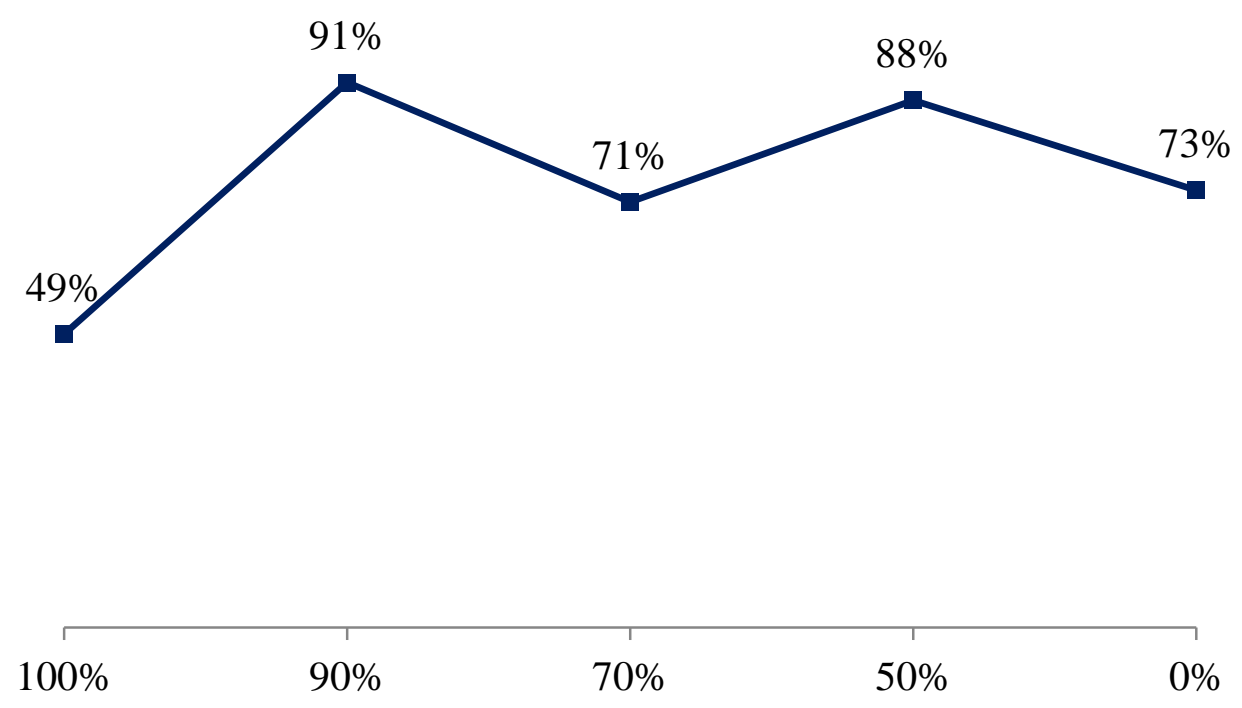

Figura 37:Resumo do \% de GUVS que perderam contraste em função da concentração de $\mathrm{POPC}$ em relação a $\mathrm{POPC}-\mathrm{OOH}$ 


\begin{tabular}{|c|c|c|c|}
\hline Medida & Contraste & \# & $\%$ \\
\hline \multirow[b]{2}{*}{ POPC_42nM ST II } & Perderam & 22 & $49 \%$ \\
\hline & $\begin{array}{c}\text { Não } \\
\text { Perderam }\end{array}$ & 23 & $51 \%$ \\
\hline \multirow[b]{2}{*}{ POPC-OOH_42nM } & Perderam & 8 & $73 \%$ \\
\hline & $\begin{array}{c}\text { Não } \\
\text { Perderam }\end{array}$ & 3 & $27 \%$ \\
\hline \multirow[b]{2}{*}{ POPC:POPC-OOH(9:1) ST II_42nM } & Perderam & 30 & $91 \%$ \\
\hline & $\begin{array}{c}\text { Não } \\
\text { Perderam }\end{array}$ & 3 & $9 \%$ \\
\hline \multirow[b]{2}{*}{ POPC:POPC-OOH(7:3) ST II_42nM } & Perderam & 25 & $71 \%$ \\
\hline & $\begin{array}{c}\text { Não } \\
\text { Perderam }\end{array}$ & 10 & $29 \%$ \\
\hline \multirow[b]{2}{*}{ POPC:POPC-OOH(1:1) ST II_42nM } & Perderam & 21 & $88 \%$ \\
\hline & $\begin{array}{c}\text { Não } \\
\text { Perderam }\end{array}$ & 3 & $13 \%$ \\
\hline \multirow[b]{2}{*}{ POPC:PazePC(9:1)_ST II 42nM } & Perderam & 20 & $83 \%$ \\
\hline & $\begin{array}{c}\text { Não } \\
\text { Perderam }\end{array}$ & 4 & $17 \%$ \\
\hline \multirow[b]{2}{*}{ POPC:PazePC(7:3)_42nM ST II } & Perderam & 13 & $38 \%$ \\
\hline & $\begin{array}{c}\text { Não } \\
\text { Perderam }\end{array}$ & 21 & $62 \%$ \\
\hline
\end{tabular}

Tabela 5: Contagem de GUVs que perderam contraste nos experimentos com ST II

Na sequência apresentamos a Tabela 6 enfatizando apenas os dados de GUVs que sofrem variação de permeabilidade durante o experimento. As imagens da evolução temporal das GUVs e os gráficos de perda de contraste destes experimentos estão disponíveis no Anexo 6.4 Gráficos do Estudo do Efeito da Toxina STII a 42 nM em GUVs com Lipídeos Oxidados 


\begin{tabular}{|c|c|c|c|c|c|}
\hline GUVs & $\begin{array}{l}\text { Amostragem } \\
\text { (\# GUVs } \\
\text { analisadas) }\end{array}$ & $\begin{array}{l}\text { Tempo para } \\
\text { início de } \\
\text { queda (s) }\end{array}$ & $\begin{array}{l}\text { Tempo até } \\
\text { atingir } \\
\text { metade } \\
\text { intensidade } \\
\text { (s) }\end{array}$ & $\begin{array}{c}\text { Nível de } \\
\text { estabilidade } \\
(\% \\
\text { Intensidade })\end{array}$ & $\begin{array}{l}\text { Tempo até } \\
\text { atingir } \\
\text { estabilidade } \\
\text { (s) }\end{array}$ \\
\hline $\begin{array}{l}\text { POPC na presença de } \\
\text { 42nM STII }\end{array}$ & 22 & 198 & 231 & 41 & 323 \\
\hline $\begin{array}{l}\text { POPC-OOH na presença } \\
\text { de } 42 \text { nM STII }\end{array}$ & 8 & 207 & 402 & 27 & 463 \\
\hline $\begin{array}{l}\text { POPC;POPC-OOH }(9 ; 1) \\
\text { na presença de } 42 \mathrm{nM} \\
\text { STII }\end{array}$ & 21 & 501 & 801 & 40 & 1456 \\
\hline $\begin{array}{l}\text { POPC;POPC-OOH }(7 ; 3) \\
\text { na presença de } 42 \mathrm{nM} \\
\text { STII }\end{array}$ & 14 & 307 & 370 & 43 & 702 \\
\hline $\begin{array}{l}\text { POPC;POPC-OOH }(1 ; 1) \\
\text { na presença de } 42 \mathrm{nM} \\
\text { STII }\end{array}$ & 19 & 507 & 902 & 38 & 1480 \\
\hline $\begin{array}{l}\text { POPC;PazePC(9:1) na } \\
\text { presença de } 42 \text { nM STII }\end{array}$ & 18 & 801 & 1001 & 26 & 1180 \\
\hline $\begin{array}{l}\text { POPC;PazePC( } 7: 3) \text { na } \\
\text { presença de } 42 \text { nM STII }\end{array}$ & 19 & 213 & 280 & 41 & 310 \\
\hline
\end{tabular}

Tabela 6: dados resumidos de perda de contraste para GUVs compostos por lipídeos oxidados

Primeiramente, com base nestes dados observa-se que todas estas GUVs analisadas perderam contraste ao longo do tempo, mas estabilizando-se em níveis diferentes de percentual. Ao analisar as medidas de POPC-OOH, nota-se que as velocidades de perda de contraste não variam de maneira correlacionada com a concentração de POPC-OOH, sugerindo num primeiro momento não haver relação entre a velocidade de perda de contraste e a composição lipídica.

As medidas feitas com POPC:PazePC também mostraram perda de contaste em algumas situações. Porém, ao aumentar a concentração de PazePC, verifica-se que a perda de contraste ocorre de maneira mais rápida.

Estudos complementares são necessários para melhor entender estes dados, e serão objeto de trabalhos futuros. 


\section{CONCLUSÕES}

Na primeira parte deste trabalho (Capítulo 3.1. Danos à Membranas de GUVs pelo efeito da fotoirradiação na presença de azul de metileno) buscou-se analisar os efeitos de fotoirradiação em GUVs sob presença de azul de metileno $10 \mu \mathrm{M}$. Verificou-se que quanto maior a concentração de lipídeos carregados negativamente, mais rapidamente as GUVs perderam contraste devido a formação de poros na membrana formada por POPC:POPG. Portanto, pelos resultados experimentais obtidos conclui-se que quanto maior a quantidade de POPG na membrana da GUV, mais é favorecida a ligação de MB na membrana por atração eletrostática. A foto-oxidação do MB gera inicialmente POPC-OOH e POPG-OOH cuja taxa de produção é maior quanto mais POPG está contido inicialmente na membrana. Ao mesmo tempo a proximidade do $\mathrm{MB}$ ao grupo $\mathrm{OOH}$ favorece a continuidade da reação de fotooxidação levando a produtos fotooxidados de cadeia lipídica truncada que desestabilizam a membrana. No caso de membranas formadas por DOPC:DOPG, o efeito de foto-oxidação lipidica é tão acentuado que as membranas se desestabilizam e rompem rapidamente (tempo menor que o possível de observação).

Na segunda etapa deste trabalho (Capítulo 3.2 Efeito das Toxinas ST I e ST II em membranas miméticas observadas por microscopia otica de GUVs), estudou-se os efeitos das toxinas ST I e ST II sob GUVs com diferentes composições lipídicas. A primeira conclusão a ser feita foi que a ação da toxina STII (na concentração de $21 \mathrm{nM}$ ) ocorre devido à existência das interfaces de separação de fases na membrana, e não mostraram dependência do papel do lipídeo SM e/ou colesterol de maneira individualizada. Ou seja, os resultados experimentais obtidos sugerem que a estrutura da membrana determina a ação da toxina ST II na concentração estudada. No caso de membranas mistas de POPC-POPC-OOH, deve ocorrer formação de dominios fluido-fluido que favorece a ligação da toxina à membrana, levando a permeação da mesma. A segunda observação feita neste estudo foi que em uma concentração de $21 \mathrm{nM}$ de St I, não notou-se permeabilização da membrana num tempo de incubação e observação de até $1800 \mathrm{~s}$ (30 min), e a mesma concentração de STII demonstra haver permeabilização das membranas estudadas.

Finalmente, as últimas medidas realizadas (capítulo 3.3 GUVs compostas por lipídeos oxidados na presença de STII) com as toxinas ST II a 42 nM e lipídeos já oxidados (POPC$\mathrm{OOH}$ e PazePC), verificou-se que não existe relação entre a concentração de lipídeos oxidados e a perda de contraste. A conclusão obtida deve-se ao fato que em diversas medidas as membranas não demonstraram perda de contraste, e, nas medidas onde houve perda de 
contraste, não foi possível relacionar a taxa temporal de permeabilidade da membrana com a variação da concentração de lipídeos já oxidados. 


\section{REFERÊNCIAS}

[1] P. Freddolino, A. Shih, "Case Studies on Lipid Bilayers". Theoretical and Computational Biophysics Group, University of Illinois at Urbana Champaign, 2006

[2] S.J. Singer, G.L. Nicolson, "The fluid mosaic model of the structure of cell membranes”. Science, 175, 720-731, 1972

[3] G. Karp, "Cell and Molecular Biology: Concepts and Experiments”. Wiley, third edition, 2002

[4] D. L. Nelson, M. M. Cox, "Lehninger Principles of Biochemistry”. Worth Publishers, third edition, 2000

[5] R.B. Gennis, "Biomembranes: Molecular Structure and Function". Springer, first edition, 1989

[6] Y.H. Chan, M. Boxer, G. Steven, "Model Membrane Systems and Their Applications", Science Direct Current Opinion in Chemical Biology, 2007. Imagem retirada foi desenhada por Tomo Narashima.

[7] S.F. Fenz, K. Sengupta, "Giant vesicles as cell models”. Integrative Biology 4 (9) 982-995, 2012

[8] ImageJ, Software de análise de imagens disponivel para download em https://imagej.nih.gov/ij/docs/intro.html

[9] Tracker Video Analysis and Modeling Tool, disponível em https://physlets.org/tracker/

[10] S.G. Sligar, K.Y.V. Grinkova, T.H. Bayburt, I.G. Denisov, J.K. Zolnercik, W.M. Atkins, "Reconstitution of Membrane Proteins in Phospholipid Bilayer Nanodiscs". Methods in Enzymology, 464, 211-231, 2009

[11] R.J. King, M.C. MacBeth, "Interaction of the Lipid and Protein Components of Pulmonarysurfactant Role of Phosphatidylglycerol and Calcium". Biochimica et Biophysica Acta (BBA) - Biomembranes. 647: 159-168, 1981

[12] O. Mertins, I.O.L. Bacellar, F. Thalmann, C.M. Marques, M.S. Baptista, R. Itri, "Physical Damage on Giant Vesicles Membrane as a Result of Methylene Blue Photoirradiation”, Biophysical Journal 106 162-171, 2014

[13] R. Itri, H.C. Junqueira, O. Mertins, M.S. Baptista, "Membrane changes under oxidative stress: the impact of oxidized lipids”, Biophys Rev 6:47-61, 2014

[14] C. K. Haluska, M.S. Baptista, A.U. Fernandes, A.P. Schroder, C.M. Marques, R. Itri, "Photo-activated phase separation in giant vesicles made from different lipid mixtures”, Biochimica et Biophysica Acta 1818 666-672, 2012 
[15] T.M. Tsubone, H.C. Junqueira, M.S. Baptista, R. Itri, “Contrasting Roles of Oxidized Lipids in Modulating Membrane Microdomains”. BBA - Biomembranes 1861660 669,2019

[16] L. Pedrera, A.B. Gomide, R.E. Sanchez, U. Ros, N. Wilke, M.E. Lanio, R. Itri, M.L. Fanani, C. Alvarez, "The Presence of Sterols Favors Sticholysin I Membrane Association and Pore Formation Regardless of Their Ability to Form Laterally Segregated Domains", Langmuir 2015

[17] V. de los Ríos, J.M. Mancheño, A. Martinez Del Pozo, C. Alfonso, G. Rivas, M. Oñaderra, "Sticholysin II, a cytolysin from the sea anemone Stichodactyla helianthus, is a monomer-tetramer associating protein”. FEBS Lett. 455:27-30, 1999

[18] G.P.B. Carretero, E.F. Vicente, E.M. Cilli, C.M. Alvarez, H. Jenssen, S. Schreier "Dissecting the mechanism of action of actinoporins. Role of the N-terminal amphipathic $\alpha$-helix in membrane binding and pore activity of sticholysins I and II". PLoS ONE 13(8), 2018

[19] W. Martins, D. Rodrigues, A.C. Viotto, R. Checchia, A.B. Gomide, R.Itri, D. Severino, M.S. Baptista, "Mechanism of Aloe Vera Extract Protection Against UVA: Shelter of Lysosomal Membrane Avoids Photodamage" Photochem. Photobiol. Sci.. 15, 2016

[20] P. Boonnoy, V. Jarerattanachat, M. Karttunen, J. Wong, "Bilayer Deformation, Pores and Micellation Induced by Oxidized Lipids”. J. Phys Chem Letters, 6, 4884-4888, 2015

[21] W. Caetano, P.S. Haddad, R. Itri, S. Divinomar, V.C. Vieira, M.S. Baptista, A.P. Schröder, C.M. Marques, "Photo-Induced Destruction of Giant Vesicles in Methylene Blue Solutions”. Langmuir, 23:1307-1314, 2007

[22] K.A. Riske, T.P. Sudbrack, N.L. Archilha, A.F. Uchoa, A.P. Schroder, C.M. Marques, M.S. Baptista, R. Itri, "Giant Vesicles Under Oxidative Stress Induced by a Membrane Snchored Photosensitizer”, Biophys. J. 97 1362-1370, 2009

[23] G. Weber, T. Charitat, M.S. Baptista, A.F. Uchoa, C. Pavani, H.C. Junqueira, R. Itri, Y. Guo, V.A. Baulin, C.M. Marques, A.P. Schroder, "Lipid Oxidation Induces Structural Changes in Biomimetic Membranes”, Soft Matter 10 4241-4247, 2014

[24] P. Siani, R.M. de Souza, T.F. Schmidt, R. Itri, L.G. Dias, H. Khandelia, “An Overview of Molecular Dynamics Simulations of Oxidized Lipid Dystems, with a Comparison of ELBA and MARTINI force fields for Coarse Grained Lipid Dimulations”, Biochim. Biophys. Acta Biomembr. 1858 2498-2511, 2016

[25] R. M. de Souza, P. Siani, T.F. Schmidt, R. Itri, L.G. Dias, ”Methylene Blue Location in (Hydroperoxized) Cardiolipin Monolayer: Implication in Membrane Photodegradation”. J. Phys. Chem.B 121, 8512-8522, 2017 
[26] R.F. de Almeida, A. Fedorov, M. Prieto, "Sphingomyelin / Phosphatidylcholine / Cholesterol Phase Diagram: Boundaries and Composition of Lipid Rafts”. Biophys. J. 85, 2406-2416, 2003

[27] F. M. Goñi, A. Alonso, L. A. Bagatolli, R. E. Brown, D. Marsh, M. Prieto, J.L. Thewalt, "Phase Diagrams of Lipid Mixtures Relevant to the Study of Membrane Raft”. Biochim. Biophys. Acta, Mol. Cell Biol. Lipids 1781, 665-684Aa, 2008

[28] C. S. Foote, D. Kessel "Photodynamic Therapy of Neoplastic Disease", vol 1 and 2, CRC: Boston, 1990.

[29] Y. Liu, R. Qin, S.A.J. Zaat, E. Breukink, M. Heger, “Antibacterial Photodynamic Therapy: Overview of a Promising Approach to Fight Antibiotic-Resistant Bacterial Infections” Journal of Clinical and Translational Research 1(3): 140-167, 2015

[30] A. A. Clifford, "Multivariate error analysis: a handbook of error propagation and calculation in many-parameter systems.” [S.1.]: John Wiley \& Sons. 1973

[31] I.O.L. Bacellar et al "Photosensitized Membrane Permeabilization Requires Contact Dependent Reactions between Photosensitizer and Lipids”, JACS 140, 9606-9615, 2018 


\section{ANEXOS:}

\subsection{Medidas com AloeVera}

Os estudos realizados com Aloe Vera marcam minha participação na publicação do artigo "Mecanism of Aloe Vera extract protection against UVA: shelter of lysosomal membrane avoids photodamage" na Photochemical \& Photobiological Sciences. A contribuição dos experimentos realizados foi principalmente verificar se as GUVs mantinham-se estáveis na presença de AloeVera, quando irradiadas a uma frequência de 665 nm.

No artigo em questão, estudam-se os efeitos do envelhecimento prematuro devido à exposição à incidência de luz (fotoenvelhecimento) da pele caracterizada por rugas, uma textura coriácea e pigmentação mottled é uma conseqüência bem documentada da exposição à luz solar. UVA é um fator de risco importante para câncer humano também associado à indução de inflamação, imunossupressão, fotoenvejamento e melanogênese.

Embora os compostos à base de plantas sejam comumente usados como fotoprotetores contra os prejudiciais efeitos da UVA, os mecanismos envolvidos na fotodinâmica não são precisamente conhecidos. Neste estudo, nós investigamos os efeitos de Aloe Vera (Aloe barbadensis mil) sobre a proteção contra célula modulada em UVA morte de queratinócitos HaCaT. Aloe Vera exibiu a notável habilidade de reduzir tanto in vitro quanto fotodamagem in vivo, mesmo que não tenha propriedades anti-radicais. Curiosamente, a proteção conferido por Aloe Vera foi associado à manutenção da integridade da membrana tanto em mimético membranas e organelas intracelulares. $\mathrm{O}$ aumento da estabilidade lisossômica levou a uma diminuição da lipofuscinogênese e morte celular. Este estudo explica por que os extratos de Aloe Vera oferecem proteção contra fotodames a um nível celular tanto no espectro UV como visível, levando ao seu uso benéfico como suplemento em formulações dermatológicas protetoras.

\subsubsection{DOPC com AloeVera}

Como é possível verificar na figura abaixo, a presença de aloe vera no sistema de DOPC e azul de metileno evita que as GUVs modifiquem sua permeabilidade da membrana, perdendo contrate. Entende-se, portanto, que o aloe vera blinda as GUVs, protegendo-as dos mecanismos de danos às membranas. 
$\checkmark$ DOPC 20uM-MB
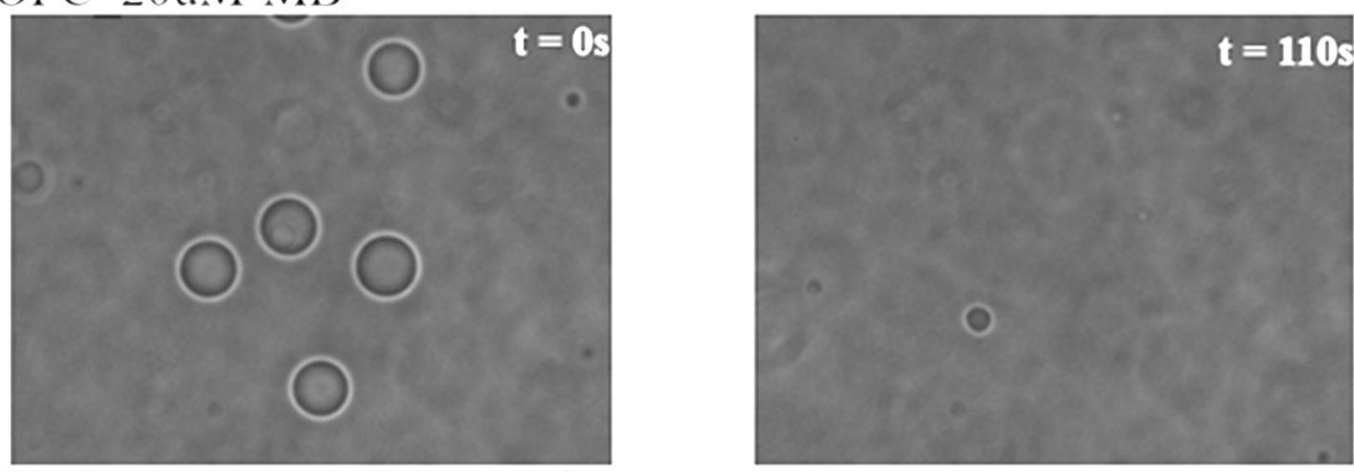

$\checkmark$ DOPC 20uM-MB $0.05 \%$-Aloe
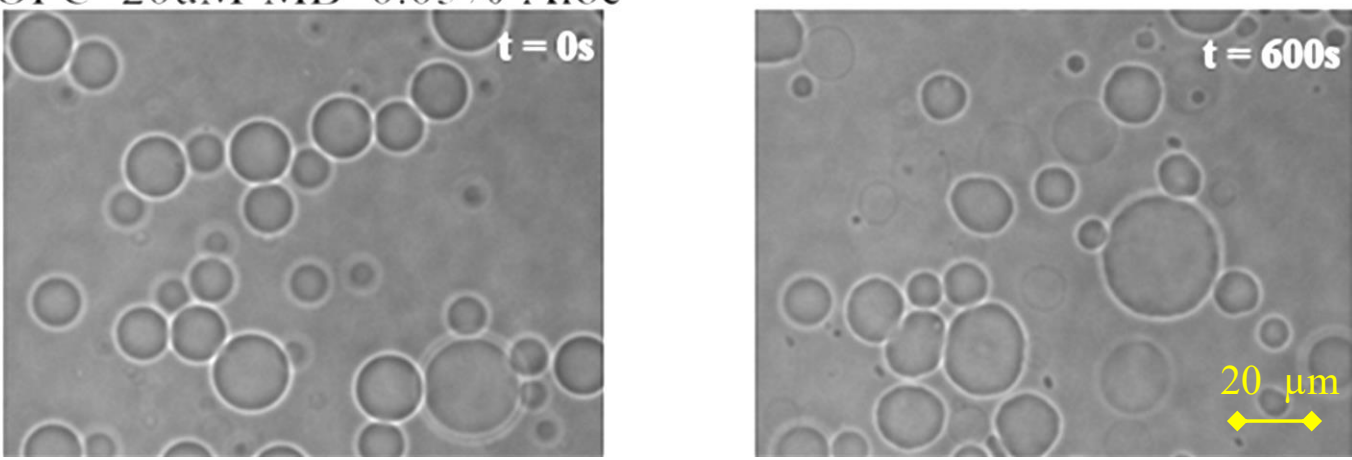

Figura 38: Fotos das GUVs perdendo ccontrate para DOPC:AloeVera em diferentes concentrações 


\subsection{Preparo e análise de GUVs com diferentes metodologias}

\subsubsection{Preparo de GUVs com diferentes metodologias: POPC:DOPS}

Nestes estudos, foram realizados três cenários para elaboração das GUVs em diferentes concentrações, para as amostras dos três grupos, cresceram as GUVs conforme especificado, e as estatísticas dos gráficos foram obtidos com a média de pelo menos 5 GUVs:

\subsubsection{GUVs criados por eletroformação}

GUVs criadas com eletroformação, nas concentrações de POPC puro, POPC:DOPS (9:1) e POPC:DOPS (7:3): Para POPC puro, parece que as membranas flutuam e voltam ao normal depois de algum tempo, sem perder contraste. Parecem sair e voltar do foco, e ao final de 30 minutos aparentemente parecem não terem perdido contraste. Para POPC:DOPS(9:1), já se nota que GUVs crescem muito menos e para POPC:DOPS(7:3), verifica-se uma flutuação significativa das membranas por foto-irradiação. O gráfico abaixo apresenta a intensidade do contrate ótico das GUVs em diferentes concentrações lipídicas ao longo do tempo. Verifica-se que o POPC puro mantem estabilidade no contraste de fase ao passo que as outras concentrações perdem contraste com o tempo:

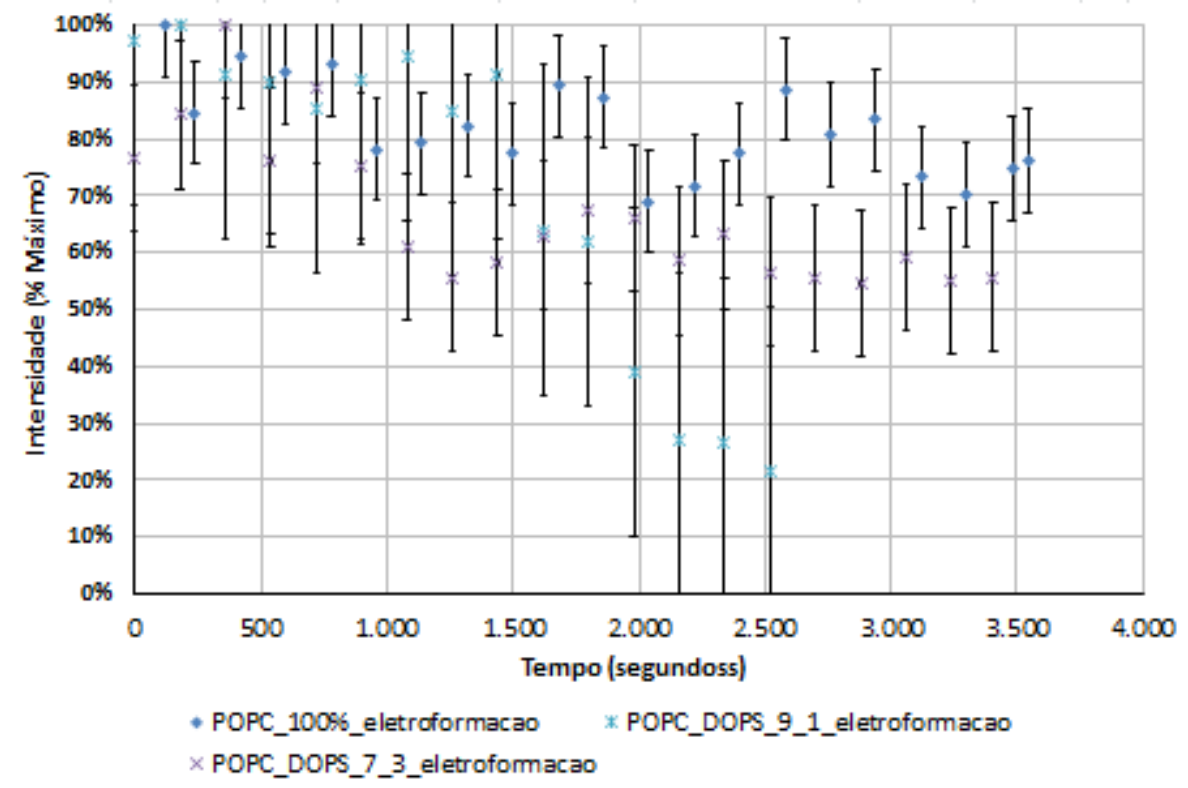

\subsubsection{GUVs criados pelo método gel}

GUVs criadas pelo método gel, nas concentrações de POPC puro, POPC:DOPS (9:1) e POPC:DOPS (7:3). Neste caso, nenhuma das medidas perdeu contraste até 2500s de gravação (após este tempo comecaram a perder, mas com velocidade menor que no caso de eletroformação), conforme pode-se notar abaixo: 


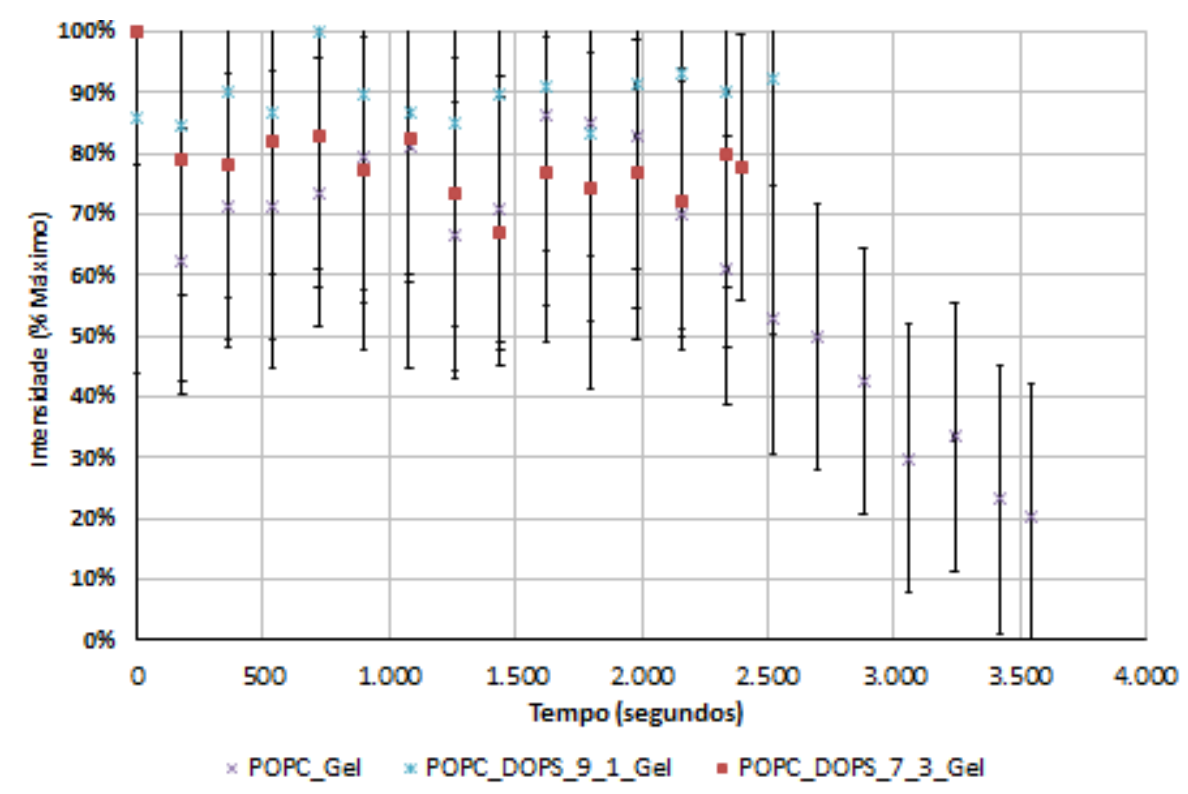

Dado este resultado e também os resultados das GUVs com eletroformação, entendese que o processo de formação com método gel de alguma forma "blinda" as GUVs, evitando que sofrem do mecanismo de perda de contraste.

\subsubsection{GUVs criados pelo método gel adicionado de "solução tampão"}

GUVs criadas pelo método gel adicionado de uma solução tampão (HEPES), nas concentrações de POPC puro, POPC:DOPS (9:1) e POPC:DOPS (7:3). Assim como no caso do método gel sem HEPES, percebe-se neste caso que não houve perda de contraste em nenhuma concentração.

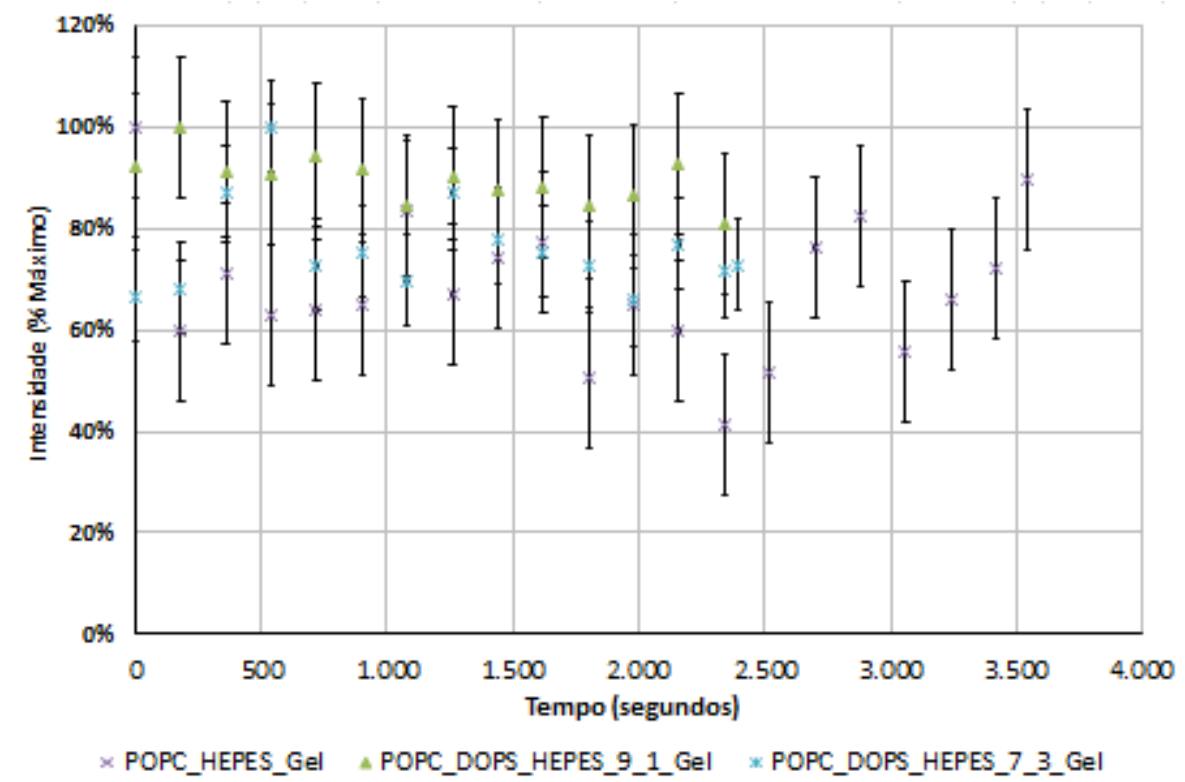

Desta maneira, o método gel com a solução tampão HEPES também protege as membranas do processo de perda de contraste. 
Com todas as medidas realizadas, buscou-se explorar qual a ação do azul de metileno sendo irradiado em membranas contendo POPC. As principais conclusões que se chegou foram que quanto maior a carga negativa na superficie da membrana (nos estudos realizados, o sistema POPC:POPG), mais rápido as GUVs perdem contraste,e portanto sofrem maiores danos à membrana (aumento de permeabilidade). Notou-se também que não houve aumento da área das GUVs em nenhum cenário, mas nos casos de perda de contraste notou-se tubulações nas membranas dependentes da concentração de carga, isto é, quanto maior a concentração de lipídeo carregado (e.g. POPG), mais tubulações formavam e mais rápido as GUVs perdiam contraste.

Nota-se também que todas as GUVs na presença de azul de metileno, porem na ausência de radiação ficam estáveis, isto é, não se nota aumento de área das GUVs e não há indicações de que aumentou a permeabilidade das membranas (pois não há perda de contraste). 


\subsection{Cálculo de incertezas nas medidas obtidas}

Dado que a análise as medidas experimentais são feitas através de imagens, os dados de fato obtidos tratam-se de uma contagem de pixels das imagens obtidas, e a inceteza das medidas medidas experimentais será função da incerteza da contagem destes pixels luminosos. A incerteza dos cálculos feitos estão conforme Clifford [30].

Nos experimentos realizados, os dados sobre intensidade luminosa relativa foram obtidas através da seguinte expressão:

$$
\text { Intensidade Relativa }{ }_{t}=I R_{t}=\left(\frac{\operatorname{Imax}_{t}-\operatorname{Imín}_{t}}{\operatorname{Imax}_{\text {exp }}-\operatorname{Imín}_{\text {exp }}}\right) \times 100
$$

Onde:

$\mathrm{IR}_{\mathrm{t}}$ : mostra a intensidade relativa em um instante relativamente à intensidade máxima obtida no experimento (intensidade máxima adotada como 100\%, e IR expressa como uma porcentagem deste valor máximo)

$\operatorname{Imax}_{\mathrm{t}:}$ Ponto de intensidade máxima obtido em dado instante do experimento

Imín $_{\mathrm{t}:}$ Ponto de intensidade mínima obtido em dado instante do experimento

$\operatorname{Imax}_{\text {exp: }}$ Ponto de intensidade máxima obtido no experimento todo

Imín $_{\text {exp: }}$ Ponto de intensidade mínimo obtido no experimento todo

Quando incertezas de grandezas medidas diretamente são independentes e aleatórias, podemos adequar a incerteza total à fórmula quadrática:

$$
\sigma_{f(x, \ldots, z)}=\sqrt{\left(\frac{\partial \mathrm{f}}{\partial \mathrm{x}}\right)^{2} \sigma_{x}^{2}+\cdots+\left(\frac{\partial \mathrm{f}}{\partial \mathrm{z}}\right)^{2} \sigma_{z}^{2}}
$$

Aplicando para o caso específico das medidas obtidas:

$$
\sigma_{I R_{t}}=\sqrt{\frac{\left(\frac{\partial \mathrm{f}}{\partial \operatorname{Imax}_{t}}\right)^{2} \sigma_{\text {Imax }_{t}}{ }^{2}+\left(\frac{\partial \mathrm{f}}{\partial \operatorname{Imín}_{t}}\right)^{2} \sigma_{I m i n_{t}}{ }^{2}+\left(\frac{\partial \mathrm{f}}{\partial \operatorname{Imax}_{\text {exp }}}\right)^{2} \sigma_{\text {Imax }}{ }_{\text {exp }}{ }^{2}+}{\left(\frac{\partial \mathrm{f}}{\partial \operatorname{Imín}_{\text {exp }}}\right)^{2} \sigma_{\text {Imín } n_{\text {exp }}}^{2}}}
$$

Considerando que os erros das medidas são de origem aleatória, considera-se que o erro na contagem de pixels em cada caso pode ser dados pela raiz quadrada da própria contagem: 


$$
\sigma_{\text {contagem }}=\sqrt{n}
$$

Aplicando novamente para o caso da medição de intensidade relativa, a incerteza das medidas pode ser expressa por:

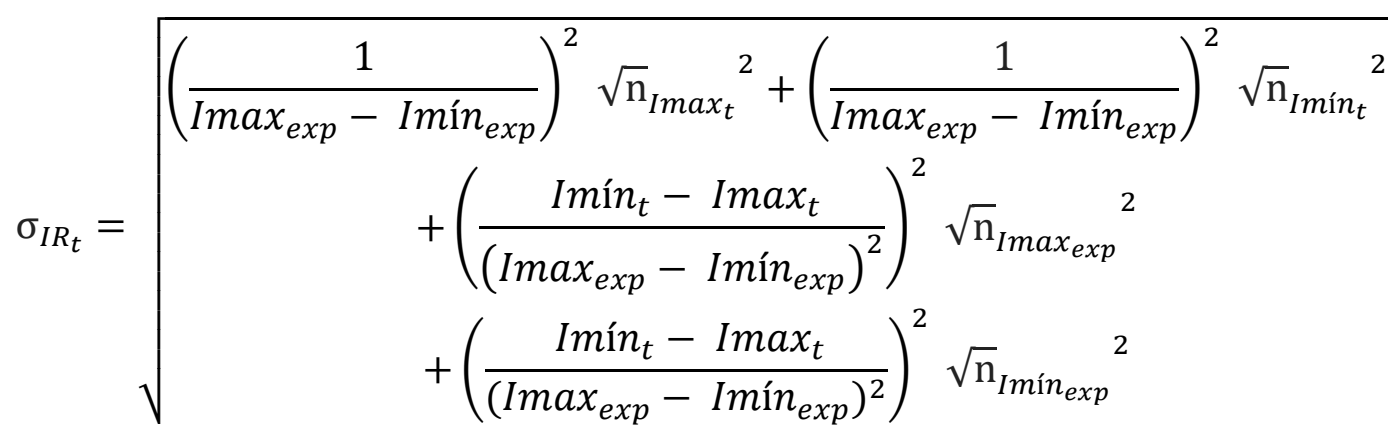




\subsection{Gráficos do Estudo do Efeito da Toxina STII a $42 \mathrm{nM}$ em GUVs com Lipídeos Oxidados}

Nesta etapa do trabalho, o objetivo foi o estudo do efeito do uso de lipídeos oxidados nas membranas das GUVs. Foram analisados GUVs cujas membranas foram compostos por diferentes lipídeos oxidados, e na sequência expostos à toxina STII e analisado a perda do contraste de fase ao longo do tempo.

Este capitulo dedica-se a estudar os efeitos do impacto do uso de lipídeos oxidados, e compara os resultados com aqueles previstos em Itri et al. [13] e Bacellar et al. [31], onde foram avaliados os impactos de lipídeos oxidados na em mudanças de membranas de GUVS.

Nos experimentos aqui realizados, foram medidos GUVs formados por POPC, PazePC e POPC-OOH, em concentrações puras, com e sem a presença de STII, para tentar isolar o efeito de cada variável. Na sequência foram variadas as proporções das misturas dos lipídeos, buscando verificar qual o impacto do aumento da concentração de lipídeos oxidados na composição das membranas.

Conforme foi verificado anteriormente, para garantir o efeito das toxinas sob as membranas, utilizou-se uma concentração maior (desta vez $42 \mathrm{nM}$ ) e para as medidas deste capítulo foram sempre utilizadas a toxina ST II, por ter se mostrado mais efetiva na formação de poros em membranas do que o ST I (conforme descrito no capítulo de resultados anterior).

Abaixo tabela resumindo a quantidade de GUVs que efetivamente perderam contraste ao longo do tempo, durante o experimento sob ação de ST II: 


\begin{tabular}{|l|l|r|r|}
\hline Medida & Contraste & $\#$ & $\%$ \\
\hline \multirow{2}{*}{ POPC_42nM ST II } & Perderam & 22 & $49 \%$ \\
\cline { 2 - 4 } & $\begin{array}{l}\text { Não } \\
\text { Perderam }\end{array}$ & 23 & $51 \%$ \\
\hline \multirow{2}{*}{ POPC-OOH_42nM } & Perderam & 8 & $73 \%$ \\
\cline { 2 - 4 } & $\begin{array}{l}\text { Não } \\
\text { Perderam }\end{array}$ & 3 & $27 \%$ \\
\hline \multirow{3}{*}{ POPC:POPC-OOH(9:1) ST II_42nM } & Perderam & 30 & $91 \%$ \\
\cline { 2 - 4 } & $\begin{array}{l}\text { Não } \\
\text { Perderam }\end{array}$ & 3 & $9 \%$ \\
\hline \multirow{3}{*}{ POPC:POPC-OOH(7:3) ST II_42nM } & Perderam & 25 & $71 \%$ \\
\cline { 2 - 4 } & $\begin{array}{l}\text { Não } \\
\text { Perderam }\end{array}$ & 10 & $29 \%$ \\
\hline \multirow{2}{*}{ POPC:POPC-OOH(1:1) ST II_42nM } & Perderam & 21 & $88 \%$ \\
\cline { 2 - 4 } & $\begin{array}{l}\text { Não } \\
\text { Perderam }\end{array}$ & 3 & $13 \%$ \\
\hline \multirow{2}{*}{ POPC:PazePC(9:1)_ST II 42nM } & Perderam & 20 & $83 \%$ \\
\cline { 2 - 4 } & $\begin{array}{l}\text { Não } \\
\text { Perderam }\end{array}$ & 4 & $17 \%$ \\
\hline \multirow{2}{*}{ POPC:PazePC(7:3)_42nM ST II } & Perderam & 13 & $38 \%$ \\
\cline { 2 - 4 } & $\begin{array}{l}\text { Não } \\
\text { Perderam }\end{array}$ & 21 & $62 \%$ \\
\hline \multirow{2}{*}{ POPC:PazePC(1:1) } & Perderam & 0 & n.a. \\
\cline { 2 - 4 } & $\begin{array}{l}\text { Não } \\
\text { Perderam }\end{array}$ & 0 & $n . a$. \\
\hline
\end{tabular}

Tabela 7: Contagem de GUVs que perderam contraste nos experimentos com ST II 6.4.1 Medidas com POPC e POPC-OOH com STII concentração de 42nM

\subsubsection{POPC_42nM STII}

Abaixo estão imagens da primeira medida mostrando a perda de contraste de GUVs formados por POPC na presença de STII com concentração de 42nM. Verifica-se que que existe a perda de contraste na maior parte das GUVs. 


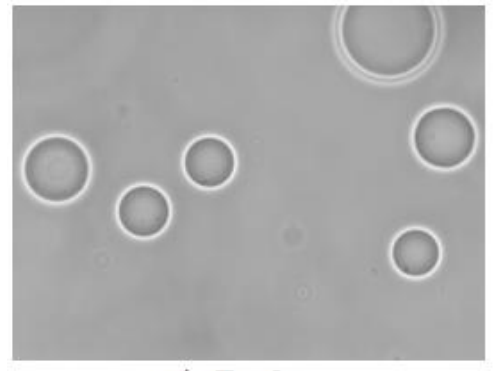

$\checkmark \quad T=0 s$

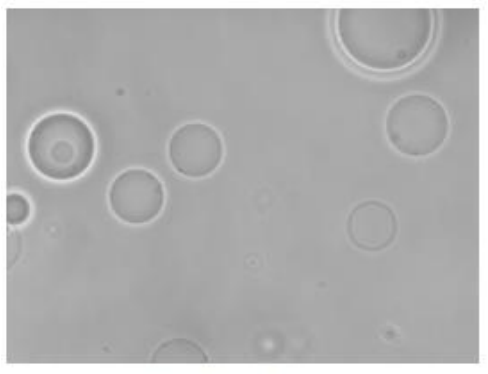

$\checkmark \quad T=450 \mathrm{~s}$

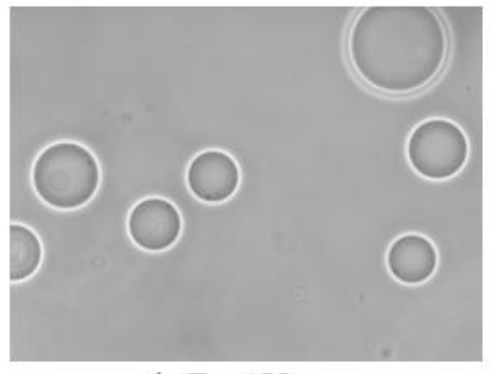

$\checkmark T=150 \mathrm{~s}$

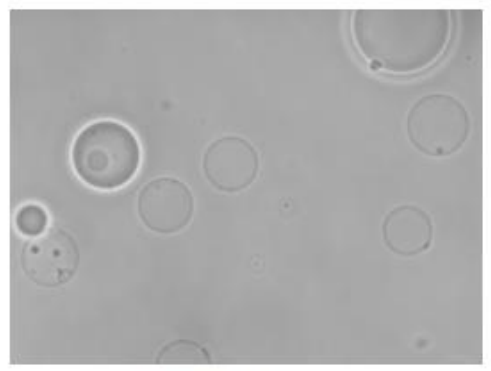

$\checkmark \quad T=600 \mathrm{~s}$
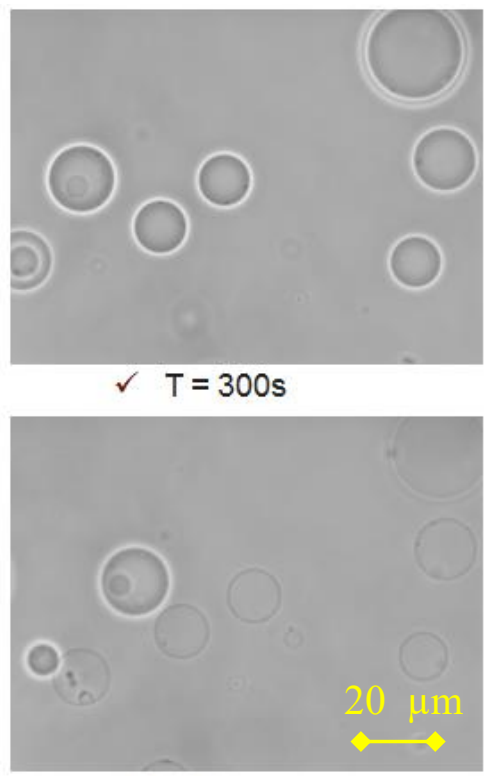

$\checkmark \quad T=720$ s

Figura 39: Evolução das imagens de GUVs POPC_42nM STII Experiment-1354.

Analisando o gráfico abaixo, pode-se confirmar o efeito das imagens registradas acima: as GUVs perdem contraste até atingir um patamar em torno de $40 \%$ da intensidade máximo medida.

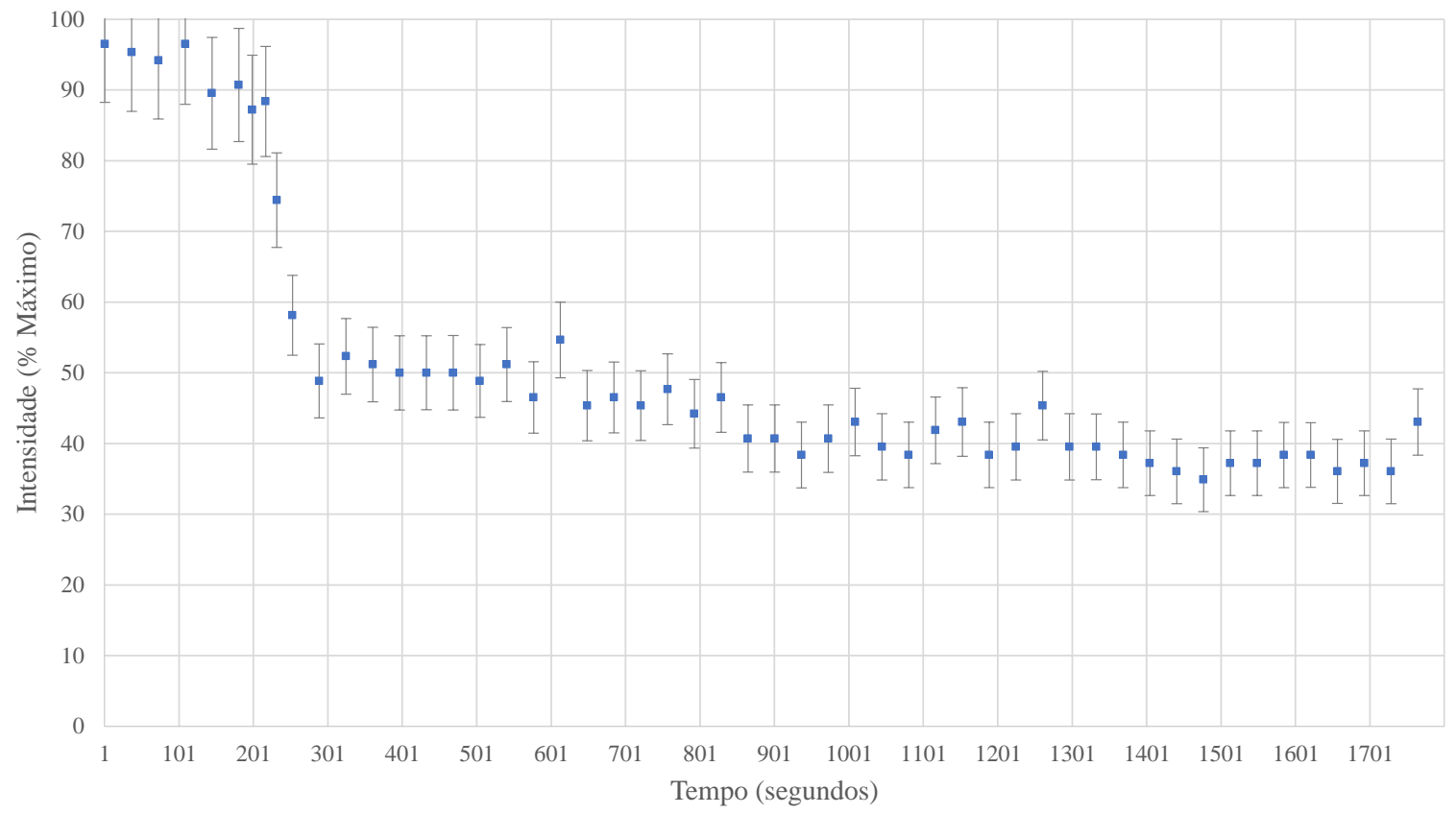

Figura 40: Média da evolução do contraste de fase GUVs de POPC na presença de 42nM STII 


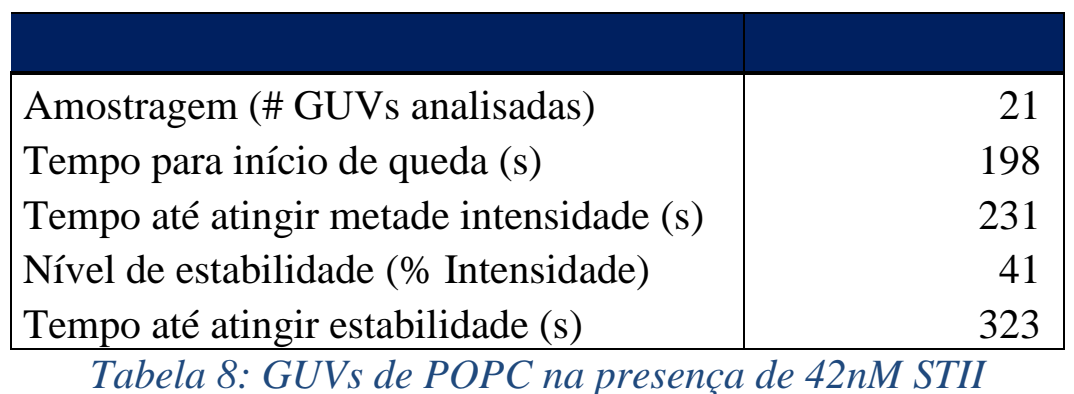

\subsubsection{POPC-OOH_42nM STII}

Nestas medidas observou-se novamente que houve perda de contraste ao longo do tempo, mas desta vez a intensidade se estabilizou em torno de $20 \%$ da intensidade máxima observada.

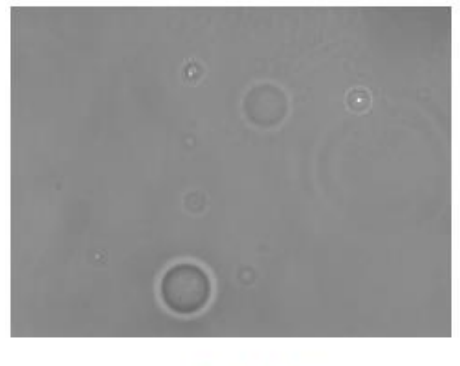

$\checkmark \mathrm{T}=\mathrm{OS}$

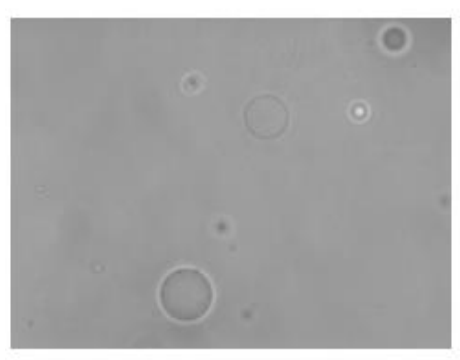

$\checkmark \quad T=900 \mathrm{~s}$

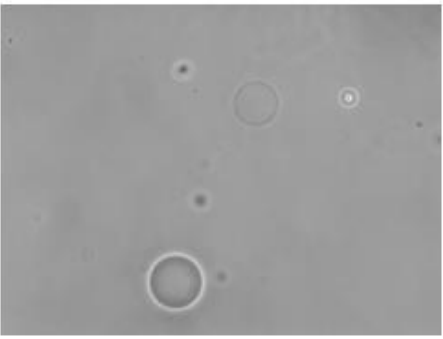

$\checkmark T=300 s$

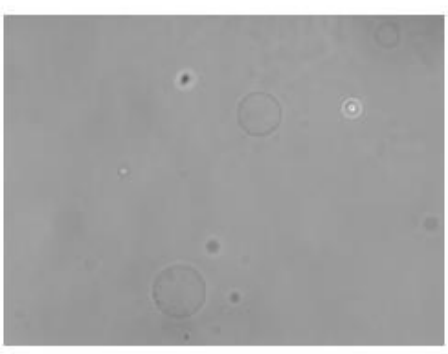

$\checkmark T=1500 \mathrm{~s}$

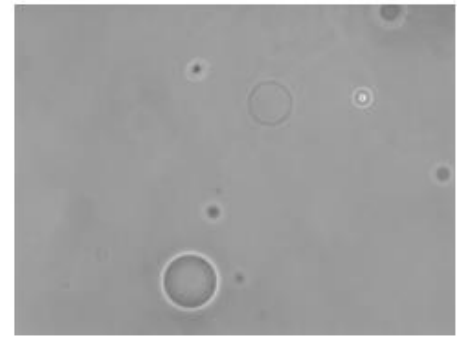

$T=600 \mathrm{~s}$

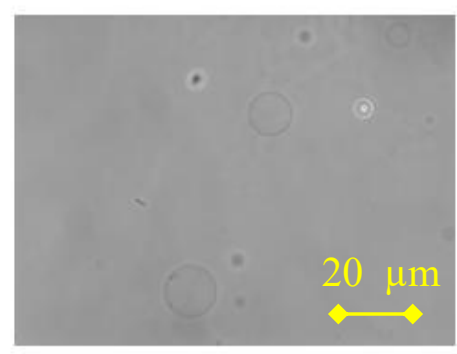

$\checkmark \quad T=1800 \mathrm{~s}$

Figura 41: Evolução das imagens de GUVs POPC-OOH_42nM STII Experiment-1409. 
A análise do gráfico abaixo comprova os resultados observados nas imagens do experimento.

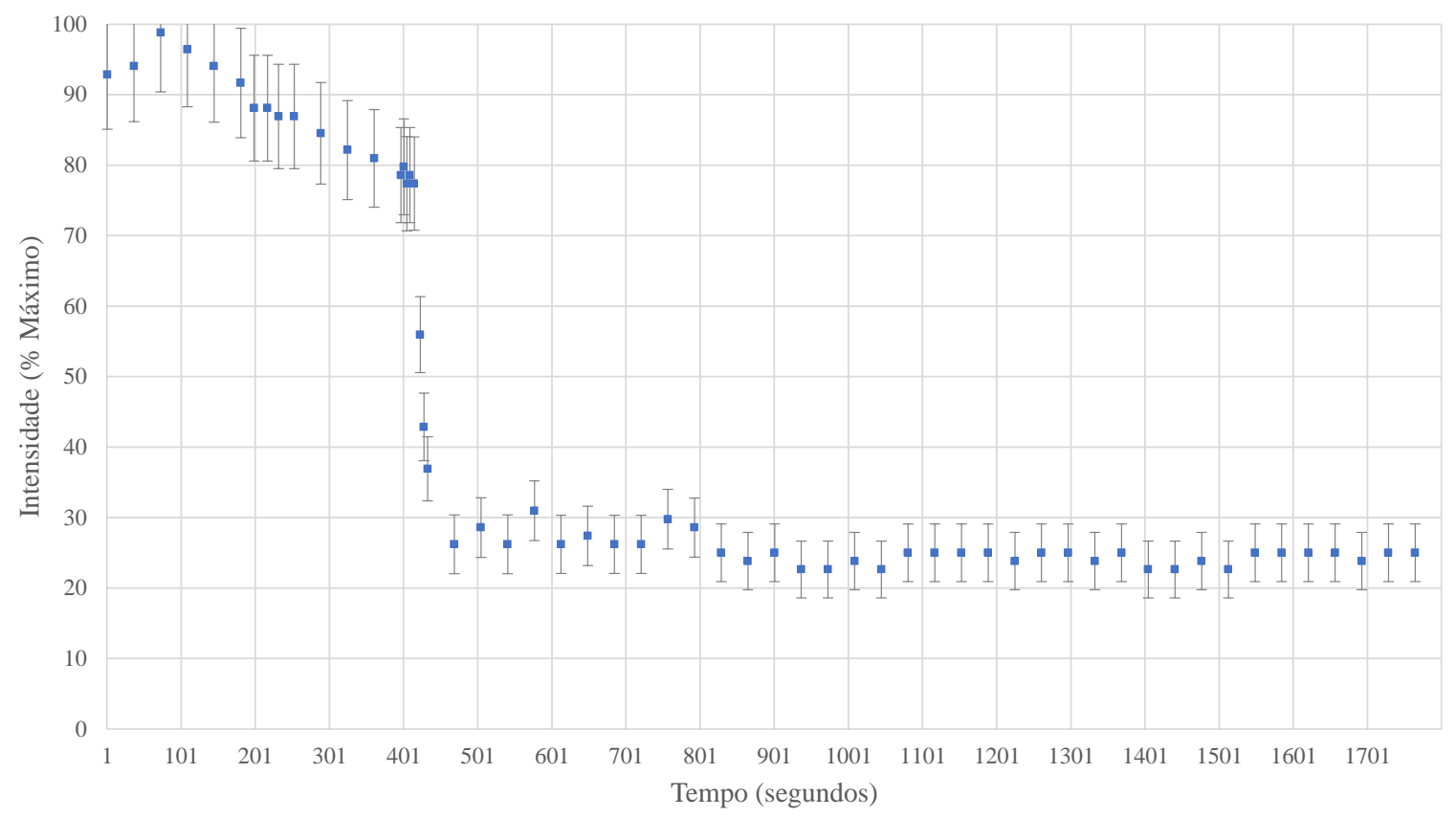

Figura 42: Média da evolução do contraste de fase GUVs de POPC-OOH na presença de 42nM STII

\begin{tabular}{|l|r|}
\hline Amostragem (\# GUVs analisadas) & 8 \\
Tempo para início de queda (s) & 207 \\
Tempo até atingir metade intensidade (s) & 402 \\
Nível de estabilidade (\% Intensidade) & 27 \\
Tempo até atingir estabilidade (s) & 463 \\
\hline \multicolumn{2}{|c|}{ Tabela 9: GUVs de POPC-OOH na presença de 42nM STII }
\end{tabular}

\subsubsection{Medidas com POPC e POPC-OOH}

\subsubsection{POPC:POPC-OOH(9:1) STII_42nM}

No caso da concentração de 9:1 também houve perda de contraste, mas pode-se notar que ocorreu de maneira mais demorada do que nos casos anteriores. A perda de contraste tambem levou mais tempo para ocorrer, se estabilizando somente ao final do experimento de 30 minutos. 


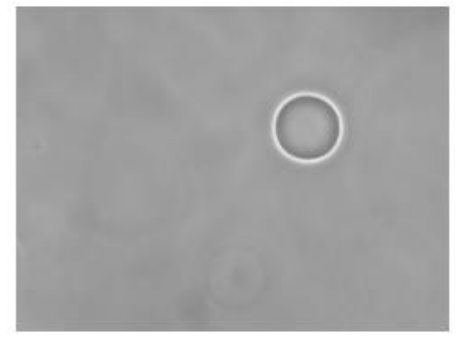

$\checkmark \quad T=0 s$

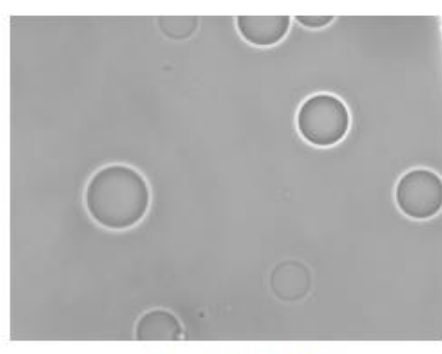

$\checkmark \quad T=900$ s

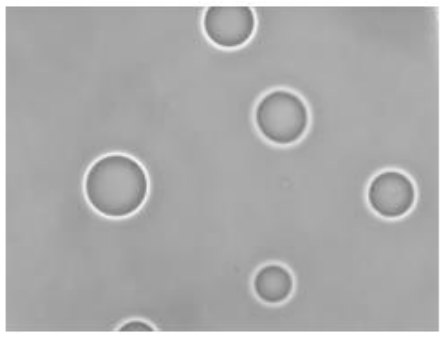

$\checkmark \quad T=300 \mathrm{~s}$

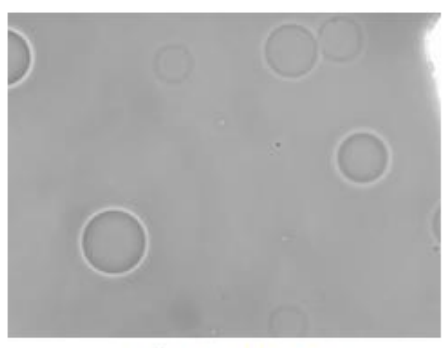

$\mathrm{T}=1500 \mathrm{~s}$

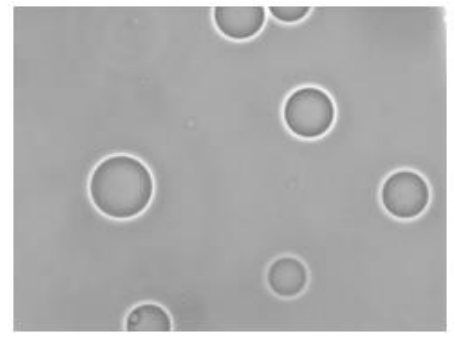

$\checkmark \quad \mathrm{T}=600 \mathrm{~s}$

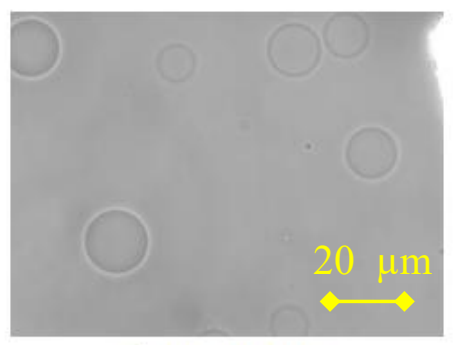

$T=1800 \mathrm{~s}$

Figura 43: POPC;POPC-OOH (9:1) STII_42nM Experiment-1387

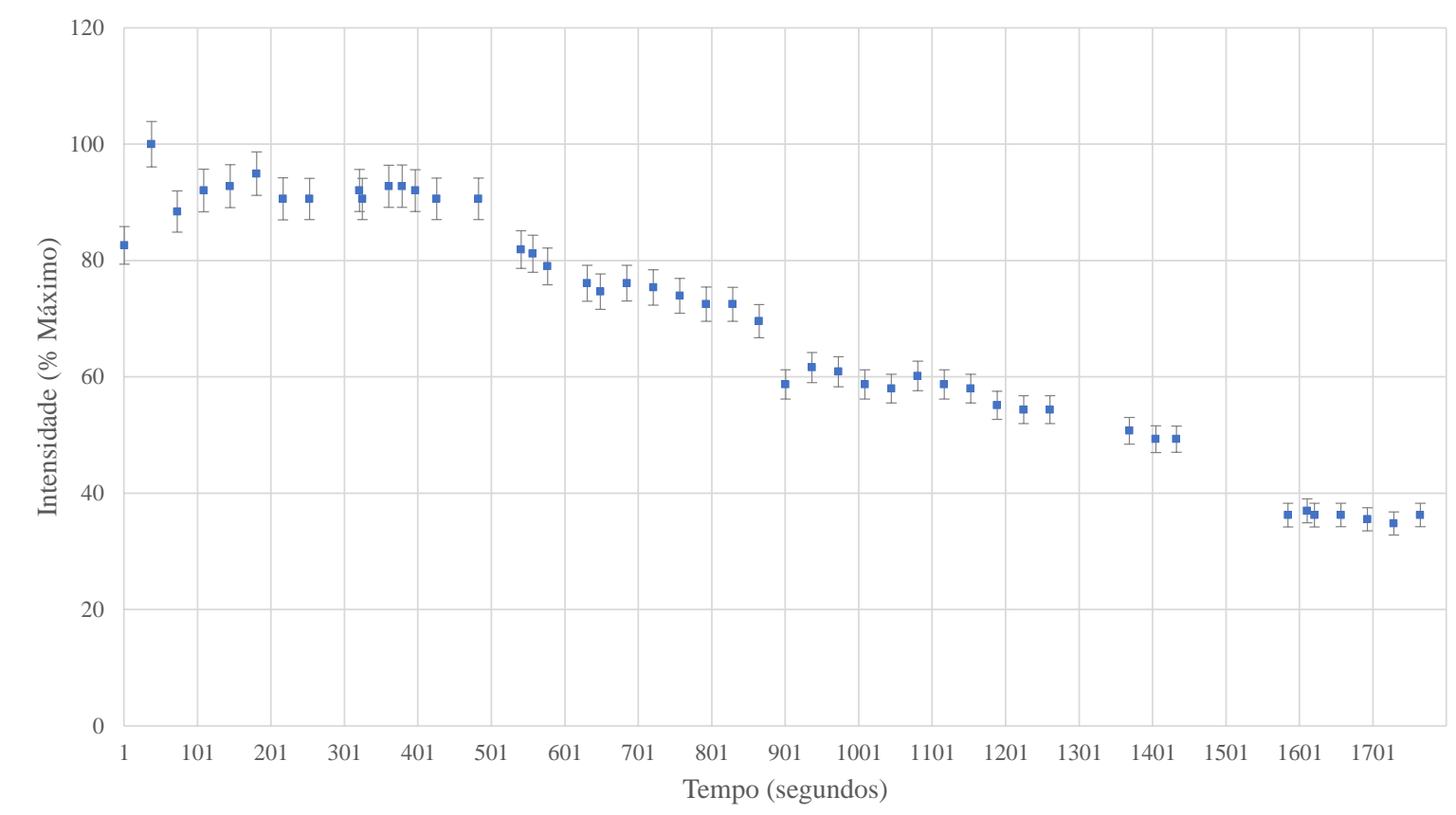

Figura 44: Média da evolução do contraste de fase GUVs de POPC;POPC-OOH(9;1) na presença de 42nM STII 
Amostragem (\# GUVs analisadas)

Tempo para início de queda (s)

Tempo até atingir metade intensidade (s)

Nível de estabilidade (\% Intensidade)

Tempo até atingir estabilidade (s)
801

40

1456

Tabela 10: GUVs de POPC;POPC-OOH(9;1) na presença de 42nM STII

\subsubsection{POPC;POPC-OOH(7:3) STII_42nM}

No caso tambem para concentração de 7:3 pode-se notar a perda de contraste, ocorrendo mais rapidamente do que no caso da maior concentração de POPC-OOH, sugerindo não haver relação com sua composição na membrana lipídica.

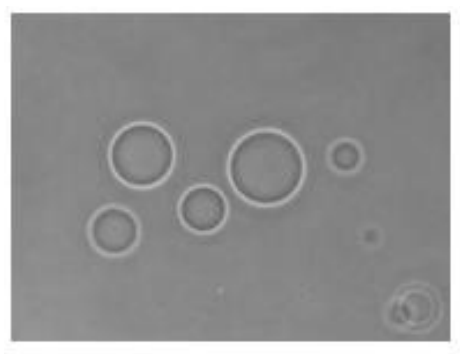

$\checkmark \quad \mathrm{T}=0 \mathrm{~S}$

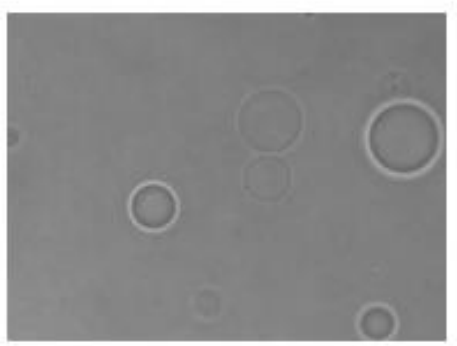

$\checkmark \quad T=900 \mathrm{~s}$

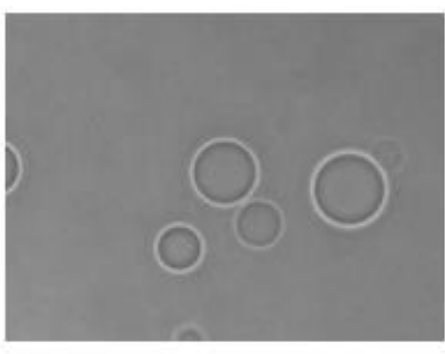

$\checkmark T=300 \mathrm{~s}$

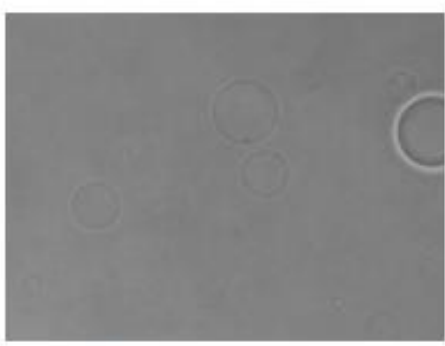

$T=1500 \mathrm{~s}$

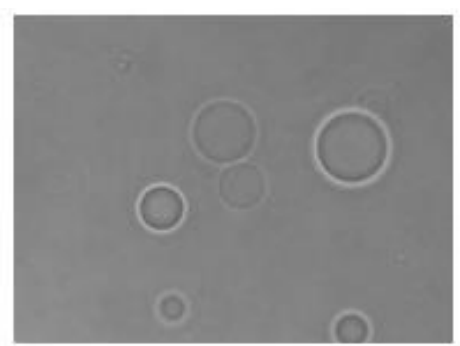

$\checkmark T=600 \mathrm{~s}$

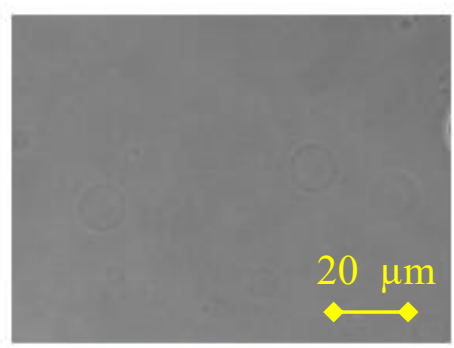

$T=1800 \mathrm{~s}$

Figura 45: POPC;POPC-OOH(7:3) STII_42nM. Experiments11799 


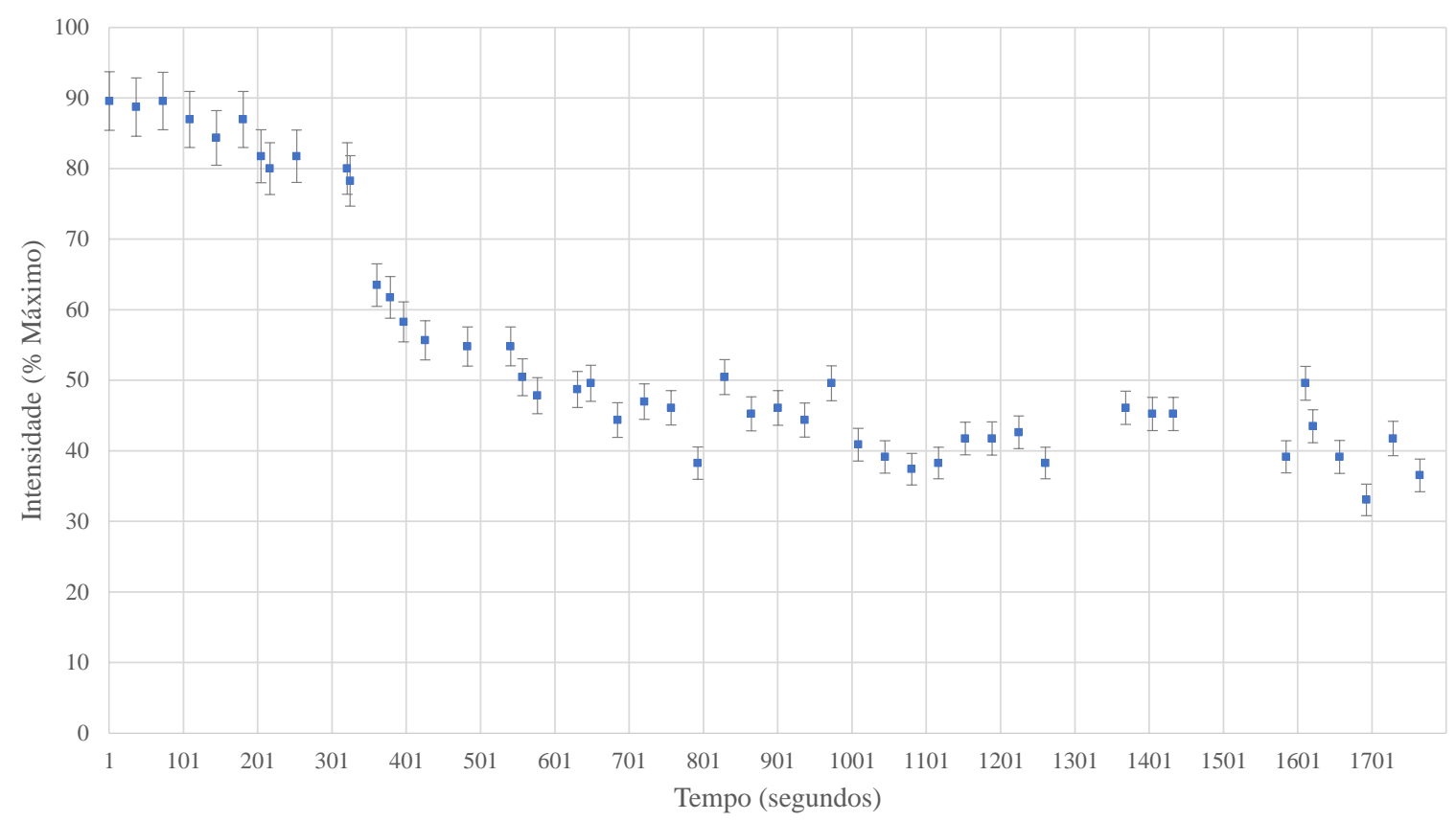

Figura 46: Média da evolução do contraste de fase GUVs de POPC;POPC-OOH(7;3) na presença de 42nM STII

\begin{tabular}{|l|r|}
\hline Amostragem (\# GUVs analisadas) & 14 \\
Tempo para início de queda (s) & 307 \\
Tempo até atingir metade intensidade (s) & 370 \\
Nível de estabilidade (\% Intensidade) & 43 \\
Tempo até atingir estabilidade (s) & 702 \\
\hline
\end{tabular}

Tabela 11: GUVs de POPC;POPC-OOH(7;3) na presença de 42nM STII

\subsubsection{POPC;POPC-OOH(1:1) STII_42nM}

As próximas medidas são análogas às feitas anteriormente, porém substituindo um lipídeo oxidado por outro (no caso POPC-OOH no lugar de PazePC). Conforme pode ser analisado nas imagens e no gráfico abaixo, existe uma perda de contraste na maior parte das GUVs observadas. 


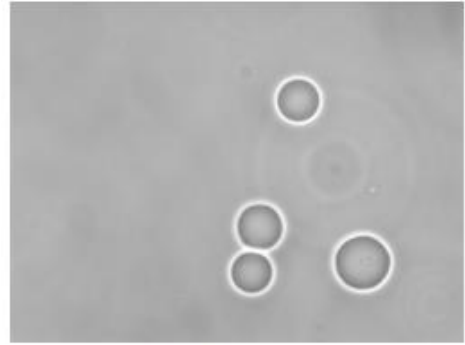

$\checkmark T=0 s$

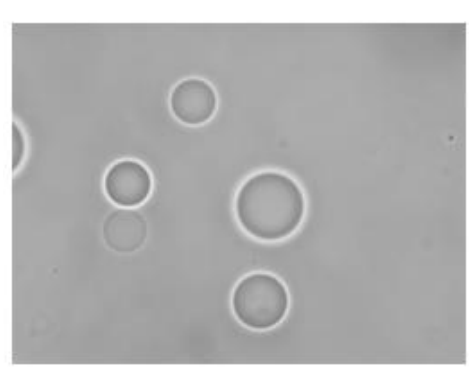

$\checkmark T=900 s$

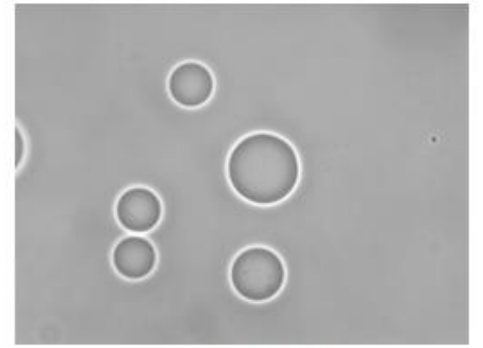

$T=300 \mathrm{~s}$

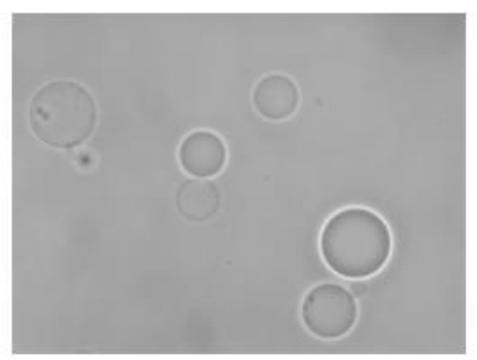

$\checkmark \quad T=1500 \mathrm{~s}$

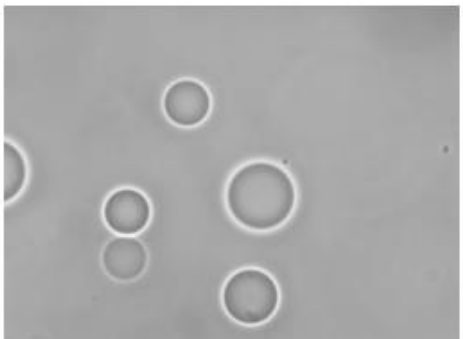

$\checkmark \quad T=600 s$

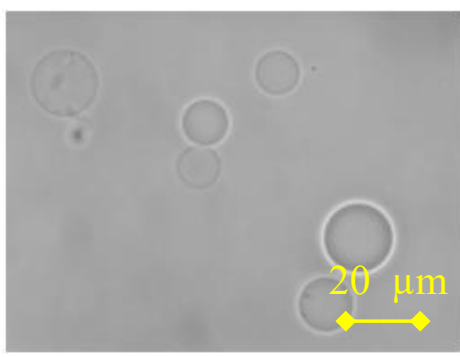

$\checkmark T=1800 \mathrm{~s}$

Figura 47: POPC;POPC-OOH(1:1) STII_42nM. Experiments1386

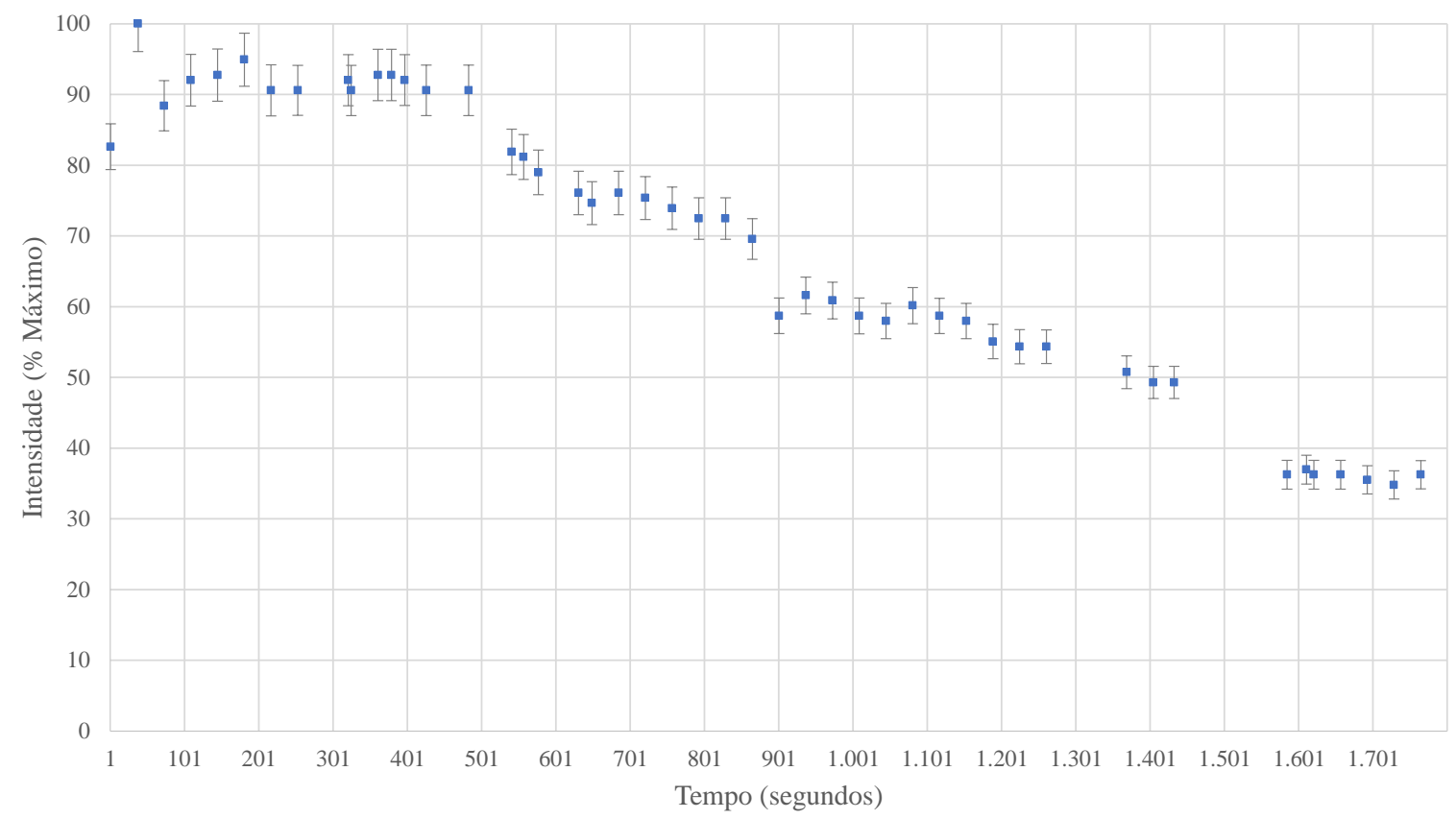

Figura 48: Média da evolução do contraste de fase GUVs de POPC;POPC-OOH(1;1) na presença de 42nM STII

\begin{tabular}{|l|r|}
\hline Amostragem (\# GUVs analisadas) & 19 \\
Tempo para início de queda (s) & 507 \\
Tempo até atingir metade intensidade (s) & 902 \\
Nível de estabilidade (\% Intensidade) & 38 \\
Tempo até atingir estabilidade (s) & 1480 \\
\hline
\end{tabular}

Tabela 12: GUVs de POPC;POPC-OOH $(1 ; 1)$ na presença de 42nM STII 


\subsubsection{Comparação Medidas com POPC e POPC-OOH}

Juntando as medidas de POPC com POPC-OOH para tentar entender a relação da concentração do lipídeo oxidado na perda de contraste das GUVs, nota-se que todas as medidas possuem tempos semelhantes de perda de contraste inclusive se estabilizam em patamares parecidos de intensidade em relação ao máximo respectivo de cada caso.

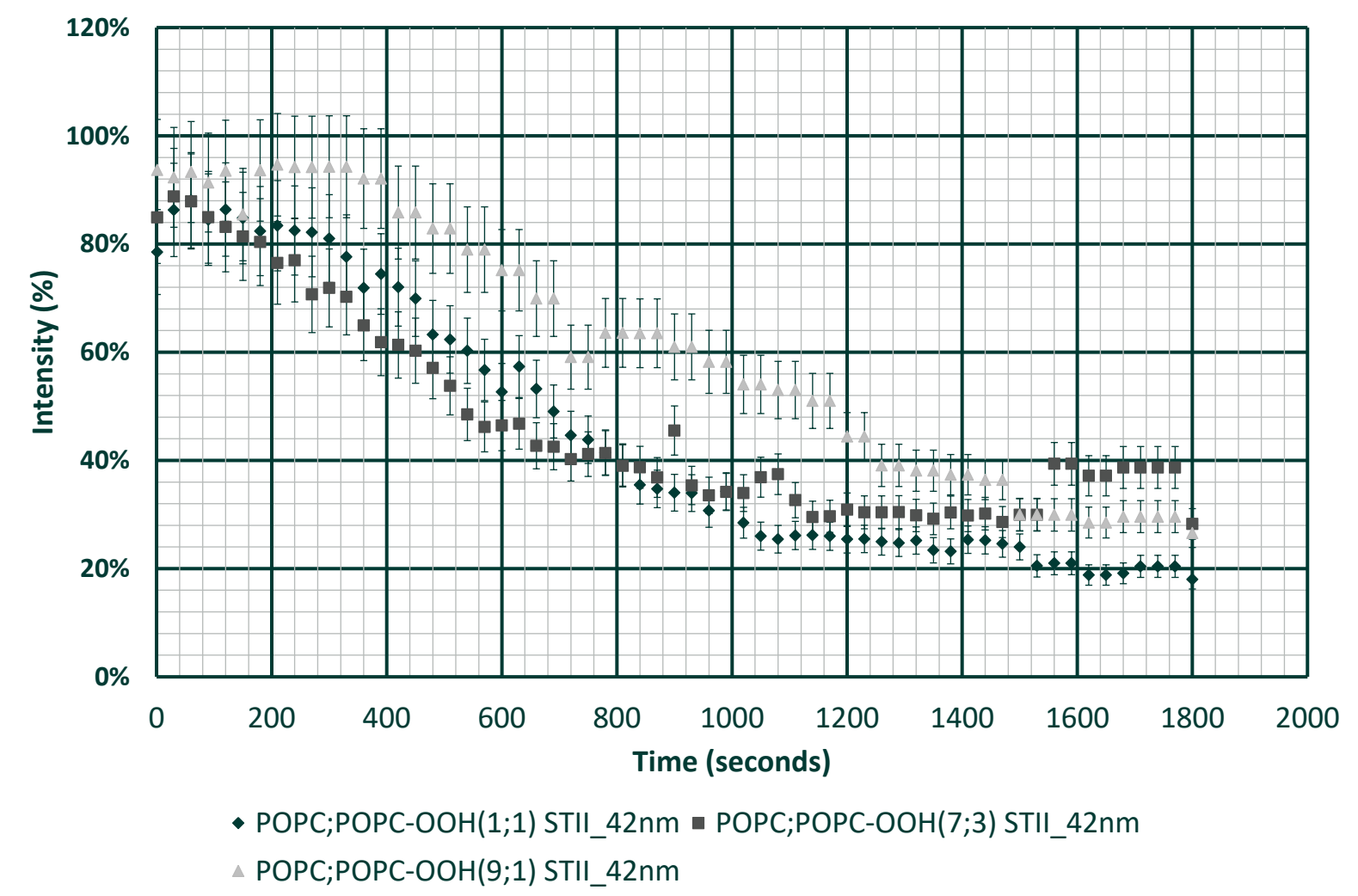

Figura 49: Comparação da evolução do contraste de fase médio das GUVs de POPC e POPC-OOH nas proporções de 1:1, 7:3 e 9:1 na presença de 42nM STII

\subsubsection{Medidas com POPC e PazePC}

\subsubsection{POPC:PazePC(9:1)_42nM STII}

Conforme pode ser verificado nas imagens e no gráfico abaixo, as membranas formadas por POPC:PazePC na proporção de 9:1 também mostraram perda de contraste ao longo do tempo. 


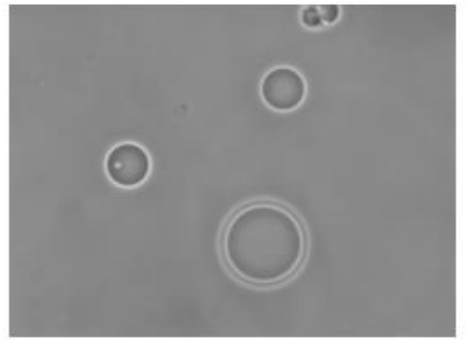

$\checkmark T=0 s$

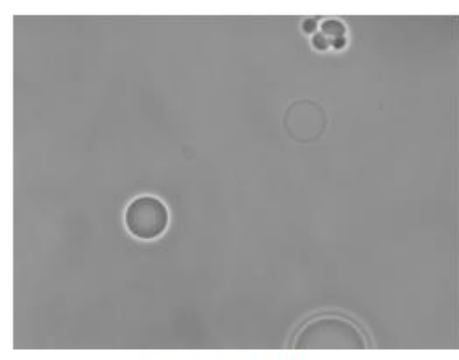

$\checkmark T=900 \mathrm{~s}$

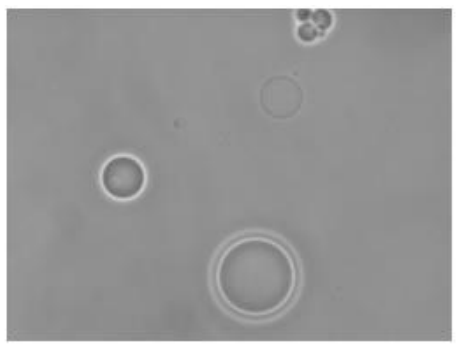

$T=300 \mathrm{~s}$

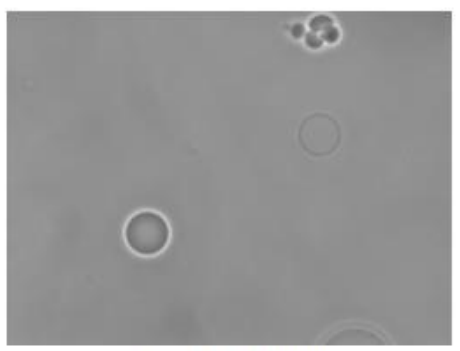

$T=1500 \mathrm{~s}$

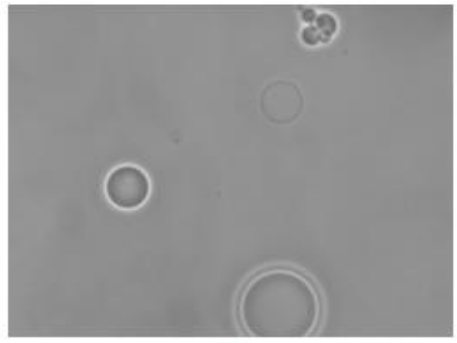

$\checkmark T=600 s$

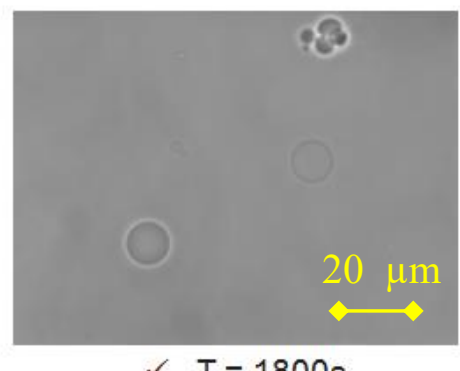

$T=1800 \mathrm{~s}$

Figura 50: Evolução das imagens de GUVs POPC;PazePC(1;1)_42nM STII Experiment1134.

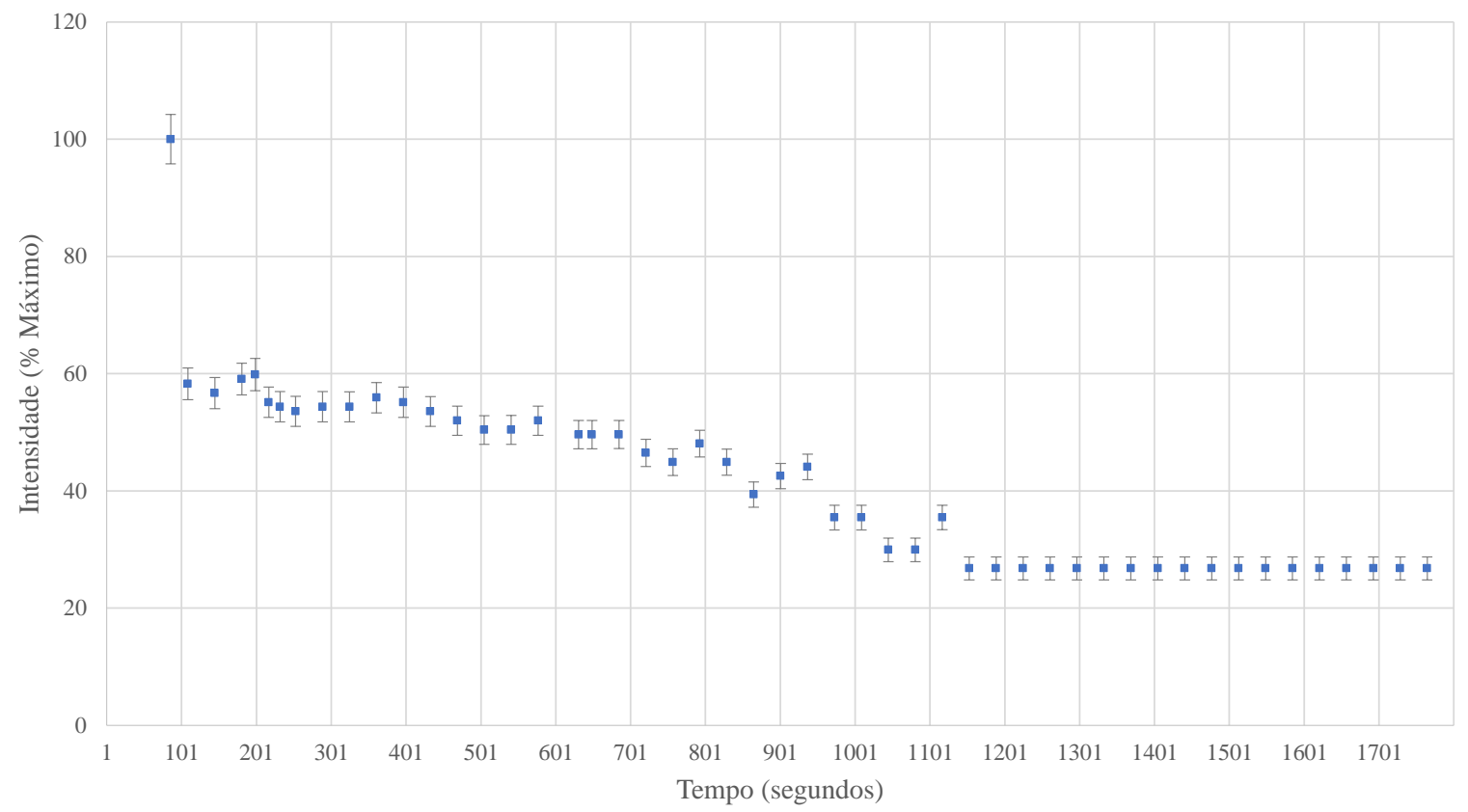

Figura 51: Média da evolução do contraste de fase GUVs de POPC;PazePC(9;1) na presença de 42 nM STII 
Amostragem (\# GUVs analisadas)

Tempo para início de queda (s)

Tempo até atingir metade intensidade (s)

Nível de estabilidade (\% Intensidade)

Tempo até atingir estabilidade (s)
801

1001

26

1180

Tabela 13: GUVs de POPC;PazePC(9;1) na presença de 42nM STII

\subsubsection{POPC:PazePC (7:3)_42nM STII}

Conforme análise do gráfico de perda de contraste, verifica-se a perda de contraste:

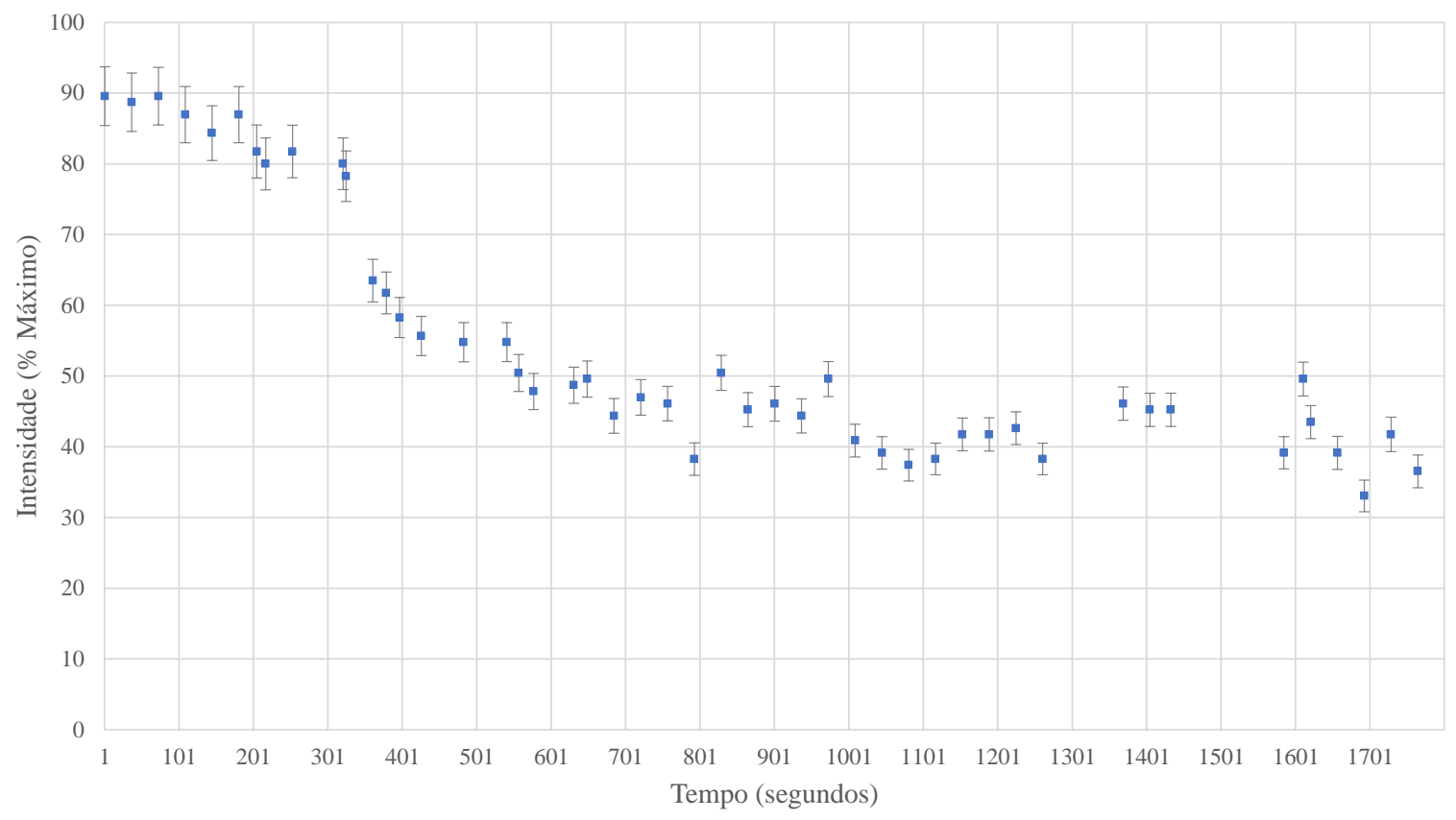

Figura 52: Média da evolução do contraste de fase GUVs de POPC;PazePC(7;3) na presença de 42nM STII

\begin{tabular}{|l|r|}
\hline & \\
\hline Amostragem (\# GUVs analisadas) & 19 \\
Tempo para início de queda (s) & 213 \\
Tempo até atingir metade intensidade (s) & 280 \\
Nível de estabilidade (\% Intensidade) & 41 \\
Tempo até atingir estabilidade (s) & 310 \\
\hline
\end{tabular}

Tabela 14: GUVs de POPC;PazePC(7;3) na presença de 42nM STII

\subsubsection{POPC:PazePC(1:1)_42nM STII}

Conforme pode ser verificado nas imagens dos três experimentos realizados abaixo, não foi possível crescer GUVs utilizando a proporção de 1:1 de POPC com PazePC. 

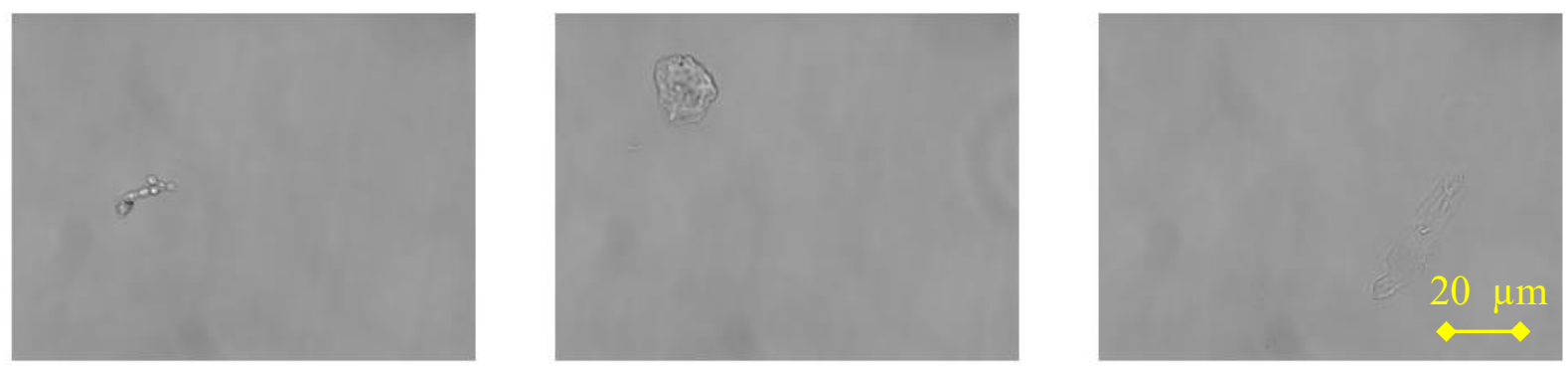

Figura 53: POPC;PazePC(1;1). Experimentos 1496, 1497 e 1498

\subsubsection{Comparação das medidas experimentais com POPC e PazePC}

Buscando entender a perda de contraste ao longo do tempo como função da concentração do lipídeo oxidado PazePC, abaixo está gráfico de intensidade para as concentrações de 9:1 e 7:3. Observa-se que a velocidade de perda de contraste é bastante semelhante, sugerindo não haver relação com a concentração de PazePC.

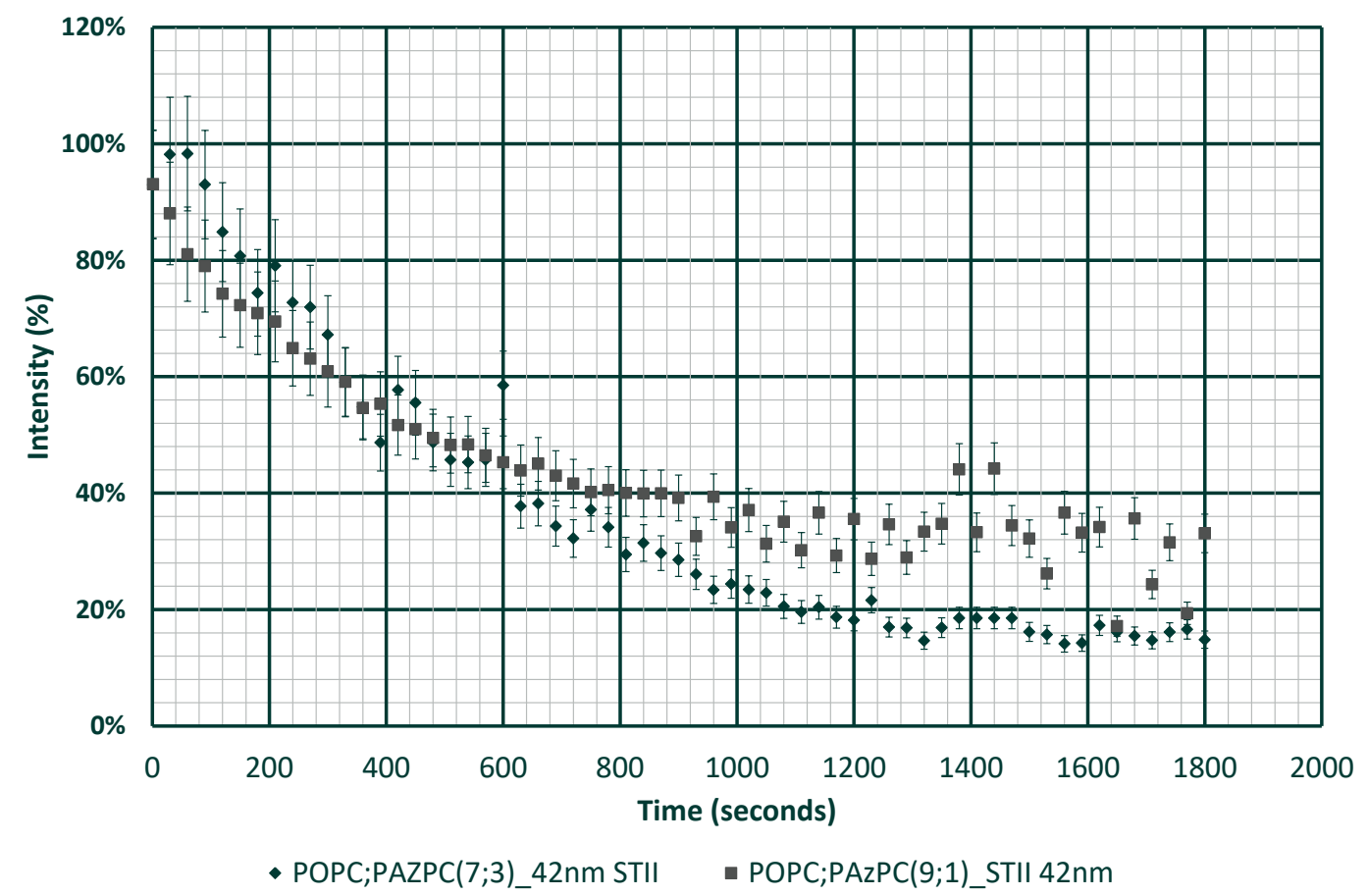

Figura 54: Média da evolução do contraste de fase GUVs de POPC e PazePCnas proporções de 7:3 e 9:1 na presença de 42nM ST II

\subsubsection{POPC-00H;SM(1;1)_21nM_STII}

Conforme pode ser verificado abaixo nas imagens e no gráfico, as GUVs perderam contraste ao longo do tempo observado. 


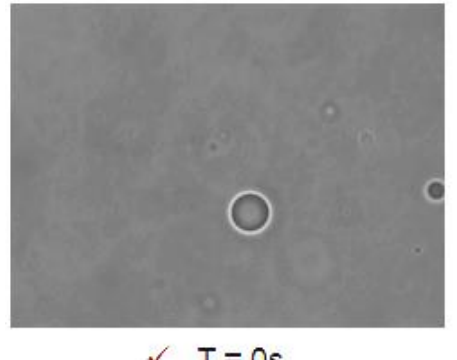

$\checkmark T=0 \mathrm{~s}$

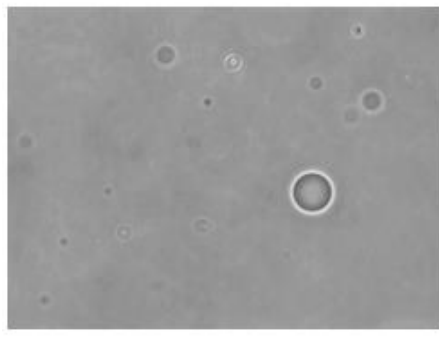

$\checkmark T=900 \mathrm{~s}$

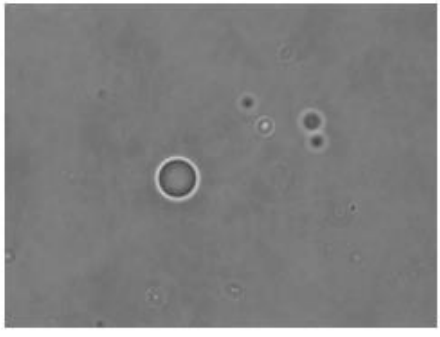

$\checkmark \quad \mathrm{T}=300 \mathrm{~s}$

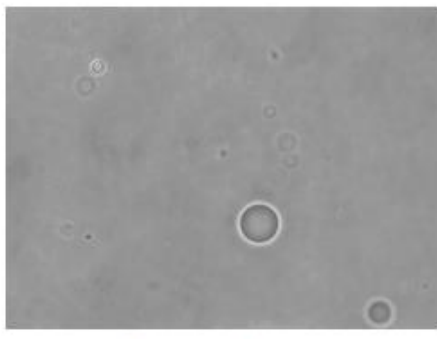

$\checkmark \quad T=1500 \mathrm{~s}$

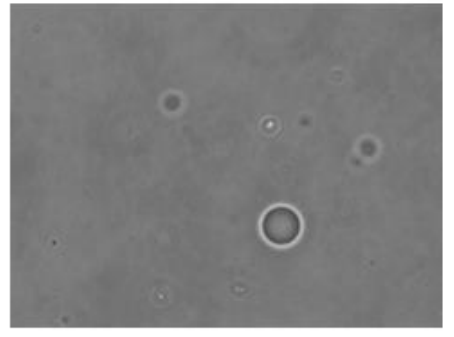

$\mathrm{T}=600 \mathrm{~s}$

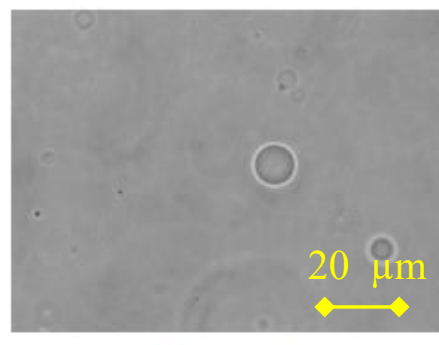

$T=1800 \mathrm{~s}$

Figura 55: POPC-OOH;SM(1;1)_21nM_STII Experiment-11913 